UNIVERSIDADE DE SÃO PAULO

FACULDADE DE ECONOMIA, ADMINISTRAÇÃO E

CONTABILIDADE DEPARTAMENTO DE ADMINISTRAÇÃO

PROGRAMA DE PÓS-GRADUAÇÃO EM ADMINISTRAÇÃO

ANÁLISE DO DESEMPENHO DO SETOR ELÉTRICO NO BRASIL 2010 A 2015

Renata Wandroski Peris

Orientador: Prof. Dr. José Roberto Ferreira Savoia

SÃO PAULO 
Prof. Dr. Marco Antonio Zago

Reitor da Universidade de São Paulo

Prof. Dr. Adalberto Américo Fischmann

Diretor da Faculdade de Economia, Administração e Contabilidade

Prof. Dr. Roberto Sbragia

Chefe do Departamento de Administração

Prof. Dr. Moacir de Miranda Oliveira Júnior

Coordenador do Programa de Pós-Graduação em Administração 


\section{ANÁLISE DO DESEMPENHO DO SETOR ELÉTRICO NO BRASIL - 2010 A 2015}

Dissertação apresentada ao Programa de Pós-Graduação em Administração do Departamento de Administração da Faculdade de Economia, Administração e Contabilidade da Universidade de São Paulo, como requisito para obtenção do título de Mestre em Ciências.

Orientador: Prof. Dr. José Roberto Ferreira Savoia

\section{SÃO PAULO}




\section{FICHA CATALOGRÁFICA}

Elaborada pela Seção de Processamento Técnico do SBD/FEA/USP

Peris, Renata Wandroski

Análise do desempenho do setor elétrico no Brasil: 2010 a 2015 /

Renata Wandroski Peris. -- São Paulo, 2016.

$115 \mathrm{p}$

Dissertação (Mestrado) - Universidade de São Paulo, 2016.

Orientador: José Roberto Ferreira Savoia.

1. Finanças das empresas 2. Desempenho 3. Setor elétrico 4. Medida provisória 579/2012 I. Universidade de São Paulo. Faculdade de Economia, Administração e Contabilidade. II. Título. 
Aos meus pais. 


\section{AGRADECIMENTOS}

A decisão de fazer um curso de Pós-Graduação não é nada fácil. A partir do momento em que escolhemos realizar esta jornada, não imaginamos o caminho árduo e trabalhoso pelo qual iremos passar. A jornada é custosa, exige muita dedicação, persistência, inteligência e sabedoria. E nesse aprendizado constante passamos a contar com a ajuda e contribuição de muitas pessoas. Por isso, agradeço a todos aqueles que contribuíram para a realização do curso de Mestrado na FEA-USP e à consecução deste trabalho.

Em especial aos meus pais Alfredo e Iraci, pelo amor e apoio incondicional.

À minha irmã Helena pelo companheirismo.

Ao namorado Dyego Ribeiro, meu maior incentivador.

Aos avós, Edite, Henrique e Renata pelo carinho.

Ao Professor Orientador Dr. José Roberto Ferreira Savoia, pela amizade, pelas contribuições e pela confiança depositada em meu trabalho.

Aos Professores membros da banca Fabiana Lopes da Silva e Wilson Toshiro Nakamura pelas importantes contribuições.

À Cristina Ananias.

Ao pessoal da Secretaria e da Biblioteca.

Aos colegas Eduardo Contani, Daniel Bergman, Priscilla Faria, Mariana Gonçalves e Rosimara Donadio.

Às amigas Marisa Cavalcante, Larissa Schulz, Julieta Ochoa, Natalia Ochoa e Sandy Pulecio.

À Ednara Neves Flores.

À Fundação CAPES pelo apoio e fomento à pesquisa. 
"O ser humano está sempre fazendo escolhas e deve-se lembrar de que uma boa escolha credencia o individuo para outras boas escolhas. O importante é definir o que se quer ter ou fazer, iniciar e não desistir. Corrigir rumos é necessário em qualquer caminhada. Saber esperar, às vezes pacientemente, também é importante. Quando se inicia um pouco mais tarde do que se deveria, a paciência é uma grande virtude, visto que os resultados não aparecem nos primeiros momentos. $E$ sempre necessário fazer antes as bases sobre as quais se assentarão as edificações" Alfredo Fonceca Peris. 


\section{RESUMO}

O objetivo principal deste trabalho se concentrou na análise do desempenho das empresas do setor elétrico no Brasil, com foco nas companhias de capital aberto. Como objetivo complementar, a análise dos efeitos da edição da Medida Provisória ${ }^{\circ}$ 579/2012 nas empresas do setor. Para isso, foi realizada revisão da literatura acerca do setor elétrico no Brasil, sua estrutura microeconômica e o modelo de regulação; avaliação do desempenho das empresas e estudos relacionados; contex to político e econômico das empresas do setor e a problemática da MP579. A análise quantitativa utilizou variáveis contábeis e de Governança, de mercado e econômicas de 24 empresas de energia elétrica listadas na BM\&FBovespa, no período de janeiro de 2010 a dezembro de 2015. Foram elaborados três estudos. O primeiro estudo foi realizado para avaliar desempenho. Foram utilizados dados trimestrais e foi realizada a aplicação do modelo de regressão com dados em painel, sendo dividido em três análises: a primeira realizada com ROE e variáveis contábeis e de Governança, que resultou nas variáveis margem líquida e liquidez corrente para avaliar o desempenho financeiro; a segunda com ROA e variáveis contábeis e de Governança e teve como variáveis significativas dívida bruta/ativo, margem líquida e liquidez corrente para desempenho operacional; e a terceira com a variável Retorno da Ação e variáveis de mercado tendo como resultantes o valor de mercado, enterprise value/ebitda e retorno do Ibovespa para explicar o desempenho de mercado. O segundo estudo utilizou dados anuais e realizou a aplicação de regressão de dados em painel utilizando as variáveis contábeis e de Governança, de mercado e econômicas, para avaliar os efeitos do contexto macroeconômico no conjunto das variáveis em duas análises separadas, a primeira com a variável ROE e a segunda, com ROA. Para a primeira análise, o resultado encontrado foi que dívida líquida/ebitda, margem líquida, capex/depreciação e amortização, enterprise value/ebitda, cotação de fechamento e o beta são significativas para explicar o desempenho financeiro. Para a segunda análise, dívida líquida/ebitda, investimento/patrimônio líquido, liquidez corrente, margem líquida, enterprise value/ebitda, dividendo pago por ação e o beta foram significativas para explicar o desempenho operacional. Não foram encontradas evidências para as variáveis econômicas. O terceiro estudo foi realizado para avaliar o efeito das mudanças produzidas pela edição da MP579 na rentabilidade das empresas do setor. Para isso, foram criadas duas janelas temporais, compreendendo três anos anteriores e três anos posteriores à edição do normativo e criada uma dummy para identificar as empresas que aderiram à Medida e as que não aderiram. Foi elaborado o teste differences-in-differences e realizadas duas regressões em painel com as variáveis ROE e ROA para compreender a consequência da adesão à Medida por parte das empresas. O resultado dos testes revelou que a Medida afetou negativamente a rentabilidade das empresas que aderiram à renovação das concessões.

Palavras-Chave: Finanças das empresas, Desempenho, Setor elétrico, Medida provisória $579 / 2012$. 


\begin{abstract}
The main objective of this work was to analyze the performance of companies at the electric sector in Brazil, with a focus on listed companies. As a complementary objective, the analysis of the effects for the issue of Provisional Measure 579/2012 in the power utilities. For this, a review of the literature was made from the electric sector in Brazil, its microeconomic structure and the regulatory model; Business performance assessment and related studies; Political and economic context of the companies in the sector and the problem of MP579. The quantitative analysis used accounting and governance, market and economic variables of 24 electric companies listed on BM\& FBovespa from January 2010 to December 2015. Three studies were prepared. The first one was conducted to evaluate performance. Quarterly data were used and the regression model with panel data was applied and divided into three analyzes: the first one performed with ROE and Accounting and Governance variables, which resulted in the variables net margin and current liquidity to evaluate financial performance; The second with ROA and accounting and governance variables had as significant variables gross/asset debt, net margin and current liquidity for operational performance; And the third with the variable Return on Stocks and market variables resulting in the market value, enterprise valuelebitda and Ibovespa return to explain the market performance. The second study used annual data and applied panel data regression using the accounting and governance variables, market and economic, to evaluate the effects of the macroeconomic context on the set of variables in two separate analyzes, the first with the variable ROE and the second with ROA. For the first analysis, net debt/ebitda, net margin, capex/depreciation and amortization, enterprise valuelebitda, closing quote and beta are significant to explain financial performance. For the second analysis, net debt/ebitda, investment/shareholders' equity, current liquidity, net margin, enterprise valuelebitda, dividend paid per share and beta were significant to explain operational performance. No evidences were found for the economic variables. The third study was conducted to evaluate the effect of the changes produced by the MP579 on the profitability of the companies. For that, two time horizons were created, comprising three years before and three years after the issue of the normative and created a dummy to identify the companies that joined to the Measure and those that did not adhere. The differences-in-differences test was produced and two panel regressions were performed with the variables ROE and ROA to understand the consequence of adherence to the Measure by the companies. The result of the tests shown that the Measure affected negatively the profitability of the companies that adhered to the renewal of the concessions.
\end{abstract}

Keywords: Business Finance, Performance, Energy Industry, Provisional Measure $579 / 2012$. 


\section{SUMÁRIO}

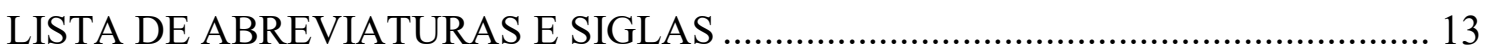

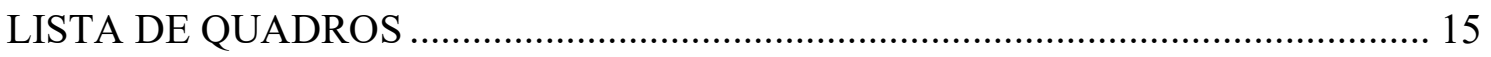

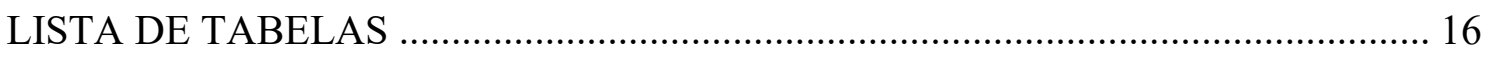

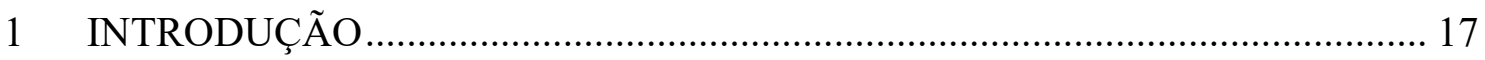

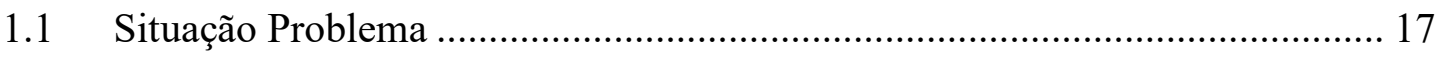

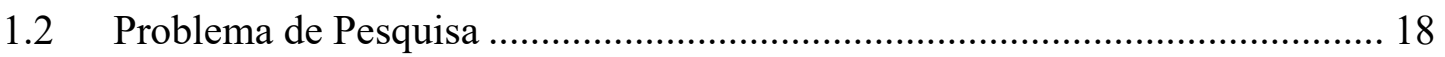

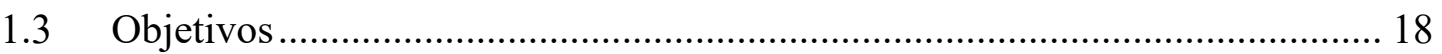

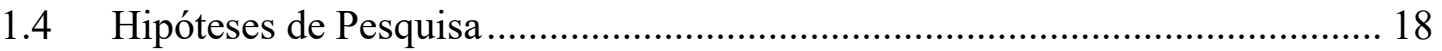

1.5 Justificativa, Importância e Contribuições.................................................... 19

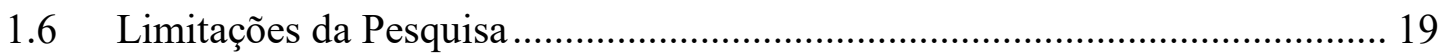

1.7 Breve Discussão Metodológica............................................................... 20

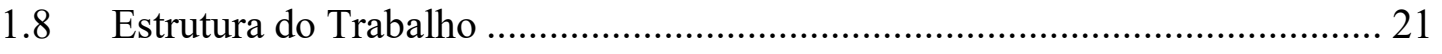

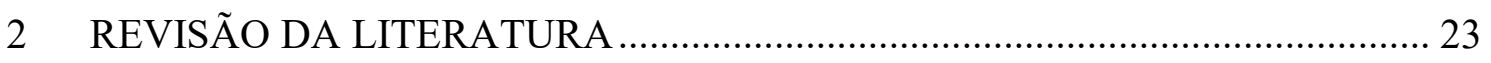

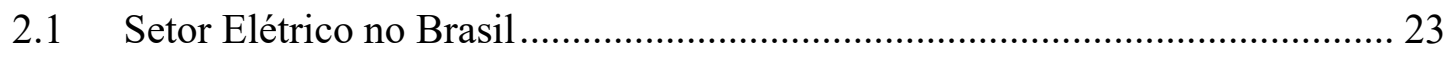

2.1.1 Retrospecto Histórico e o Novo Modelo do Setor Elétrico ...................... 24

2.1.2 Estrutura do Setor Elétrico no Brasil .................................................... 25

2.1.3 Modelo de Regulação do Setor Elétrico do Brasil .................................. 26

2.2 Desempenho Financeiro, Operacional e de Mercado ..................................... 27

2.3 Evidências Empíricas dos Determinantes de Desempenho Financeiro,

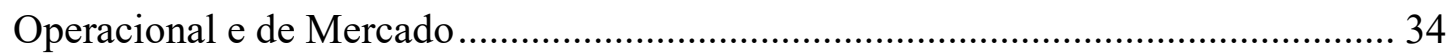

2.3.1 Evidências Empíricas - Variáveis Financeiras e Operacionais................. 34

2.3.2 Evidências Empíricas - Aspectos de Governança.................................... 38

2.3.3 Evidências Empíricas - Variáveis de Mercado......................................... 39

2.3.4 Novo Modelo de Contabilidade Societária para o Brasil ........................ 41 
2.4 Efeitos do Contexto Econômico e Político no Desempenho das Empresas do

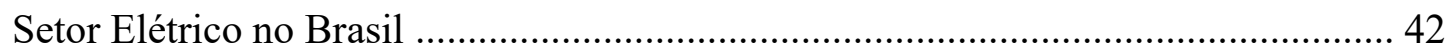

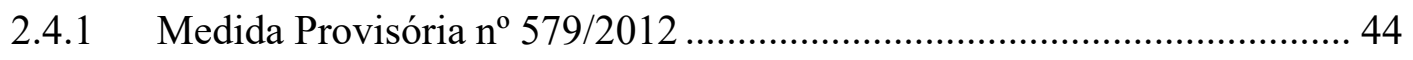

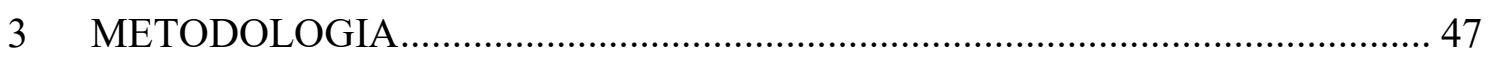

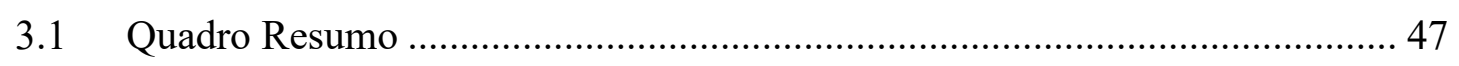

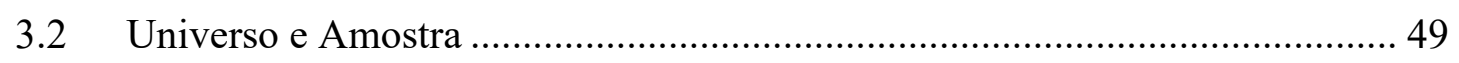

3.2.1 Características das Empresas da Amostra ........................................... 49

3.3 Definição Teórica e Operacional das Variáveis.............................................. 51

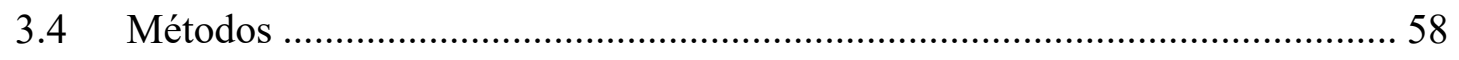

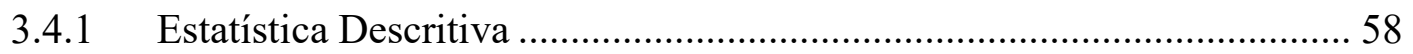

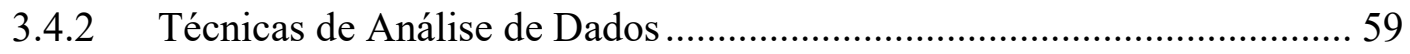

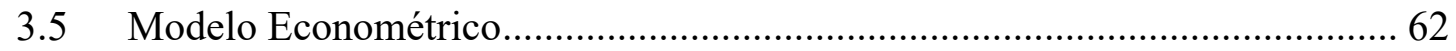

3.5.1 Primeiro Estudo: Desempenho e Variáveis Contábeis, de Governança e de Mercado

3.5.2 Segundo Estudo: Desempenho e Variáveis Econômicas ......................... 64

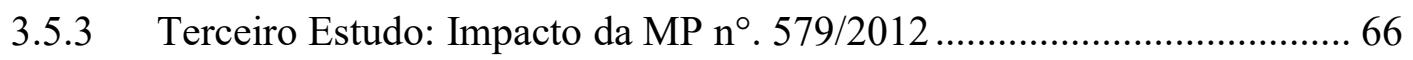

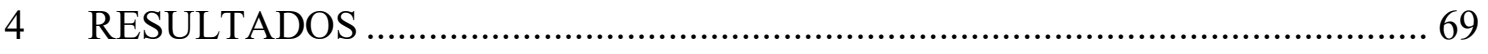

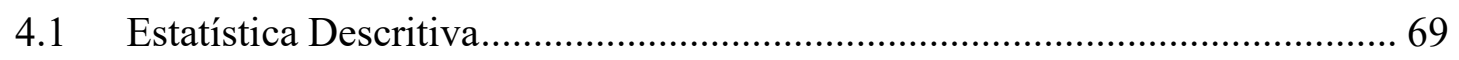

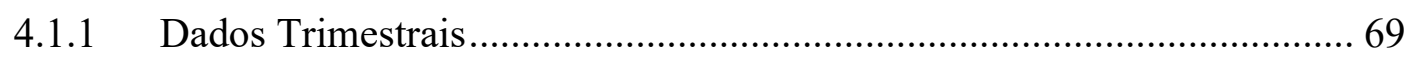

4.1.2 Dados Anuais.............................................................................. 71

4.2 Primeiro Estudo: Análise de Dados em Painel - Desempenho e Variáveis Contábeis, de Governança e de Mercado ................................................................. 73

4.2.1 Primeiro Painel: Desempenho e Variáveis Contábeis e de Governança com a Variável Dependente ROE....................................................................... 73

4.2.2 Segundo Painel: Desempenho e Variáveis Contábeis e de Governança com a Variável Dependente ROA .............................................................................. 75

4.2.3 Terceiro Painel: Desempenho e Variáveis de Mercado com a Variável Dependente Retorno da Ação ......................................................................... 77 
4.3 Segundo Estudo: Análise de Dados em Painel - Desempenho, Variáveis Contábeis, de Governança e de Mercado e Variáveis Econômicas. 79

4.3.1 Primeiro Painel: Desempenho, Variáveis Contábeis e de Governança, Variáveis de Mercado e Variáveis Econômicas com a Variável Dependente ROE79

4.3.2 Segundo Painel: Desempenho, Variáveis Contábeis e de Governança, Variáveis de Mercado, de Governança e Variáveis Econômicas com a Variável Dependente ROA. 81

4.4 Terceiro Estudo: Teste Diff-in-Diff e a Análise do Impacto da MP n . 579/2012 83

4.4.1 Estimador diff-in-diff para as variáveis ROE e ROA 84

4.4.2 Estimação Differences-in-Differences e Análise do Impacto da MP $\mathrm{n}^{\circ}$ 579/2012 através do estimador DID 85

5 CONSIDERAÇÕES FINAIS 89

REFERÊNCIAS 91 APÊNDICES 98 


\section{LISTA DE ABREVIATURAS E SIGLAS}

ACP - Análise de Componentes Principais

ACR - Ambiente de Contratação Regulada

AHP - Analytic Hierarchy Process

ANEEL - Agência Nacional de Energia Elétrica

BCB - Banco Central do Brasil

BNDES - Banco Nacional de Desenvolvimento Econômico e Social

CAPM - Capital Asset Pricing Model

CCC - Conta de Consumo de Combustíveis

CCEE - Câmara de Comercialização de Energia Elétrica

CDE - Conta de Desenvolvimento Energético

CMSE - Comitê de Monitoramento do Setor Elétrico

CNPE - Conselho Nacional de Política Energética

COPOM - Comitê de Política Monetária

CPC - Conselho Federal de Contabilidade

CVM - Comissão de Valores Mobiliários

DEA - Análise Envoltória de Dados

DID - Differences-in-Differences Estimator

EBITDA - Earnings Before Interest, Taxes, Depreciation and Amortization

EPE - Empresa de Pesquisa Energética

IASB - International Accounting Standards Board

IBGE - Instituto Brasileiro de Geografia e Estatística

IEE - Índice de Energia Elétrica

IFRS - International Financial Reporting Standards

IPEADATA - Base de Dados do Instituto de Pesquisa Econômica Aplicada

LAJIRDA - Lucro Antes dos Juros, Impostos, Depreciação e Amortização

LPA - Lucro por ação

MME - Ministério de Minas e Energia

NDGC - Níveis Diferenciados de Governança Corporativa

O\&M - Tarifa de Operação e Manutenção

ONS - Operador Nacional do Sistema Elétrico

$\mathrm{PCH}$ - Pequenas Centrais Hidrelétricas 
PIB - Produto Interno Bruto

PLD - Preço de Liquidação de Diferenças

RE-SEB - Reestruturação do Setor Elétrico Brasileiro

RGR - Reserva Global de Reversão

RNOA - Retorno Sobre Ativo Operacional Líquido

ROA - Retorno sobre o Ativo

ROCE - retorno sobre o capital empregado

ROE - Retorno sobre o patrimônio líquido

ROI - Retorno sobre o investimento

SEO - Seasoned Equity Offerings

SIN - Sistema Interligado Nacional

TEJ - Taiwan Economics Journal 


\section{LISTA DE QUADROS}

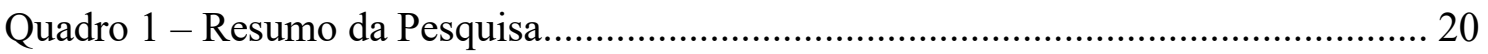

Quadro 2 - Quadro Resumo da Pesquisa .................................................................... 48

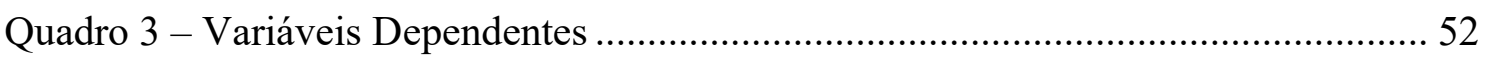

Quadro 4 - Variáveis Contábeis e Dummies ……..................................................... 52

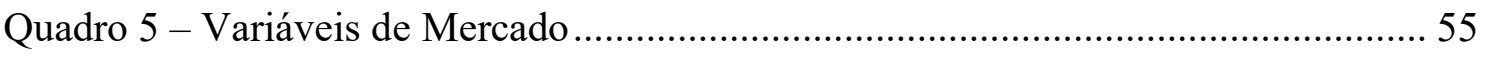

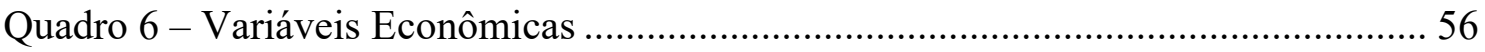




\section{LISTA DE TABELAS}

Tabela 1 - Descrição das Empresas de Energia Elétrica da Amostra ........................... 49

Tabela 2 - Estatística Descritiva das Variáveis Contábeis...........................................6 69

Tabela 3 - Estatística Descritiva das Variáveis de Mercado ......................................... 70

Tabela 4 - Estatística Descritiva das Variáveis Contábeis.......................................... 71

Tabela 5 - Estatística Descritiva das Variáveis de Mercado .......................................... 72

Tabela 6- Estatística Descritiva das Variáveis Econômicas ........................................... 72

Tabela 7 - Estimação com Erro-Padrão Robusto por Efeitos Fixos para a Variável ROE

Tabela 8 - Estimação com Erro-Padrão Robusto por Efeitos Fixos para a Variável ROA

Tabela 9 - Estimação com Erro-Padrão Robusto por Efeitos Fixos para a Variável

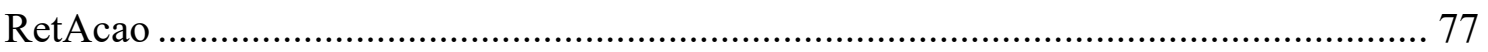

Tabela 10 - Estimação com Erro-Padrão Robusto por Efeitos Fixos para a Variável ROE

Tabela 11 - Estimação com Erro-Padrão Robusto por Efeitos Fixos para a Variável ROA 82

Tabela 12 - Estimador diff-in-diff para Variável Dependente ROE.............................. 84

Tabela 13 - Estimador diff-in-diff para Variável Dependente ROA .............................. 84

Tabela 14 - Resultados da Regressão com Erro-Padrão Robusto para Variável

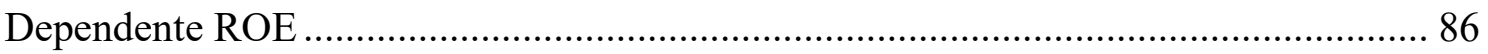

Tabela 15 - Resultados da Regressão para Variável Dependente ROA ........................ 87 


\section{INTRODUÇÃO}

\subsection{Situação Problema}

O setor de infraestrutura no Brasil passou a se desenvolver no início do século vinte, a partir de investimentos realizados ora pelo setor público, ora pelo setor privado, através de concessões. Ao longo das décadas posteriores, a proeminência passou para o setor público, que se tornou o majoritário operador das empresas de infraestrutura. Porém, a partir da década de 1990, as privatizações reabriram o caminho para a atuação do capital privado e, a partir de 2004, com a edição da Lei Federal n 11.079/04, houve a aprovação das parcerias público-privadas, o que ampliou ainda mais esta tendência.

Grandes empresas investem no setor por meio dos contratos de concessão nas áreas de infraestrutura social, bem como na infraestrutura econômica. Por isso, é questão amplamente discutida no Brasil o surgimento de riscos inesperados, normalmente produzido pela intervenção de agentes no âmbito das atividades exercidas de prestação de serviços públicos. Embora haja um aparato jurídico e operacional, desenvolvido pelas Agências Reguladoras, não é possível excluir a possibilidade de ocorrerem intervenções do Governo na execução das atividades ou na sua remuneração, o chamado risco regulatório, que pode alterar significativamente o resultado do negócio.

A título de exemplo, em 11 de setembro de 2012 o Governo Federal implementou a Medida Provisória ${ }^{\circ} 579$ com o intuito de promover a redução no custo final de energia elétrica para os consumidores. Foi dada a opção para o concessionário aderir, ou não, à medida naquele momento, o que implicou na renovação ou não da concessão para as empresas, ou no seu retorno ao Poder Concedente.

$\mathrm{O}$ anúncio da medida trouxe consequências diretas para todas as empresas do setor elétrico, em virtude da futura redução de receitas. Nos dias seguintes ao anúncio, as ações das empresas do setor caíram mais de $20 \%$, o que repercutiu inclusive nas empresas de outros segmentos da infraestrutura que sofriam regulação tarifária, devido ao temor que tal procedimento viesse a ser estendido para outras atividades. Embora a proposta da medida fosse reduzir os encargos de energia para o consumidor final, ela gerou impactos negativos sobre o desempenho das concessionárias de energia do país.

O presente estudo intenta contribuir para a análise do desempenho das empresas do setor elétrico, realizando um recorte sobre os impactos da MP579/2012. É examinada a 
rentabilidade das empresas a partir de variáveis contábeis e de Governança, de mercado e econômicas para os anos 2010 a 2015. Adicionalmente, o trabalho oferece uma análise das variáveis relatadas com o intuito de apresentar um painel sobre o setor, refletindo a dinâmica desse período recente.

\subsection{Problema de Pesquisa}

O presente trabalho busca responder à seguinte questão: Quais são os determinantes do desempenho das empresas do setor elétrico no Brasil?

\subsection{Objetivos}

\section{Objetivo Geral}

Avaliar o desempenho das empresas de energia elétrica no Brasil sob a ótica de variáveis contábeis e de governança, de mercado e econômicas para o período de janeiro de 2010 a dezembro de 2015.

\section{Objetivos Específicos}

1. Avaliar os efeitos do ambiente macroeconômico sobre a rentabilidade do setor elétrico;

2. Avaliar os impactos da interferência da edição da MP579 sobre a rentabilidade do setor elétrico.

\subsection{Hipóteses de Pesquisa}

As seguintes hipóteses de pesquisas foram levantadas:

H1: Os indicadores contábeis explicam o desempenho

H2: Os indicadores de mercado explicam o desempenho

H3: O ambiente macroeconômico afetou negativamente a rentabilidade das empresas

H4: A edição da MP n 579/2012 afetou negativamente a rentabilidade das empresas do setor elétrico no Brasil 


\subsection{Justificativa, Importância e Contribuições}

Este trabalho se insere num conjunto de obras que vem sendo realizadas para aprofundar o conhecimento do setor de infraestrutura e, em particular, das empresas de energia elétrica. Partindo da premissa que reguladores sofrem os efeitos da captura pelos agentes políticos e por concessionárias, o estudo se concentra na visão do desempenho como métrica de avaliação da companhia.

Avaliando a problemática do setor elétrico e seus segmentos, geração, transmissão, distribuição e comercialização, trata-se de um setor altamente regulado, fato que gera desafios maiores para que o setor seja de fato competitivo. Ainda, essa intervenção do Governo altera a estrutura de custos das empresas e requer altos investimentos cujos retornos são a longo prazo.

A importância do trabalho reside na sua atualidade, gerando uma contribuição ao estudo das empresas do setor, primeiramente devido às cinco análises produzidas sobre o desempenho, com variáveis contábeis e de governança, de mercado e econômicas como um conjunto e, ainda, a análise da Medida Provisória $n^{\circ}$ 579/2021 com o teste diff-in-diff, modelo ainda não encontrado na literatura com o mesmo propósito de avaliação, isto é, a rentabilidade das empresas que renovaram suas concessões.

Após a realização dos estudos, foram elencadas as variáveis que mais contribuem para a avaliação do desempenho das elétricas no Brasil no período estudado, 2010 a 2015, bem como o impacto da MP579 na rentabilidade das empresas.

\subsection{Limitações da Pesquisa}

O estudo realizado apresenta limitações importantes em relação ao tamanho da amostra do terceiro estudo com a técnica diff-in-diff para avaliar o impacto da MP579 na rentabilidade das empresas do setor elétrico. Isto porque, da amostra utilizada no trabalho, apenas três empresas não aderiram à medida em 2012. Ao todo, das companhias abertas do setor elétrico brasileiro, quatro empresas rejeitaram o pacote de mudanças proposto pelo Governo com a edição da Medida.

Com isso, este fato não inviabiliza a aplicação da técnica, bem como seus resultados, pois a técnica permite a separação da amostra de forma heterogênea. 


\subsection{Breve Discussão Metodológica}

A fim de compreender melhor o modelo conceitual do estudo, foi desenvolvido um quadro-resumo, contemplando o problema de pesquisa, os objetivos, as hipóteses correspondentes aos objetivos e a metodologia empregada para se atingir os objetivos propostos e testar as hipóteses elucidadas na pesquisa.

\section{Quadro 1 - Resumo da Pesquisa}

\begin{tabular}{|c|c|c|c|}
\hline $\begin{array}{c}\text { Problema de } \\
\text { Pesquisa }\end{array}$ & Objetivos & $\begin{array}{c}\text { Hipóteses } \\
\text { Correspondentes }\end{array}$ & Metodologia \\
\hline \multirow{3}{*}{$\begin{array}{l}\text { Quais são os } \\
\text { determinantes do } \\
\text { Desempenho das } \\
\text { Empresas do } \\
\text { Setor Elétrico no } \\
\text { Brasil? }\end{array}$} & $\begin{array}{l}\text { Geral: } \\
\text { Avaliar o desempenho } \\
\text { das empresas de energia } \\
\text { elétrica no Brasil sob a } \\
\text { ótica de variáveis } \\
\text { contábeis e de } \\
\text { Governança, de } \\
\text { mercado } \\
\text { macroeconômicas para } \\
\text { o período de janeiro de } \\
2010 \text { a dezembro de } \\
2015 \text {. }\end{array}$ & $\begin{array}{l}\text { H1: Os indicadores } \\
\text { contábeis explicam o } \\
\text { desempenho. } \\
\text { H2: Os indicadores de } \\
\text { mercado explicam o } \\
\text { desempenho. }\end{array}$ & $\begin{array}{l}\text { 1) Revisão da literatura sobre } \\
\text { desempenho e variáveis } \\
\text { contábeis e de mercado; } \\
\text { 2) Aplicação do modelo de } \\
\text { Regressão Linear Múltipla com } \\
\text { Dados em Painel, tendo como } \\
\text { dependente a variável ROE, } \\
\text { ROA e Retorno da Ação e } \\
\text { variáveis contábeis, de } \\
\text { Governança e de mercado como } \\
\text { explicativas. }\end{array}$ \\
\hline & $\begin{array}{l}\text { Específicos: } \\
\text { 1. Avaliar os efeitos do } \\
\text { ambiente econômico } \\
\text { sobre a rentabilidade do } \\
\text { setor elétrico; }\end{array}$ & $\begin{array}{lr}\text { H3: } \quad \text { O ambiente } \\
\text { econômico } & \text { afetou } \\
\text { negativamente } & \text { a } \\
\text { rentabilidade } & \text { das } \\
\text { empresas. } & \end{array}$ & $\begin{array}{l}\text { 3) Aplicação do modelo de } \\
\text { Regressão de Dados em Painel } \\
\text { para as variáveis ROE e ROA } \\
\text { como dependentes e variáveis } \\
\text { contábeis e de Governança, de } \\
\text { mercado e econômicas } \\
\text { históricas como explicativas. }\end{array}$ \\
\hline & $\begin{array}{l}\text { 2. Avaliar os impactos } \\
\text { da interferência da } \\
\text { edição da MP579 sobre } \\
\text { a rentabilidade do setor } \\
\text { elétrico. }\end{array}$ & $\begin{array}{l}\text { H4: A edição da MP } \mathrm{n}^{\circ} \\
\text { 579/2012 afetou } \\
\text { negativamente } \\
\text { rentabilidade a } \\
\text { empresas das } \\
\text { elétrico no Brasil. }\end{array}$ & $\begin{array}{l}\text { 4) Revisão da literatura sobre a } \\
\text { MP579/2012; } \\
\text { 5) Aplicação do teste diff-in-diff } \\
\text { para verificar rentabilidade das } \\
\text { empresas do setor elétrico antes } \\
\text { e após adoção da MP579/2012. }\end{array}$ \\
\hline
\end{tabular}




\subsection{Estrutura do Trabalho}

O estudo se apresenta composto por cinco capítulos, incluída esta introdução. No Capítulo 2 é desenvolvida a revisão da literatura a respeito do setor elétrico no Brasil, sua estrutura e o modelo de regulação. No Capítulo 3 é detalhada a metodologia empregada na pesquisa, a partir da composição da amostra das empresas, a definição das variáveis elencadas no estudo, os métodos utilizados para análise de dados e, ainda, os modelos propostos para fundamentar os três estudos elaborados. O Capítulo 4 apresenta os resultados dos três estudos, bem como suas derivações. No Capítulo 5 são apresentadas as considerações finais do trabalho, sua contribuição para a literatura e as sugestões de estudos futuros. 


\section{REVISÃO DA LITERATURA}

\subsection{Setor Elétrico no Brasil}

A nível mundial, a partir da década de 1990, o setor elétrico passou por reformas, com a ideia predominante de redução da participação do Estado e aumento da parcela do setor privado, buscando aumento da eficiência e autonomia econômica para a realização dos investimentos, com o objetivo de tornar o setor mais competitivo. Desta forma, poderia ser atendido o aumento da demanda dos consumidores, em termos de geração, transmissão e comercialização de energia. No Brasil, a reestruturação fez com que estes três setores passassem a ser administrados e operados por entes distintos.

O setor elétrico é altamente regulado, e um dos setores mais modernos do mundo. Dispõe de um sistema que interliga todas as regiões do país, o SIN - Sistema Interligado Nacional para realização de uma distribuição mais efetiva de energia elétrica, o que possibilita um serviço mais barato através da energia gerada pelas hidrelétricas e fontes renováveis, evitando fontes de energias mais caras como as termoelétricas, por exemplo (Assis, 2013).

Seu funcionamento está baseado em concessões, através das quais o Governo brasileiro cede o direito de prestar serviços públicos de geração, transmissão, distribuição e comercialização de energia elétrica às empresas privadas por período determinado por contratos. Seu objetivo predominante é a modicidade tarifária, isto é, uma tarifa acessível a todos os cidadãos em território nacional. Para isso, são realizados reajustes anuais e revisões tarifárias periódicas, algumas previstas nos contratos de concessão, e outras extraordinárias, a exemplo da edição da Medida Provisória n 579/2012 (Assis, 2013).

O setor elétrico é particularmente relevante para o estudo da infraestrutura no Brasil. Possui grande importância para a construção do desenvolvimento econômico do país e apresenta empresas em diferentes estágios e portes variados. O setor consiste, portanto, em geração de energia, transmissão, distribuição, comercialização e consumo. Para que todas essas partições funcionem adequadamente é necessário estabelecer condutas que sejam, sobretudo, eficazes.

Para compreender melhor o sistema, foi elaborado um resgate histórico do crescimento do setor e sua estruturação no país. 


\subsubsection{Retrospecto Histórico e o Novo Modelo do Setor Elétrico}

O aparecimento da energia elétrica no Brasil se deu no período da República Velha, a partir de 1880, fruto de iniciativas privadas, através da implantação dos primeiros empreendimentos, em regime de monopólio. Posteriormente, entre 1931 a 1945, no Governo Vargas, o Estado estabeleceu um importante marco regulatório para o setor, que enfrentava aumento na demanda de energia em função da aceleração no desenvolvimento econômico. A partir de 1946, com o intuito de elevar a oferta, o Estado aumentou sua participação, realizando investimentos públicos em todas as frentes.

Outro marco, foi a criação, em 1962, da Eletrobrás. Da década de 1960 até o final da década de 1970, ela atuou como no fomento da nacionalização e estatização do setor, consolidando um novo modelo institucional, que se perpetuou até 1979.

A década de 1980, marcada por forte recessão e restrições fiscais e produziu a redução dos investimentos, ocasionando atrasos ao setor e às iniciativas empresariais.

A partir de 1993, até 2002, o modelo que se solidificou foi o chamado Modelo Híbrido, com a Lei $n^{\circ} 8.631 / 93$, equacionando os débitos gerados pela alta inadimplência até 1992 . Outra mudança ocorrida nesta época foi a privatização das companhias operadoras através da Lei $\mathrm{n}^{\circ}$. 9.427, de dezembro de 1996, que instituiu a Agência Nacional de Energia Elétrica - Aneel. Ao final desse período, em 2002, as atividades do setor elétrico eram, em sua grande maioria, controladas por empresas estatais. Somente a distribuição era majoritariamente privada (Gomes e Vieira, 2009).

É importante ressaltar que especialmente após a década de 1960, as mudanças do modelo privado para o estatal tiveram falhas de planejamento, problemas contratuais e regulatórios, sobretudo devido à falta de coordenação entre os órgãos do Governo. Isto resultou no esgotamento do modelo, gerando sobrecarga de demanda ao setor e dificuldades na expansão da oferta de energia. Esses fatores combinados culminaram no racionamento que ocorreu entre 2001 e 2002 e fez o setor entrar em profunda crise (Pires, Giambiagi e Sales, 2002).

No início de 2001, o órgão operador nacional do sistema elétrico - ONS - constatou que era necessário efetuar uma redução de $20 \%$ do consumo de energia elétrica no país, como única saída para impedir o esvaziamento dos reservatórios devido à forte estiagem da época. Por isso, o Governo colocou em prática um programa de racionamento estabelecendo metas de redução de consumo. Ainda, foi criado um mecanismo de venda 
de direitos de consumo de energia entre as empresas, o que gerou diversas transações entre elas, bem como na bolsa de valores. O racionamento foi encerrado em fevereiro de 2002 (Pires, Giambiagi e Sales, 2002).

A partir de 2004, pós racionamento, o Governo Federal estabeleceu diretrizes para o funcionamento de um novo modelo do setor elétrico, a fim de reestruturar este segmento. O Novo Modelo teve como base o projeto RE-SEB - Reestruturação do Setor Elétrico Brasileiro - criado em 1996 e encerrado em 1998, cujo propósito era assegurar eficiência econômica e proporcionar investimentos ao setor. O novo modelo alterou toda a regulamentação vigente e marcou a retomada da responsabilidade do Estado no planejamento do setor (Cuberos, 2008).

O Novo Modelo teve como objetivos principais garantir a segurança no suprimento de energia elétrica; promover a modicidade tarifária e a inserção social através programas de universalização (como o Luz para Todos). Sua nova estrutura tomou como base muitas características do modelo da década de 1990, com a liberalização nas atividades, o que exigiu a cisão das companhias em geradoras, transmissoras e distribuidoras, sendo que as atividades de distribuição e transmissão continuaram altamente reguladas, enquanto a atividade de produção das geradoras passou a ser negociada no mercado livre por meio de contratos bilaterais (Aneel, 2015).

\subsubsection{Estrutura do Setor Elétrico no Brasil}

Ainda na década de 90, foram constituídas entidades atuantes no novo modelo institucional, como a Aneel, agência reguladora, e o ONS, que é órgão coordenador e supervisor da operação centralizada do sistema. A partir de 2004, através das leis $\mathrm{n}^{\circ}$. 10.847/2004 e n ${ }^{\circ}$ 10.848/2004 o Governo Federal manteve como atribuição do Poder Executivo Federal a formulação de políticas para o setor através do Ministério de Minas e Energia (MME), com assessoramento do Conselho Nacional de Política Energética (CNPE) e do Congresso Nacional.

A partir desses arranjos, novos agentes foram criados: a EPE - Empresa de Pesquisa Energética, vinculada ao MME, para realização dos estudos de planejamento de expansão do setor; a CCEE - Câmara de Comercialização de Energia Elétrica, que executa as operações no mercado livre. Ainda, vinculado ao MME, foi criado o CMSE - Comitê de 
Monitoramento do Setor Elétrico com a função de acompanhar e avaliar a continuidade e a segurança do suprimento de energia elétrica no país.

A Aneel disponibiliza o Atlas de Energia Elétrica, que reproduz a atual estrutura institucional do setor elétrico brasileiro, que trata:

(i) Das Políticas: Congresso Nacional, Presidência da República, Conselho Nacional de Política Energética e Ministério de Minas e Energia.

(ii) Regulação e Fiscalização: Agência Nacional de Energia Elétrica, Agências Estaduais, Agência Nacional do Petróleo, Conselhos de Consumidores, Entidades de Defesa do Consumidor, Secretaria de Direito Econômico vinculada ao Ministério da Justiça, Conselho Administrativo de Defesa Econômica, Secretaria de Acompanhamento Econômico, Secretaria Nacional de Recursos Hídricos e Ambiente Urbano, Ministério do Meio Ambiente, Agência Nacional de Águas, Conselho Nacional do Meio Ambiente.

(iii) Mercado: Câmara de Comercialização de Energia Elétrica, Operador Nacional do Sistema Elétrico.

(iv) Agentes Institucionais: Empresa de Pesquisa Energética, Centrais Elétricas Brasileiras S.A., Concessionárias e Banco Nacional do Desenvolvimento Econômico e Social.

\subsubsection{Modelo de Regulação do Setor Elétrico do Brasil}

Como propósito fundamental, a regulação tende a proteger os interesses dos consumidores, sobretudo da falta de concorrência, os chamados monopólios naturais (Malko e Skinner, 2011).

O modelo de regulação adotado pelo Brasil para o setor de energia elétrica é o price cap, que faz parte dos modelos da chamada regulação por incentivos. Nesse modelo, o regulador define o teto máximo a ser cobrado pelo serviço ou a receita máxima pela concessionária no período estabelecido. A partir desse período, é feita uma revisão, que considera os ganhos de eficiência gerados e as mudanças ocorridas no cenário regulatório, promovendo alterações e/ou estabelecendo limites. Este período se concentra atualmente de três a cinco anos, mas anualmente podem ser atualizados os preços de acordo com os reajustes de inflação (Medeiros, 2014). 
O modelo price cap permite certa liberdade às concessionárias quanto às modificações nos preços. Assim, estas têm a possibilidade de melhorar sua margem operacional, observando o preço-teto estabelecido. Todavia, o regulador deve observar essas mudanças nos preços relativos, para evitar que práticas abusivas ocorram. O regulador pode utilizar como critério o estabelecimento de um preço-teto médio ou estabelecer price-caps diferenciados para cada segmento da concessionária. No primeiro caso, o regulador consegue impedir muita liberdade de variação dos preços relativos. No segundo caso, consegue neutralizar a prática de subsídios cruzados entre os segmentos das concessionárias (Pires e Piccinini, 1998).

\subsection{Desempenho Financeiro, Operacional e de Mercado}

A avaliação do desempenho de uma empresa é de extrema importância para o seu planejamento estratégico e a tomada de decisões. Geralmente, ela é realizada com o apoio de índices econômico-financeiros calculados a partir das demonstrações financeiras.

Assaf Neto (2014) afirma que a análise através das demonstrações financeiras propicia prognóstico de tendências futuras da empresa e avalia os resultados da tomada de decisões da mesma sobre sua liquidez, estrutura patrimonial e rentabilidade. $\mathrm{O}$ autor explica que o uso de índices para avaliar o desempenho é a técnica mais regularmente empregada.

Matarazzo (2008) explica que, para se atingir o grau de profundidade de análise da situação econômica e financeira da empresa, é necessário escolher um conjunto de índices apropriados, de acordo com o tipo de informação que se deseja encontrar. A eficácia dos índices é aumentada desta forma, evitando-se a situação em que o analista passa a ter um rendimento decrescente ao se adicionar grande quantidade de índices novos à análise. Portanto, há uma relação ideal de custo versus benefício ao se acrescentar mais índices para se obter a informação desejada.

Szuster et al (2011) indicam que o uso de índices serve como "termômetro" para analisar a situação econômico-financeira da empresa, no entanto, não devem ser considerados de forma singular, mas sim analisados dentro de um contexto mais amplo.

Com isso, Matarazzo (2008) divide os índices da seguinte maneira: para se avaliar a situação financeira da empresa, utilizam-se índices de estrutura de capital e de liquidez; para se avaliar a situação econômica da empresa, índices de rentabilidade. Os índices de 
estrutura de capital evidenciam a obtenção e aplicação de recursos, mediante decisões financeiras.

São eles: participação do capital de terceiros, composição do endividamento, imobilização do patrimônio líquido, imobilização dos recursos não correntes. Quanto aos índices de liquidez, estes procuram medir quão sólida apresenta-se a base da situação financeira da empresa, se esta tem capacidade de saldar suas dívidas. São eles: liquidez geral, liquidez corrente e liquidez seca. Em relação aos índices de rentabilidade, o autor considera que estes sinalizam o grau de êxito econômico da empresa, a saber: giro do ativo, margem líquida, rentabilidade do ativo e rentabilidade do patrimônio líquido.

Szuster et al (2011) separa os indicadores em cinco grupos: indicadores de liquidez, indicadores de endividamento, indicadores de lucratividade, indicadores de rentabilidade, indicadores de prazos médios e indicadores dos fluxos de caixa.

Em relação aos indicadores de liquidez, os autores afirmam que estes retratam quanto a empresa possui de bens e direitos realizáveis, associados às obrigações exigíveis, no mesmo período: liquidez corrente, liquidez seca, liquidez imediata e liquidez geral. Quanto aos indicadores de endividamento, os autores mencionam que estes avaliam a segurança que a empresa produz aos capitais de terceiros que ela utiliza em sua gestão. São eles: endividamento geral, composição das exigibilidades, endividamento oneroso, composição do passivo oneroso e imobilização do patrimônio líquido. Os indicadores de lucratividade, por sua vez, refletem o percentual que sobra da receita para constituir o resultado da empresa, a saber: margem bruta, margem de lucro genuinamente operacional, margem operacional líquida e margem líquida. Em relação aos indicadores de rentabilidade, para todos eles, quanto maior, melhor. São eles: retorno sobre o patrimônio líquido e retorno sobre o ativo. Quanto aos indicadores de prazos médios, estes auxiliam no entendimento da gestão do capital de giro da empresa: prazo médio de estocagem, prazo médio de recebimento de clientes, prazo médio de pagamento a fornecedores, ciclo operacional e ciclo financeiro.

Assaf Neto (2014) separa os índices econômico-financeiros de análise em cinco categorias: indicadores de liquidez, indicadores de atividade, indicadores de endividamento e estrutura, indicadores de rentabilidade e indicadores de análises de ações. Para o autor, os indicadores de liquidez têm por finalidade mensurar a competência da empresa para cumprir de forma correta suas obrigações passivas, sendo consideradas a liquidez corrente, liquidez seca, liquidez imediata e liquidez geral. Como indicadores 
de atividade, Assaf Neto (2014) considera: prazo médio de estocagem, prazo médio de pagamento a fornecedores e prazo médio de cobrança. Os indicadores de endividamento e estrutura aferem a composição das fontes passivas de recursos da empresa, sendo eles: relação de capital de terceiros/capital próprio, relação capital de terceiros/passivo total, imobilização de recursos permanentes. Em relação aos indicadores de rentabilidade, estes descrevem os resultados alcançados pela empresa: retorno sobre o ativo, retorno sobre o investimento, retorno sobre o patrimônio líquido, rentabilidade das vendas. Assaf Neto (2014) menciona também os indicadores de análise de ações, que propõem avaliar a resposta do desempenho da empresa em relação às suas ações. São eles: lucro por ação e índice preço/lucro.

Para sintetizar, os índices mais utilizados na avaliação de desempenho, por categoria, são: Índices de estrutura de Capital:

(i) Participação de capitais de terceiros: razão de capitais de terceiros sobre o patrimônio líquido e indica o quanto a empresa tem de capitais de terceiros tomados para cada $\$ 100$ de capital próprio investido. Quanto menor, melhor (Matarazzo, 2008);

(ii) Composição do endividamento, cujo cálculo divide o passivo circulante pelo conjunto de capitais de terceiros e revela qual o percentual de obrigações de curto prazo a empresa tem em relação ao total de suas obrigações. Quanto menor, melhor (Matarazzo, 2008);

(iii) Imobilização do patrimônio líquido: razão do ativo permanente sobre o patrimônio líquido e demonstra o quanto a empresa tem aplicado no ativo permanente para cada $\$ 100$ de patrimônio líquido. Quanto menor, melhor (Matarazzo, 2008);

(iv) Imobilização dos recursos não correntes: ativo permanente sobre o patrimônio líquido somado ao exigível a longo prazo e indica que percentual de recursos não correntes a empresa possui aplicado em seu ativo permanente. Quanto menor, melhor (Matarazzo, 2008).

Índices de Liquidez:

(i) Liquidez corrente: ativo circulante sobre o passivo circulante, configura o quanto a empresa possui no ativo circulante para cada $\$ 1,00$ de passivo circulante e sabe-se que quanto maior, melhor (Matarazzo, 2008). Indica 
quanto a empresa dispõe de recursos de curto prazo para pagar suas dívidas circulantes (Szuster et al, 2011);

(i) Liquidez Geral: representado pela razão da soma do ativo circulante mais o realizável a longo prazo pela soma do passivo circulante mais o exigível a longo prazo e revela o quanto a empresa possui em seu ativo circulante e realizável a longo prazo para cada $\$ 1,00$ de dívida. Entende-se que quanto maior este índice, melhor (Matarazzo, 2008). Trata-se de uma medida da eficiência de pagamento de todo o passivo exigível da empresa, fazendo uso de todos os seus ativos realizáveis para cumprir seus compromissos com terceiros (Szuster et al, 2011). Representa a saúde financeira a longo prazo da empresa (Assaf Neto, 2014);

(i) Liquidez Imediata: quociente entre as disponibilidades e o passivo circulante. Indica a parcela das dívidas de curto prazo que a empresa consegue saldar com o saldo de caixa e equivalente (Szuster et al, 2011);

(ii) Liquidez seca: representado pela divisão entre o disponível somado às aplicações financeiras mais clientes de rápida conversibilidade em dinheiro sobre o passivo circulante, e demonstra o quanto a empresa possui de ativo líquido para cada $\$ 1,00$ de passivo circulante. Quanto maior, melhor (Matarazzo, 2008). É uma medida mais rigorosa e indica o quanto a empresa poderá utilizar de recursos circulantes, sem vender seus estoques e sem amortizar as despesas antecipadas, para cumprir com suas obrigações de curto prazo (Szuster et al, 2011).

Índices de Rentabilidade:

(i) Giro do ativo: representado pela razão entre as vendas líquidas e o ativo, indica quanto a empresa vendeu para cada $\$ 1,00$ de investimento total e quanto maior, melhor (Matarazzo, 2008);

(ii) Margem líquida: representada pela divisão entre lucro líquido e vendas líquidas, apresentando o quanto a empresa obteve de lucro para cada $\$ 100$ vendidos. Quanto maior, melhor (Matarazzo, 2008);

(i) Rentabilidade do ativo (ROA): divisão do lucro líquido pelo ativo, utilizado para compreender o quanto a empresa obteve de lucro para cada $\$ 100$ de investimento total e entende-se que quanto maior, melhor (Matarazzo, 2008). O ROA revela o retorno produzido pelas aplicações 
que a empresa realiza em seus ativos (Assaf Neto, 2014). Os autores Szuster et al (2011) compreendem o retorno sobre o ativo como a divisão entre o somatório do lucro líquido deduzido das despesas financeiras líquidas do efeito tributário e o ativo total médio. Afirmam que este reflete a que taxa a empresa remunera os investimentos totais que são aplicados na mesma;

(ii) Rentabilidade do patrimônio líquido (ROE): razão entre o lucro líquido e o patrimônio líquido médio, revela o quanto a empresa obteve de lucro para cada $\$ 100$ de capital próprio investido e prevê-se que quanto maior, melhor (Matarazzo, 2008). Mede a remuneração dos capitais próprios investidos na empresa (Szuster et al, 2011);

(iii) Retorno sobre o investimento (ROI): é determinado pela divisão entre o lucro gerado pelos ativos e o investimento médio. É uma medida alternativa ao ROA, porém sobre o investimento, isto é, sobre os recursos que a empresa aplica em seus negócios, o capital que deve necessariamente ser remunerado (Assaf Neto, 2014);

(iv) Rentabilidade das vendas: mensura a eficiência que a empresa possui para realizar lucro através das vendas. Pode ser apurada através do cálculo da margem operacional e da margem líquida (Assaf Neto, 2014).

Indicadores de Endividamento:

(i) Endividamento Geral: divisão entre a soma do passivo circulante e o passivo não circulante e o ativo. Revela o grau de endividamento total da empresa (Szuster et al);

(ii) Composição das Exigibilidades: razão entre o passivo circulante e o somatório do passivo circulante com o passivo não circulante. É um indicador da qualidade do passivo da empresa, em relação a prazos (Szuster et al);

(iii) Endividamento Oneroso: quociente entre o somatório do passivo circulante oneroso com o passivo não circulante oneroso pelo ativo total (Szuster et al);

(iv) Composição do Passivo Oneroso: divisão entre o passivo circulante oneroso e o somatório do passivo circulante oneroso com o passivo não 
circulante oneroso. Medida que compara o total de dívidas onerosas no curto prazo com o passivo oneroso total (Szuster et al);

(v) Imobilização do Patrimônio Líquido: quociente entre o ativo imobilizado e o patrimônio líquido. Revela o quanto do ativo imobilizado da empresa é financiado pelo seu patrimônio líquido (Szuster et al);

(vi) Relação de capital de terceiros/capital próprio: é a divisão entre o exigível total sobre o patrimônio líquido. Aponta o nível de endividamento da empresa associado a recursos próprios (Assaf Neto, 2014);

(vii) Relação capital de terceiros/passivo total: é mensurado com base na divisão entre o exigível total e o passivo total. Identifica a porcentagem de recursos de terceiros que a empresa utiliza para se financiar (Assaf Neto, 2014);

(viii) Imobilização de recursos permanentes: calculado através da razão entre o ativo permanente e o exigível a longo prazo somado ao patrimônio líquido. Apresenta a proporção dos recursos permanentes que estão imobilizados em itens do ativo permanente (Assaf Neto, 2014).

Indicadores de Atividade:

(i) Prazo médio de estocagem: estoque médio sobre o custo dos produtos vendidos. Mede a eficiência da gestão de estoques e a influência que exercem na dinâmica global da empresa (Assaf Neto, 2014);

(ii) Prazo médio de pagamento a fornecedores: é calculado a partir da razão entre as contas a pagar a fornecedores, na média, sobre as compras anuais a prazo. Indica o tempo médio que a empresa demora para pagar suas dívidas de fornecedores, a prazo (Assaf Neto, 2014);

(iii) Prazo médio de cobrança: obtido pela divisão entre valores a receber provenientes de vendas a prazo, na média, e as vendas anuais a prazo. Representa o tempo média que a empresa leva para receber as vendas a prazo (Assaf Neto, 2014);

(iv) Prazo Médio de Recebimento de Clientes: corresponde à razão da média aritmética do saldo da conta clientes medidos no início e no final do período contábil sobre a receita bruta. Apresenta, em média, quanto tempo a empresa financia seus clientes, através das vendas a prazo (Szuster et al, 2011); 
(v) Ciclo Operacional: tempo decorrido entre a compra de mercadorias e o recebimento do valor das vendas (Szuster et al, 2011);

(vi) Ciclo Financeiro: diferença entre o prazo médio de pagamento a fornecedores e o ciclo operacional (Szuster et al, 2011).

Indicadores de Lucratividade:

(i) Margem Bruta: quociente entre o lucro bruto e a receita. É uma medida de lucratividade das vendas (Szuster et al, 2011);

(ii) Margem de Lucro Genuinamente Operacional: divisão entre o lucro antes do resultado financeiros e tributos e a receita. Medida que avalia o ganho da empresa que é decorrente da atividade operacional em relação a seu faturamento. Representa a capacidade operacional real da empresa em gerar resultado com suas vendas (Szuster et al, 2011);

(iii) Margem Operacional Líquida: quociente entre o lucro das operações continuadas e a receita. Avalia o ganho operacional da empresa sobre seu faturamento (Szuster et al, 2011);

(iv) Margem Líquida: é o lucro líquido sobre a receita. Reflete o ganho líquido da empresa em cada unidade de venda realizada (Szuster et al, 2011).

Indicadores de Análise de Ações:

(i) Lucro por ação (LPA): aufere o benefício obtido pelas ações emitidas pela empresa individualmente em determinado período. É mensurado pela divisão entre o lucro líquido e o número de ações emitidas (Assaf Neto, 2014);

(ii) Índice preço/lucro (P/L): é calculado pela razão entre o preço de mercado da ação sobre o lucro por ação e indica quantos anos um investidor demora para recuperar o capital aplicado na ação da empresa (Assaf Neto, 2014).

Para finalizar, conforme definem Neely, Gregory e Platts (1995), a mensuração de desempenho é o processo de quantificar a eficiência e a eficácia de uma ação. Uma medida de desempenho pode ser entendida como um instrumento para realizar essa quantificação. E, por fim, um sistema de medição de desempenho é um conjunto de métricas que se utiliza para quantificar a eficiência e a eficácia dessas ações. Neely (1998), por sua vez, definiu a mensuração de desempenho como o processo de quantificar a eficiência e a efetividade de ações passadas, por meio da aquisição, coleta, classificação, análise, interpretação e disseminação dos dados, a fim de ser 
insumos para gerar informações para que ações preventivas e/ou corretivas sejam realizadas de forma efetiva.

\subsection{Evidências Empíricas dos Determinantes de Desempenho Financeiro, Operacional e de Mercado}

A revisão de literatura sobre desempenho se apresenta (i) pelas evidências empíricas das variáveis financeiras e operacionais, (ii) pelas evidências empíricas dos aspectos de Governança e (iii) pelas evidências empíricas das variáveis de mercado, conforme segue.

\subsubsection{Evidências Empíricas - Variáveis Financeiras e Operacionais}

Beaver (1966) fez uso de índice financeiros para desenvolver um indicador que fosse melhor diferenciado entre as empresas que sofreram fracasso e não fracasso empregando técnicas de análise univariada.

Altman (1968) usou índices financeiros para prever falência. Ele relatou que o modelo de falência possui $93 \%$ de precisão, sendo considerado muito bem sucedido para previsões de falência nas empresas.

Ohlson (1980) empregou índices financeiros para prever crise nas empresas. Elencou quatro fatores que afetam a vulnerabilidade de uma empresa: escala da empresa, estrutura financeira, desempenho e liquidez.

Bernstein (1988) dividiu índices financeiros em quatro categorias para avaliar o desempenho da empresa: solvência, estrutura de capital, rentabilidade e volume de negócios.

Feng e Wang (2000) procuraram construir um processo de avaliação de desempenho para as companhias aéreas, utilizando indicadores financeiros.

Estudos mais recentes como os de Parker (1997), Shaoul (1997), Sirtaine et al. (2005), Lin, Liu e Chu (2005), Bekana e Abitie (2012), Delen, Kuzey e Uyar (2013) e Reynaud e Thomas (2013) utilizaram indicadores financeiros a partir da análise das demonstrações financeiras como métrica para verificar a contribuição dos diversos elementos operacionais para a composição do resultado.

Parker (1997) estudou as 24 principais empresas reguladas e os retornos obtidos pelos investidores pós-privatização no Reino Unido sob o regime de regulação conhecido como 
price cap, revendo o lucro obtido por essas empresas do setor de infraestrutura. Para avaliar a rentabilidade, o autor utilizou a margem de lucro operacional e o ROCE - retorno sobre o capital empregado - como medida. Os resultados evidenciaram que as empresas reguladas e privatizadas forneceram altos retornos aos investidores devido em parte da sub-precificação das flutuações das ações do setor de serviços públicos (utilities).

Shaoul (1997) elaborou um estudo de caso com dados financeiros e contábeis das empresas da indústria da água no Reino Unido que foram privatizadas. Realizou uma análise sobre a distribuição do excedente gerado pela indústria para verificar a afirmação do Governo de aumento da eficiência e benefícios com a privatização. A forma de análise se baseou na proporção de compras sobre a receita de vendas, distribuição interna do valor adicionado, distribuição externa e nas relações entre os três itens. A receita de vendas aumentou rapidamente após a privatização. Como conclusão, encontrou que não houve aumento de eficiência devido a privatização, e quanto a distribuição do excedente, verificou-se que os verdadeiros beneficiários eram em grande parte "invisíveis" no caso do Governo.

Sirtaine et al (2005) estimaram os retornos realmente obtidos pelos investidores privados em projetos de infraestrutura realizados na América Latina e avaliaram a adequação desses retornos associados aos riscos, levando em conta o custo do capital e o impacto da qualidade da regulação nesses países. Foram estudados os dados de 34 concessionárias na área de infraestrutura - telecomunicações, água, energia elétrica e transportes - dos países Argentina, Brasil, Bolívia, Chile, Colômbia, El Salvador, México, Peru e Venezuela. O estudo foi construído através do modelo CAPM - Capital Asset Pricing Model - para verificar os retornos esperados em relação aos riscos. Para as medidas de retornos financeiros, os autores utilizaram quatro variáveis: taxa interna de retorno dos acionistas, ROE, taxa interna de retorno do projeto e ROCE. Os resultados empíricos evidenciaram que os retornos variam entre setores, países e concessionárias e que a variação entre concessionárias depende da qualidade da regulação, e que os países devem realizar esforços para melhorá-la.

Lin, Liu e Chu (2005) utilizaram indicadores financeiros para avaliar o desempenho da indústria de transporte, com modelo de análise envoltória de dados (DEA) a fim de calcular a eficiência operacional de 14 empresas de navegação em 2003 com banco de dados do TEJ - Taiwan Economics Journal. Para medir a eficiência de cada firma, os autores elaboraram duas regressões, uma com o ROA e outra com o ROE como variável 
dependente para contrastar com o DEA. Compararam, portanto, os resultados da análise com DEA e com indicadores financeiros e concluíram que nesse caso somente o uso de indicadores financeiros para avaliação de desempenho não fizeram com que esta análise fosse mais eficiente.

Bekana e Abitie (2012) estudaram o desempenho financeiro do setor de construção e banco de negócios da Etiópia. Utilizaram indicadores de utilidade e eficiência de ativos, movimentação de depósitos, desempenho dos empréstimos, indicadores de liquidez, alavancagem financeira, indicadores de rentabilidade, índices de solvência e índices de cobertura para avaliar o desempenho financeiro para o período 2002/2003 até 2009/2010. Apontaram como conclusões que a análise das demonstrações financeiras do banco sobre movimentação de depósitos, desempenho do crédito, utilização de ativos, saldo dos fundos e a capacidade de desembolso da dívida mostraram ser fracas. Os resultados da análise de indicadores revelaram que a margem ebitda e os índices de rentabilidade em geral aumentaram ao longo do período de estudo considerado. $\mathrm{O}$ banco deve reforçar a estratégia de aumentar suas receitas, mantendo o seu custo de operação para o nível mínimo possível. Portanto, é vantajoso para o banco a compreensão destes índices críticos para avaliar seu desempenho financeiro e tomar novas decisões.

Delen, Kuzey e Uyar (2013) empregaram análise fatorial para identificar e validar algumas dimensões dos indicadores financeiros, seguido de uma modelagem de métodos para investigar as relações entre desempenho da empresa e indicadores financeiros. Os autores utilizaram quatro algoritmos de árvore de decisão (CHAID, C5.0, QUEST e C \& RT) e desenvolveram modelos de previsão com o intuito de medir a importância relativa das variáveis independentes com a base de dados do software FINNET com empresas de capital aberto da bolsa de valores de Istambul, Turquia, para o período de 2005 a 2011. Como indicadores financeiros, utilizaram indicadores de liquidez, índices de volume de negócios, indicadores de rentabilidade, indicadores de margem de lucro, indicadores de crescimento, indicadores de estrutura de capital e índices de solvência. As variáveis dependentes utilizadas foram o ROA e o ROE. Os resultados mostraram que os algoritmos CHAID e C5.0 foram mais precisos na previsão. Os resultados da análise de sensibilidade indicaram que Ebitda e Margem de lucro líquido são as duas variáveis mais importantes para determinar o desempenho das firmas.

Reynauld e Thomas (2013) analisaram a rentabilidade de 71 empresas cuja atividade principal é a provisão de água para os consumidores finais. $\mathrm{O}$ estudo considerou nove 
países: Marrocos, Alemanha, China, Espanha, Chile, Reino Unido, França, Estados Unidos e México. Para avaliar a rentabilidade, utilizaram o ROE e a Margem de lucro líquido como proxies. As informações financeiras foram avaliadas entre os anos 2006 a 2009. Como resultados, encontraram possíveis determinantes da rentabilidade das empresas, como o tamanho das firmas, o ambiente macroeconômico (medido pelo crescimento do PIB), e, em específico para o setor de água, as características da regulação implementada nesses países faz diferença e pode explicar seu nível de rentabilidade. A regulação pode ser uma importante medida de rentabilidade das empresas cujos países estão sob o regime de price cap.

No Brasil, os estudos de Rocha, Camacho e Braganca (2007), Buccini (2012), Ribeiro, Macedo e Marques (2012) e Curcino, Lemes e Botinha (2014) buscaram avaliar o desempenho das empresas, inclusive do setor elétrico e infraestrutura, produzindo análises temporais sobre os indicadores.

Rocha, Camacho e Bragança (2007) analisaram o segmento de distribuição de energia elétrica no Brasil pós privatização, de 1998 a 2005, a fim de avaliar se o retorno sobre o capital investido se mostrou proporcional ao risco sistemático. Os autores encontraram que a equidade do retorno foi negativa até 2003, e somente em 2005 o segmento começou a se recuperar. O estudo evidenciou que para suportar o ritmo de crescimento do setor de, em média, 3,7\% ao ano para a próxima década, o setor irá exigir US\$ 7 bilhões gastos, na proporção: $67 \%$ para geração, 16\% para transmissão e $17 \%$ para a distribuição de energia no país. Para tanto, se faz necessário investimento de capital privado e revisão tarifária a ser feita pelo órgão regulador, para assegurar taxa de retorno consistente com o custo real de oportunidade do segmento, assim como em países com a Argentina e os Estados Unidos.

Buccini (2012) buscou identificar os direcionadores de avaliação de empresas prestadoras de serviço público (public utilities) no Brasil através de demonstrações financeiras. Empregou análise de dados em painel para empresas de saneamento, distribuição de energia elétrica e telecomunicações entre 2004 e 2010. Para mensurar rentabilidade, a autora utilizou vários indicadores, dentre eles o ROE, RNOA (retorno sobre ativo operacional líquido), margem de lucro operacional, giro do ativo e alavancagem financeira. Obteve como resultados, com base na análise de indicadores contábeis, baixa rentabilidade, margem de lucro reduzidas, investimentos de capital intensivo e elevada alavancagem financeira. 
Ribeiro, Macedo e Marques (2012) examinaram a relevância de indicadores financeiros e não financeiros sobre o desempenho de empresas brasileiras do segmento de distribuição de energia elétrica. Realizaram um estudo de caráter exploratório utilizando as técnicas Delphi e Análise Hierárquica (AHP). Utilizaram 38 indicadores em três categorias: financeira, operacional e socioambiental e aplicaram questionário com analistas do BNDES - Banco Nacional de Desenvolvimento Econômico e Social. Como resultados, obtiveram que os índices Cobertura de Juros, ROE e Perfil de Endividamento são os mais importantes no aspecto financeiro; os indicadores Margem Ebitda, FEC (número de interrupções ocorridas, em média, em cada unidade consumidora) e DEC (duração de interrupção equivalente por consumidor) para a perspectiva operacional; e Taxa de Comprometimento Ambiental e Rentabilidade Agregada dos Investimentos para a perspectiva socioambiental.

Curcino, Lemes e Botinha (2014) produziram estudo sobre o resultado dos indicadores financeiros de rentabilidade das empresas brasileiras de capital aberto presentes no Índice Bovespa após a adoção das normas internacionais de contabilidade em 2010. Utilizaram as variáveis ROE e LPA para identificar modificações nos níveis de rentabilidade dessas empresas. A amostra final compreendeu 32 empresas para o cálculo do ROE e 38 empresas para o cálculo do LPA entre o período de 2010 a 2012. Os autores explicam que devido a convergência às Normas Internacionais de Contabilidade, o plano de contas das empresas sofreu alterações. Essas modificações influenciaram a forma de calcular os indicadores financeiros, além da adaptação e elucidação de possíveis efeitos da forma de mensuração de lucro sobre outros indicadores financeiros de rentabilidade (ROA e ROI, por exemplo).

Assim como os indicadores financeiros, as variáveis de mercado também são utilizadas para avaliar desempenho.

\subsubsection{Evidências Empíricas - Aspectos de Governança}

Bernardino, Peixoto e Ferreira (2015) relacionaram Governança Corporativa e eficiência nas empresas de capital aberto do setor elétrico brasileiro de 2008 a 2012, aplicando as técnicas ACP - Análise dos Componentes Principais, DEA - Análise Envoltória de Dados e regressões com dados em painel. Construíram um índice de Governança com doze variáveis e o indicador de desempenho LAJIRDA - Lucro Antes dos Juros, 
Impostos, Depreciação e Amortização para desempenho contábil. Como resultado, encontraram associação positiva entre Governança e eficiência tanto para a relação entre o indicador de Governança e o escore de eficiência quanto para os índices de Governança e a variável LAJIRDA corroborando à ideia de que empresas com boas práticas de Governança são mais eficientes no mercado.

De Souza et al (2015) relacionaram Governança Corporativa e Desempenho para 18 empresas do setor elétrico listadas na BM\&FBovespa através do comportamento das ações, do coeficiente beta e do Índice de Energia Elétrica (IEE) como valor de mercado. A janela temporal foi estabelecida para os períodos de janeiro de 2009 a junho de 2011 e outubro de 2012 a outubro de 2013. O estudo apontou que a Governança pode ser responsável por balizar a volatilidade das ações das empresas desse setor, a exemplo do período da crise internacional de 2008, a Governança as manteve menos voláteis no mercado. Em relação aos níveis diferenciados de Governança, os resultados apontaram comportamento uniforme das ações das empresas de energia. Os autores destacam o impacto da MP579/2012 sobre a Governança no setor, em especial o caso da Eletrobras, com maior porcentagem de participação no IEE e que teve a maior disparidade acionária entre as empresas da amostra. Ainda, explicam que há relação entre Governança Corporativa, risco e valor de mercado dentro do equilíbrio e estabilidade que práticas de Governança trazem às elétricas.

Ferreira e Silva (2016) estudaram Governança Corporativa e Valor para o setor elétrico brasileiro para o período de 1998 a 2012 através da investigação sobre risco e retorno das ações das empresas do setor e a associação com a adesão aos Níveis Diferenciados de Governança Corporativa - NDGC criados pela BM\&FBovespa. Os autores produziram a matriz de correlação e aplicaram teste de hipóteses. Os resultados apontaram que os retornos anormais aumentaram após a adesão e estatisticamente não puderam afirmar que a média desses retornos foram maiores após a adesão e que houve aumento de valor das companhias.

\subsubsection{Evidências Empíricas - Variáveis de Mercado}

Minardi et al (2007) realizaram um estudo com variáveis contábeis e de mercado para apurar o custo de capital de terceiros de empresas a valor de mercado. Coletaram dados de rating de crédito das agências Moody's e Standard \& Poor's com uma amostra de 627 
empresas americanas. Utilizaram o modelo logístico ordenado para selecionar as variáveis que explicam os ratings de crédito das agências e desenvolveram um modelo classificatório de rating de crédito.

Acharya e Schnabl (2010) estudaram o desequilíbrio global da crise financeira de 2008, no período de 2007 a 2009, através da análise das condutas comerciais dos grandes bancos. Utilizaram o retorno da ação para analisar a resposta a nível de banco e encontraram que os bancos com maior exposição foram mais afetados pela crise de 2008 . Demirgüç-Kunt e Huizinga (2010) examinaram os impactos da atividade bancária nas estratégias de financiamento de curto prazo para estudar risco e retorno dos bancos, utilizando uma amostra de 1.334 bancos em 101 países, que antecederam a crise financeira de 2008. Realizaram teste de robustez utilizando o índice de Sharpe para verificar o retorno; e quanto ao risco, utilizaram como proxy a variabilidade do retorno da ação do banco e o desvio padrão do retorno da ação do banco com dividendos. Utilizaram variáveis macroeconômicas e institucional e de regulação como variáveis de controle. O objetivo do trabalho era entender quais rendimentos e estratégias funcionam bem para produzir bancos rentáveis e estáveis. As regressões indicaram que em baixos níveis de receita sem juros e não-depósito podem ocorrer benefícios de diversificação de risco. Os resultados sugeriram que estratégias sobre o rendimento sem juros ou financiamento sem depósito são muito arriscados para os bancos.

Edmans (2011) estudou a relação entre a satisfação do empregado e o retorno da ação a longo prazo. O portfólio foi construído comas 100 melhores empresas para trabalhar na América entre 1984 e 2005 divulgado pela Revista Fortune. As teorias centradas no capital humano afirmam que a satisfação dos empregados é positivamente correlacionada com os retornos dos acionistas. Os resultados foram consistentes com as teorias. A satisfação do empregado superior causou uma parte do retorno anormal mensal. $\mathrm{O}$ autor concluiu que os programas favoráveis aos empregados podem melhorar notavelmente o valor para os acionistas.

No Brasil, Nagano, Merlo e Silva (2003) verificaram se o mercado de ações brasileiro se comportou conforme o modelo de precificação de ativos CAPM ou se existiram outras variáveis fundamentalistas que são significativas para a análise dos retornos das ações negociadas na Bovespa. Utilizou retorno das ações, o beta, ativo total sobre valor patrimonial, ativo total sobre valor de mercado, dividendos sobre preço, fluxo de caixa sobre preço, liquidez em bolsa, valor de mercado da empresa, valor patrimonial sobre 
preço, lucro sobre preço e vendas sobre preço. O período estudado foi de 1995 a 2000. Os resultados apontaram que o CAPM está mal especificado pois há a possibilidade de inclusão de outras variáveis no comportamento dos retornos dos ativos além do beta.

Mellone Junior e Saito (2004) avaliaram os principais determinantes na substituição de executivos de empresas listadas na Bolsa de Valores de São Paulo nos anos de 1997 a 2001 através de dois fatores preponderantes: o desempenho da empresa e o monitoramento interno. Utilizaram informações sobre substituição de executivos, retornos de ações e dados contábeis. Encontraram como resultados que o desempenho é determinante na substituição de diretoria executiva, mas não ao principal executivo da companhia, que a substituição do principal executivo da empresa é positivamente correlacionada com o tamanho do conselho de administração e com a baixa liquidez da empresa, o que evidenciam o monitoramento interno exercido pelos acionistas da empresa.

Bragança, Pessoa e Rocha (2015) estudaram a intervenção regulatória nos setores de telecomunicações e elétrico utilizando uma metodologia de heterocedasticidade condicional autorregressiva generalizada - GARCH - multivariado a fim de avaliar os impactos diretos e cruzados na volatilidade do retorno setorial das ações das empresas dos setores de energia elétrica e de telecomunicações. O estudo utilizou também a metodologia VIRF desenvolvida por Hafner e Herwartz (2006) para analisar a magnitude e persistência dos choques associados às medidas regulatórias da Anatel e Aneel, órgãos reguladores dos setores no ano de 2012. Como resultado, encontraram que o modelo estimado GARCH-BEKK mostrou que as volatilidades dos dois setores estão conectadas e que o aumento do risco em um dos setores, na média, afeta o risco do outro. Ainda, que as agências reguladoras precisam contrapor o aumento potencial do risco regulatório aos benefícios de determinada medida regulatória. A redução do risco regulatório pode aumentar o investimento nos setores de infraestrutura brasileiro.

Com base nesses estudos, há amparo da literatura sobre as variáveis utilizadas e se torna possível estabelecer uma abordagem metodológica para o trabalho.

\subsubsection{Novo Modelo de Contabilidade Societária para o Brasil}

Em 2007, o Governo Federal sancionou a Lei ${ }^{\circ}$ 11.638, complementada pela Medida Provisória $n^{\circ} 449 / 2008$ que foi convertida na Lei $n^{\circ} 11.941 / 2009$, que alterou e revogou 
dispositivos da Lei $n^{\circ}$ 6.404/1976, em vigor até 2007 no Brasil, efetuando melhorias nas condições do processo de harmonização da contabilidade societária brasileira com a contabilidade internacional. De 2008 a 2011, o Conselho Federal de Contabilidade (CPC) fez a convergência de normas contábeis aplicáveis às transações e aos eventos das entidades, e várias delas foram referendadas pela Aneel através dos Despachos $\mathrm{n}^{\circ}$ 4.796/2008 e n 4.722/2009 (Leite, 2012).

São dois conjuntos de normas que o International Accounting Standards Board - IASB e o CPC emitem: as IFRSs plenas e as relativas às pequenas e médias empresas. As demonstrações obrigatórias são o Balanço Patrimonial, a Demonstração do Resultado Abrangente, a Demonstração do Resultado, a Demonstração dos Fluxos de Caixa, a Demonstração das Mutações do Patrimônio Líquido, a Demonstração do Valor Adicionado (companhias abertas) e as notas explicativas. No caso das companhias abertas, com a aprovação por parte da CVM - Comissão de Valores Mobiliários de todos os pronunciamentos do CPC, a adoção é total: normas integrais das IFRSs nas demonstrações individuais, bem como nas consolidadas (Martins, Diniz \& Miranda, 2012).

\subsection{Efeitos do Contexto Econômico e Político no Desempenho das Empresas do Setor Elétrico no Brasil}

As modificações do cenário econômico e político podem influenciar direta e/ou indiretamente o setor elétrico, bem como o desempenho das empresas participantes. Neste sentido, estudos como os de Klagsbrunn et al (2011), Assis (2013), De Castro et al (2013) e Brambilla e Mueller (2015) buscaram compreender esta relação entre o contexto econômico e político e o setor elétrico no Brasil.

Klagsbrunn et al (2011) identificaram a existência de uma correlação forte e direta entre a atividade econômica e o setor elétrico e que esta inter-relação ocorre (i) no longo prazo devido à necessidade que o setor possui no sentido de ampliar sua capacidade produtiva a fim de manter o equilíbrio entre oferta e demanda de energia elétrica e (ii) no curto prazo, sendo mais visível, pois as variações no ritmo da produção econômica produzem efeitos diretos no consumo de energia.

Brambilla e Mueller (2015) analisaram se as variações produzidas no consumo industrial de energia elétrica são propagadas para o crescimento econômico do país, avaliado 
através do PIB. Os autores identificaram que o Brasil tende a se ajustar de forma rápida à eventuais desequilíbrios e que, no longo prazo, os preços das tarifas médias e o consumo de energia tendem a impactar de forma positiva o PIB.

Assis (2013) encontrou evidências de que os aspectos políticos foram bastante relevantes para influenciar na decisão das concessionárias quanto à renovação dos contratos de concessão, mediante adesão à Medida $n^{\circ}$ 579/2012. A autora evidenciou que para concessionárias nas quais o governo estadual estava alinhado politicamente ao Governo Federal, a probabilidade de renovação aumentava de forma significativa, e que a pressão para renovação não foi tão forte nos estados nos quais não havia tal alinhamento. Esta pressão se devia ao objetivo fundamental do Governo de proporcionar modicidade tarifária à população.

Pós novo modelo instaurado a partir de 2004, as ações do Governo se pautaram na redução do custo das tarifas, para gerar competitividade na indústria (De Castro et al, 2013).

Assim, aspectos como oferta e demanda de energia, fontes renováveis de energia, eficiência energética, fazem parte do escopo de amparo do crescimento econômico sustentável de um país.

Em relação ao Brasil, Tolmasquim (2012) afirma que o país é referência mundial na área energética: extrai petróleo em águas profundas, produz etanol, possui parque de geração hidrelétrico com alta capacidade, possui aproveitamento de energia eólica, e é reconhecido pela renovabilidade de sua matriz energética.

A EPE - Empresa de Pesquisa Energética produz estudos sobre a oferta e a demanda de energia no país a longo prazo e afirma que a demanda por energia tende a crescer de forma superior à oferta até 2030, o que se deve a uma maior eficiência energética de ambos os lados. Esse crescimento da demanda é esperado em um cenário de crescimento econômico sustentado. Por isso, a matriz energética do país deve se fortalecer e considerar o uso eficiente das mais diversas fontes (Tolmasquim, Gerreiro \& Gorini, 2007).

O Brasil é rico em fontes de produção de energia e necessita dispor de energia nas condições de quantidade e qualidade a custos competitivos, a fim de promover desenvolvimento econômico. O contexto do país é uma nação em desenvolvimento, ainda insuficiente, com baixo consumo específico de energia, carência nas áreas de infraestrutura e concentração do uso das riquezas naturais. Assim, o Governo tem papel 
fundamental na condução do setor, em especial na resolução de conflitos de interesses entre os agentes participantes desse mercado (Tolmasquim, Guerreiro \& Gorini, 2007). Como intervenções relevantes, pode-se citar o Novo Modelo do Setor Elétrico, implementado após 2004, que reestruturou o setor e a Medida Provisória $n^{\circ} 579$ editada em 2012, cuja repercussão é discutida a seguir.

\subsubsection{Medida Provisória n⿳0 579/2012}

A Medida Provisória $\mathrm{n}^{\mathrm{o}}$ 579/2012 foi promulgada em 11 de setembro de 2012 pelo Governo e teve como foco a redução no custo final de energia elétrica com o intuito maior de diminuir os custos das atividades de produção no país, em conformidade com o princípio da modicidade tarifária e a segurança energética, por meio da promoção da universalização do serviço de energia elétrica no país; garantia de recursos para atendimento aos consumidores finais de baixa renda; o fornecimento de recursos para os gastos da Conta de Consumo de Combustíveis - CCC; a promoção de competitividade no segmento de produção através do carvão mineral, bem como fontes eólica, pequenas centrais hidrelétricas, biomassa e gás natural e a criação da Conta de Desenvolvimento Energético - CDE (Assunção, Takamatsu \& Bressan, 2015).

A Medida deliberava sobre as concessões de geração, transmissão e distribuição de energia elétrica, a redução dos encargos setoriais, a modicidade tarifária, e demais providências. Dentre as várias condições que foram estabelecidas para as empresas, destacam-se: a remuneração por tarifa calculada pela Aneel para cada usina hidrelétrica; a submissão aos padrões de qualidade do serviço fixados pela Aneel; o excedente de energia elétrica não consumido pelas unidades consumidoras do titular da concessão de autoprodução seria liquidado no mercado de curto prazo ao Preço de Liquidação de Diferenças - PLD; as concessões de geração, transmissão e distribuição de energia elétrica que não aderissem à Medida, não seriam prorrogadas, e seriam licitadas, na modalidade leilão ou concorrência, por até trinta anos.

As concessionárias tiveram a opção de aderir ou não à medida, sendo condicionadas a aceitar essa nova conjuntura de reestruturação do setor como um todo.

A adesão à medida resultou em redução das tarifas de energia, antecipação do vencimento das concessões para o ano de 2013 com pagamento de indenização pelos ativos não amortizados pelas concessionárias, licitação dos ativos das empresas que não aderiram, 
redução de encargos setoriais, recebimento de tarifa única - O\&M (Operação e Manutenção) para as empresas que aderiram à medida, destinação da energia das usinas prorrogadas de forma exclusiva para o ACR - Ambiente de Contratação Regulada ${ }^{1}$.

As empresas que não aderiram à medida foram: Cesp - Companhia Energética de São Paulo, Cemig - Companhia Energética de Minas Gerais e Copel - Companhia Paranaense de Energia. Assis (2013) elaborou um estudo a respeito da decisão de renovação das concessões e explica que Cesp, Cemig e Copel representam juntas grande parte dos contratos de concessão de geração de energia e a não prorrogação dos mesmos impactou na velocidade e no tamanho do efeito da Medida nas tarifas de energia, o que indicou que o tamanho das concessionárias e usinas afetadas pesaram na decisão de aderir ou não à Medida.

A medida trabalhou em duas frentes: redução de encargos e redução de custos da indústria de energia elétrica. A redução de encargos justifica-se pelo argumento de que os consumidores devem arcar apenas com encargos inerentes ao setor e os encargos de natureza social, custeados pelo Tesouro Nacional. A MP 579 decretou o fim da cobrança da CCC, da RGR - Reserva Global de Reversão e reduziu o valor da CDE para 25\% nas tarifas. Em relação aos custos da indústria de energia, o Governo trabalhou com a proposta de renovação das concessões das usinas hidrelétricas e de linhas de transmissão que venceriam entre 2015 a 2017 com as opções de licitar os ativos ou renovar de forma onerosa (De Castro et al, 2013).

Uma questão fundamental sobre a qual a Medida deliberava era a proposta de indenização dos ativos. Grande parte dos ativos das concessionárias estavam amortizados e depreciados, por isso a intenção era desonerar esta parcela da tarifa para o consumidor. Os investimentos que não estivessem amortizados seriam indenizados e em contrapartida as concessionárias renovariam as concessões por um prazo de até trinta anos (Costellini \& Holanda, 2014).

Prado Jr e Da Silva (2013) explicam que os ativos ainda não depreciados das concessionárias seriam indenizados a vista até janeiro de 2013 e estes deveriam ser indenizados pelo Valor Novo de Reposição. O Governo contava que os recursos da RGR

$1 \mathrm{O}$ mercado de energia no Brasil divide-se em ACR (Ambiente de Contratação Regulada), onde estão os consumidores cativos, que são aqueles que compram a energia das concessionárias de distribuição às quais estão ligados e ACL (Ambiente de Contratação Livre), formado pelos consumidores livres, que são aqueles que compram energia diretamente dos geradores ou comercializadores, através de contratos bilaterais (Fonte: Mercado Livre de Energia Elétrica). 
cobririam este passivo. Contudo, analistas e mesmo algumas concessionárias apontaram que os recursos da RGR não seriam suficientes. A Eletrobrás obtinha expectativa de indenização no valor de até $\mathrm{R} \$ 28$ bilhões e, no entanto, a disponibilidade dos fundos da RGR era de R\$9 bilhões.

Ainda sobre essa questão, ao final de 2012, foi editada a MP 591 incluindo os ativos de transmissão antecedentes a maio de 2000 que ainda não estavam depreciados na indenização às transmissoras e este valor seria indenizado ao longo de trinta anos, corrigidos pelo IPCA, viabilizando a adesão destas à MP 579 (Costellini \& Holanda, 2014).

Em relação às empresas que optaram por renovar as concessões, o recebimento da indenização dos ativos ocorreu com valor menor do que os valores registrados nos balanços contábeis e, por outro lado, ainda sofreram redução na receita das atividades de geração e transmissão de energia. As incertezas em relação à metodologia empregada para a indenização dos ativos e passivos não amortizados geraram, ainda, queda no valor das ações dessas empresas (Vieira, 2015).

$\mathrm{O}$ anúncio da Medida, portanto, resultou em impactos como perda no valor de mercado das empresas de imediato, independentemente de suas decisões quanto à adesão à Medida, e às incertezas dos investidores quanto ao setor elétrico brasileiro (Assis, 2013); reestruturação da equipe de profissionais das concessionárias, ponderação da legalidade das medidas, diminuição de arrecadação de impostos pelos Estados, migração de energia já contratada pelo livre mercado para o mercado regulado e, ainda, exigência de rapidez na escolha de adesão ou não à medida por parte das empresas Prado Jr e Da Silva (2013). O impacto das renovações ocorreu de forma mais intensa sobre as empresas de geração e transmissão, haja vista que as distribuidoras já eram reguladas para transferir os ganhos de produtividade para os consumidores nos ciclos previstos de revisão tarifária. Esse impacto se estendeu ao longo de 2013 nas ações das empresas: Eletrobras teve baixa de 49,7\% do valor de mercado, Cesp 40\% e Cemig 33\% (De Castro et al, 2013).

A Medida foi convertida no dia 11 de janeiro de 2013 na Lei no $12.783 / 2013$. A conversão em Lei, em 2013, discorre sobre as concessões de geração, transmissão e distribuição de energia elétrica sobre a redução dos encargos setoriais e a modicidade tarifária. 


\section{METODOLOGIA}

Neste capítulo apresentam-se os métodos e instrumentos utilizados para o teste das hipóteses formuladas nesta pesquisa e que possibilitaram a elaboração deste trabalho. A seção 3.1 contém o quadro resumo do trabalho, com o problema de pesquisa, os objetivos, hipóteses de pesquisa e a metodologia utilizada. A seção 3.2 compreende a exposição da amostra, as características das empresas que a compõem. A seção 3.3 contém a definição teórica e operacional das variáveis consideradas. A seção 3.4 descreve os métodos empregados na pesquisa, a saber: a estatística descritiva da amostra e as técnicas de análise de dados utilizadas. A seção 3.5 apresenta o modelo econométrico proposto para cada um dos três estudos.

Para a determinação do desempenho do setor elétrico no Brasil, a pesquisa parte do levantamento de dados trimestrais das empresas de capital aberto do setor de energia elétrica no Brasil, com variáveis contábeis, de governança e de mercado. Os dados foram coletados na base Economática para o primeiro trimestre de 2010 ao quarto trimestre de 2015.

Para compreender as interferências do ambiente econômico na rentabilidade das empresas do setor elétrico no Brasil, foram coletados dados anuais econômicos e das empresas, nas bases do Balanço Energético Nacional fornecido pelo MME - Ministério de Minas e Energia, do IBGE - Instituto Brasileiro de Geografia e Estatística, IPEADATA - base de dados do Instituto de Pesquisa Econômica Aplicada, do Banco Central do Brasil, bem como os dados das empresas na base Economática para os anos de 2010 a 2015.

A abordagem de pesquisa é quantitativa e o período de estudo está compreendido, portanto, entre janeiro de 2010 e dezembro de 2015, isto é, três anos anteriores e três anos posteriores à edição da MP 579/2012.

\subsection{Quadro Resumo}

A fim de propiciar melhor entendimento a respeito do modelo conceitual deste trabalho, foi elaborado um quadro-resumo que contém: o problema de pesquisa, objetivos, metodologia empregada, fundamentação teórica e as hipóteses de pesquisa. 
Quadro 2 - Quadro Resumo da Pesquisa

\begin{tabular}{|c|c|c|c|}
\hline $\begin{array}{c}\text { Problema de } \\
\text { Pesquisa }\end{array}$ & Objetivos & $\begin{array}{c}\text { Hipóteses } \\
\text { Correspondentes }\end{array}$ & Metodologia \\
\hline \multirow{3}{*}{$\begin{array}{l}\text { Quais são os } \\
\text { determinantes do } \\
\text { Desempenho das } \\
\text { Empresas do } \\
\text { Setor Elétrico no } \\
\text { Brasil? }\end{array}$} & $\begin{array}{l}\text { Geral: } \\
\text { Avaliar o desempenho } \\
\text { das empresas de energia } \\
\text { elétrica no Brasil sob a } \\
\text { ótica de variáveis } \\
\text { contábeis e de } \\
\text { Governança, } \\
\text { mercado de } \\
\text { macroeconômicas para } \\
\text { o período de janeiro de } \\
2010 \text { a dezembro de } \\
2015 \text {. }\end{array}$ & $\begin{array}{l}\text { H1: Os indicadores } \\
\text { contábeis explicam o } \\
\text { desempenho. } \\
\text { H2: Os indicadores de } \\
\text { mercado explicam o } \\
\text { desempenho. }\end{array}$ & $\begin{array}{l}\text { 1) Revisão da literatura sobre } \\
\text { desempenho e variáveis } \\
\text { contábeis e de mercado; } \\
\text { 2) Aplicação do modelo de } \\
\text { Regressão Linear Múltipla com } \\
\text { Dados em Painel, tendo como } \\
\text { dependente a variável ROE, } \\
\text { ROA e Retorno da Ação e } \\
\text { variáveis contábeis, de } \\
\text { Governança e de mercado como } \\
\text { explicativas. }\end{array}$ \\
\hline & $\begin{array}{l}\text { Específicos: } \\
\text { 1. Avaliar os efeitos do } \\
\text { ambiente econômico } \\
\text { sobre a rentabilidade do } \\
\text { setor elétrico; }\end{array}$ & $\begin{array}{lr}\text { H3: O } & \text { ambiente } \\
\text { econômico } & \text { afetou } \\
\text { negativamente } & \text { a } \\
\text { rentabilidade } & \text { das } \\
\text { empresas. } & \end{array}$ & $\begin{array}{l}\text { 3) Aplicação do modelo de } \\
\text { Regressão de Dados em Painel } \\
\text { para as variáveis ROE e ROA } \\
\text { como dependentes e variáveis } \\
\text { contábeis e de Governança, de } \\
\text { mercado e econômicas } \\
\text { históricas como explicativas. }\end{array}$ \\
\hline & $\begin{array}{l}\text { 2. Avaliar os impactos } \\
\text { da interferência da } \\
\text { edição da MP579 sobre } \\
\text { a rentabilidade do setor } \\
\text { elétrico. }\end{array}$ & $\begin{array}{l}\text { H4: A edição da MP } \mathrm{n}^{\circ} \\
\text { 579/2012 afetou } \\
\text { negativamente } \\
\text { rentabilidade a } \\
\text { empresas do setor } \\
\text { elétrico no Brasil. }\end{array}$ & $\begin{array}{l}\text { 4) Revisão da literatura sobre a } \\
\text { MP579/2012; } \\
\text { 5) Aplicação do teste diff-in-diff } \\
\text { para verificar rentabilidade das } \\
\text { empresas do setor elétrico antes } \\
\text { e após adoção da MP579/2012. }\end{array}$ \\
\hline
\end{tabular}




\subsection{Universo e Amostra}

Para este estudo foram selecionadas empresas de capital aberto do setor de energia elétrica no Brasil disponíveis na base Economática ${ }^{\circledR}$.

As empresas pertencem às atividades de Geração, Transmissão, Distribuição e Comercialização de Energia Elétrica, assumindo na maioria dos casos mais de uma atividade simultaneamente.

Para seleção da amostra foram adotados os seguintes critérios:

i) para empresas com mais de uma ação, opção pelas $\mathrm{ON}$ - ordinárias;

ii) atividade principal: geração, transmissão, distribuição e comercialização, ou seja, holdings foram excluídas;

iii) se necessária exclusão de outliers e missing values, tratados pela técnica estatística.

A base coletada na Economática apresentou 87 ações de 43 empresas. Dessas 87 ações, foram selecionadas apenas as ordinárias. Com isso, 44 ações foram retiradas da amostra inicialmente. Dentre as 44, 39 eram preferenciais e 5 eram units. Restaram 43 empresas com ações ordinárias. Do total de 43 empresas, 19 holdings foram excluídas. A amostra final portanto é composta por 24 empresas.

\subsubsection{Características das Empresas da Amostra}

Com a reordenação da amostra, portanto, sua composição final foi de 24 empresas do setor elétrico.

A Tabela 1 apresenta o nome da ação, seu nome de pregão, a atividade que a empresa desenvolve, composição do capital e seu estado de origem para melhor compreensão das empresas que compões a amostra final.

Tabela 1 - Descrição das Empresas de Energia Elétrica da Amostra 


\begin{tabular}{|c|c|c|c|c|c|}
\hline Número & $\begin{array}{l}\text { Nome da } \\
\text { Ação }\end{array}$ & Ticker & Atividade & Composição do Capital & $\begin{array}{c}\text { Estado de } \\
\text { Origem }\end{array}$ \\
\hline 1 & $\begin{array}{l}\text { AES Tiete E } \\
\text { ON }\end{array}$ & TIET3 & $\begin{array}{l}\text { Geração e } \\
\text { Comercialização }\end{array}$ & Misto: AES Corp e BNDES & São Paulo \\
\hline 2 & Afluente ON & AFLU3 & Geração & Privado: Grupo Neoenergia & Bahia \\
\hline 3 & Afluente T ON & AFLT3 & Transmissão & Privado: Grupo Neoenergia & Bahia \\
\hline 4 & $\begin{array}{l}\text { Ampla Energ } \\
\text { ON }\end{array}$ & CBEE3 & $\begin{array}{l}\text { Distribuição e } \\
\text { Comercialização }\end{array}$ & $\begin{array}{l}\text { Privado: Chilectra Inversud, } \\
\text { Ele Brasil, Chilectra, Enersis }\end{array}$ & $\begin{array}{l}\text { Rio de } \\
\text { Janeiro }\end{array}$ \\
\hline 5 & Ceee-D ON & CEED3 & Distribuição & $\begin{array}{l}\text { Misto: CEEE Participações e } \\
\text { Eletrobras }\end{array}$ & $\begin{array}{l}\text { Rio Grande } \\
\text { do Sul }\end{array}$ \\
\hline 6 & Ceee-Gt ON & EEEL3 & Geração e Transmissão & Misto: CEEE Participações & $\begin{array}{l}\text { Rio Grande } \\
\text { do Sul }\end{array}$ \\
\hline 7 & Celpa ON & CELP3 & Geração e Distribuição & Privado: Rede Energia & Pará \\
\hline 8 & Celpe ON & CEPE3 & $\begin{array}{l}\text { Geração, Distribuição e } \\
\text { Comercialização }\end{array}$ & Privado: Grupo Neoenergia & Pernambuco \\
\hline 9 & Cemar ON & ENMA3B & $\begin{array}{l}\text { Geração, Transmissão e } \\
\text { Distribuição }\end{array}$ & $\begin{array}{l}\text { Privado: Controlada pela } \\
\text { Equatorial Energia }\end{array}$ & Maranhão \\
\hline 10 & Cemig ON & CMIG3 & $\begin{array}{l}\text { Geração, Transmissão e } \\
\text { Distribuição }\end{array}$ & Estatal & Minas Gerais \\
\hline 11 & Cesp ON & CESP3 & $\begin{array}{l}\text { Geração e } \\
\text { Comercialização }\end{array}$ & Estatal & São Paulo \\
\hline 12 & Coelba ON & CEEB3 & Distribuição & $\begin{array}{l}\text { Privado: Grupo Neoenergia, } \\
\text { Fundo de Pensão PREVI }\end{array}$ & Bahia \\
\hline 13 & Coelce ON & COCE3 & Distribuição & $\begin{array}{l}\text { Privado: Grupo Enel Brasil e } \\
\text { Enersis }\end{array}$ & Ceará \\
\hline 14 & Copel ON & CPLE3 & $\begin{array}{l}\text { Geração, Transmissão, } \\
\text { Comercialização e } \\
\text { Distribuição }\end{array}$ & $\begin{array}{l}\text { Estatal: Estado do Paraná, } \\
\text { BNDESPAR, Eletrobras }\end{array}$ & Paraná \\
\hline 15 & Cosern ON & CSRN3 & Distribuição & Privado: Grupo Neoenergia & $\begin{array}{l}\text { Rio Grande } \\
\text { do Norte }\end{array}$ \\
\hline 16 & Elektro ON & EKTR3 & $\begin{array}{l}\text { Geração, Transmissão e } \\
\text { Distribuição }\end{array}$ & Privado: Iberdrola Brasil & São Paulo \\
\hline 17 & $\begin{array}{l}\text { AES } \\
\text { Eletropaulo } \\
\text { ON }\end{array}$ & ELPL3 & Distribuição & Misto: AES Corp e BNDES & São Paulo \\
\hline 18 & Emae ON & EMAE3 & Geração & Estatal & São Paulo \\
\hline
\end{tabular}




\begin{tabular}{|c|l|l|l|l|l|}
\hline 19 & $\begin{array}{l}\text { Energisa Mt } \\
\text { ON }\end{array}$ & ENMT3 & Distribuição & Privado: Grupo Energisa & Mato Grosso \\
\hline 20 & Eneva ON & ENEV3 & $\begin{array}{l}\text { Geração e } \\
\text { Comercialização }\end{array}$ & Privado & $\begin{array}{l}\text { Maranhão, } \\
\text { Ceará e }\end{array}$ \\
\hline 21 & $\begin{array}{l}\text { Engie Brasil } \\
\text { ONapá }\end{array}$ & EGIE3 & $\begin{array}{l}\text { Geração e } \\
\text { Comercialização }\end{array}$ & Privado: Grupo Engie & $\begin{array}{l}\text { Santa } \\
\text { Catarina }\end{array}$ \\
\hline 22 & $\begin{array}{l}\text { Ger Paranap } \\
\text { ON }\end{array}$ & GEPA3 & $\begin{array}{l}\text { Geração e } \\
\text { Comercialização }\end{array}$ & $\begin{array}{l}\text { Porporation } \\
\text { Privado: Duke Energy }\end{array}$ & Para Paulo e \\
\hline 23 & Renova ON & RNEW3 & $\begin{array}{l}\text { Geração de Energia } \\
\text { Elétrica Renovável }\end{array}$ & $\begin{array}{l}\text { Risto: Cemig GT, Light e } \\
\text { BNDErticipações, }\end{array}$ & Bahia \\
\hline \multirow{2}{*}{24} & $\begin{array}{l}\text { Tran Paulist } \\
\text { ON }\end{array}$ & TRPL3 & Transmissão & Misto: ISA, Eletrobras & São Paulo \\
\hline
\end{tabular}

Apresentadas as empresas da amostra, segue a descrição das variáveis utilizadas.

\subsection{Definição Teórica e Operacional das Variáveis}

Após realizada a revisão bibliográfica do tema foram identificadas as variáveis mais utilizadas em estudos para análise do desempenho de empresas.

Desta forma, o Quadro 3 detalha as variáveis dependentes, variáveis proxy utilizadas para aferir o desempenho das empresas da amostra de pesquisa e os autores que utilizaram esses indicadores em seus estudos. O Quadro 4 apresenta as variáveis contábeis, dummy de Governança e a dummy de Adesão à MP n ${ }^{\circ}$ 579/2012. O Quadro 5 evidencia as variáveis de mercado e o Quadro 6, as variáveis macroeconômicas. 
Quadro 3 - Variáveis Dependentes

\begin{tabular}{|c|c|c|c|}
\hline Variável & Definição & Autores & Sigla \\
\hline $\begin{array}{l}\text { Retorno sobre o } \\
\text { Patrimônio Líquido }= \\
\frac{\text { Lucro Líquido }}{\text { PL }} \times 100\end{array}$ & $\begin{array}{l}\text { Indica o lucro obtido pela } \\
\text { empresa em relação ao } \\
\text { capital próprio investido. }\end{array}$ & $\begin{array}{l}\text { Shaoul (1997); Lin, Liu e Chu (2005); } \\
\text { Sirtaine et al (2005); Rocha, Camacho e } \\
\text { Bragança (2007); Matarazzo (2008), } \\
\text { Cerqueira, Soares e David (2009); De Lima } \\
\text { et al (2009); Szuster et al (2011), Buccini } \\
\text { (2012); Bekana e Abitie (2012); Ribeiro, } \\
\text { Macedo e Marques (2012); Delen, Kuzey e } \\
\text { Uyar (2013); Reynaud e Thomas (2013); } \\
\text { Assaf Neto (2014); Curcino, Lemes e } \\
\text { Botinha (2014). }\end{array}$ & $R O E$ \\
\hline $\begin{array}{l}\text { Rentabilidade do Ativo } \\
= \\
\frac{\text { Lucro Líquido }}{\text { Ativo Total }} \times 100\end{array}$ & $\begin{array}{l}\text { Indica o lucro obtido pela } \\
\text { empresa em relação a seu } \\
\text { investimento total. }\end{array}$ & $\begin{array}{l}\text { Shaoul (1997); Lin, Liu e Chu (2005); } \\
\text { Minardi et al (2007); Matarazzo (2008); } \\
\text { Cohen e Zarowin (2010); Demirgüç-Kunt e } \\
\text { Huizinga (2010); Szuster et al (2011); } \\
\text { Bekana e Abitie (2012); Ribeiro, Macedo e } \\
\text { Marques (2012); Delen, Kuzey e Uyar } \\
\text { (2013); Assaf Neto (2014). }\end{array}$ & $R O A$ \\
\hline Retorno da Ação & $\begin{array}{l}\text { Principal balizador } \text { das } \\
\text { decisões. } \\
\text { ganhos gerados por um } \\
\text { ativo em certo tempo. } \\
\text { Compreende as entradas de } \\
\text { caixa e valorização do ativo. }\end{array}$ & $\begin{array}{l}\text { Nagano, Merlo e Silva (2003); Mellone } \\
\text { Junior e Saito (2004); Acharya e Schnabl } \\
\text { (2010); Demirgüç-Kunt e Huizinga (2010); } \\
\text { Edmans (2011); Assaf Neto (2014); } \\
\text { Bragança, Pessoa e Rocha (2015). }\end{array}$ & Retacao \\
\hline
\end{tabular}

Quadro 4 - Variáveis Contábeis e Dummies

\begin{tabular}{|c|c|c|c|}
\hline Variável & Definição & Autores & Sigla \\
\hline $\begin{array}{l}\text { Dívida Bruta/Ativo }= \\
\qquad \frac{\text { Dívida Bruta }}{\text { Ativo }} \times 100\end{array}$ & $\begin{array}{l}\text { Relação que avalia o } \\
\text { nível } \\
\text { endividamento } \\
\text { empresa. }\end{array}$ & $\begin{array}{l}\text { Deakin (1972); Deakin } \\
\text { (1977); Minardi et al } \\
\text { (2007); Cerqueira, Soares e } \\
\text { David (2009); Bekana e } \\
\text { Abitie (2012); Assaf Neto } \\
\text { (2014). }\end{array}$ & Divbrat \\
\hline
\end{tabular}




\begin{tabular}{|c|c|c|c|}
\hline Variável & Definição & Autores & Sigla \\
\hline $\begin{array}{l}\text { Dívida Líquida/Ebitda }= \\
\qquad \frac{\text { Dívida Líquida }}{\text { Ebitda }}\end{array}$ & 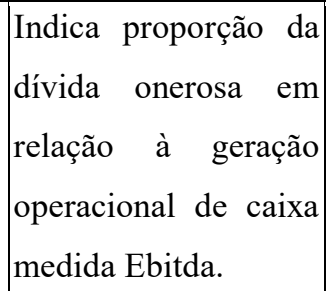 & $\begin{array}{l}\text { De Lima et al (2009); Delen, } \\
\text { Kuzey e Uyar (2013); } \\
\text { Guzella e Rodrigues (2015). }\end{array}$ & Divebitda \\
\hline $\begin{array}{l}\text { Investimento/PL }= \\
\qquad \frac{\text { Investimento }}{\text { Patrimônio Líquido }} \times 100\end{array}$ & $\mid \begin{array}{lr}\text { Investimentos } & \mathrm{em} \\
\text { Subsidiárias } & \mathrm{e} \\
\text { Outros/Patrimônio } & \\
\text { Líquido } & \end{array}$ & $\begin{array}{l}\text { Rocha, Camacho } \\
\text { Bragança } \\
\text { Matarazzo (2008); Pereira e } \\
\text { Martins (2012). }\end{array}$ & Invpl \\
\hline $\begin{array}{l}\text { Liquidez Corrente }= \\
\qquad \frac{\text { Ativo Circulante }}{\text { Passivo Circulante }}\end{array}$ & \begin{tabular}{|lr} 
Calculada & a partir da \\
razão entre os direitos \\
a $r$ curto & prazo da \\
empresa & (Caixas, \\
bancos, & estoques, \\
clientes) e as dívidas a \\
curtor r prazo \\
(Empréstimos, \\
financiamentos, \\
impostos, \\
fornecedores).
\end{tabular} & 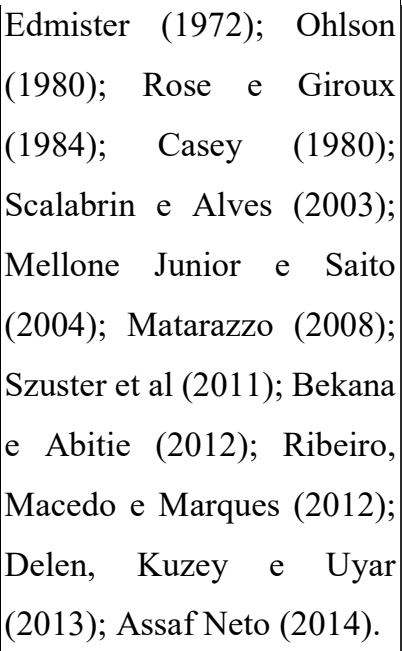 & Liqcor \\
\hline $\begin{array}{l}\text { Capital de Giro = Ativo Circulante - } \\
\text { Passivo Circulante }\end{array}$ & $\begin{array}{llr}\text { A necessidade } & \text { de } \\
\text { capital de giro é chave } \\
\text { para análise de caixa } \\
\text { da empresa } & \text { e } & \text { de } \\
\text { estratégias } & & \text { de } \\
\text { financiamento, } & \\
\text { crescimento } & \\
\text { lucratividade. }\end{array}$ & $\begin{array}{l}\text { Winakor e Smith (1935); } \\
\text { Merwin (1942); Edmister } \\
(1972) ; \text { Rose e Giroux } \\
(1984) ; \quad \text { Takahashi e } \\
\text { Kurokawa (1985); Buccini } \\
\text { (2012); Bekana e Abitie } \\
\text { (2012); Ribeiro, Macedo e } \\
\text { Marques (2012). }\end{array}$ & Capgir \\
\hline
\end{tabular}




\begin{tabular}{|c|c|c|c|}
\hline Variável & Definição & Autores & Sigla \\
\hline $\begin{array}{l}\text { Margem Líquida }= \\
\frac{\text { Lucro Líquido }}{\text { Receita Líquida Operacional }} \times 100\end{array}$ & 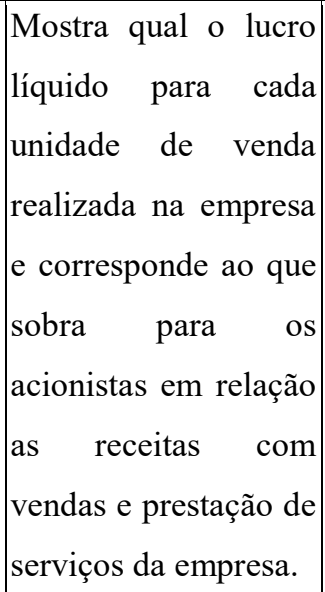 & $\begin{array}{l}\text { Matarazzo (2008); } \\
\text { Cerqueira, Soares e David } \\
\text { (2009); Szuster et al (2011); } \\
\text { Reynaud e Thomas (2013). }\end{array}$ & Mliq \\
\hline Receita $=\ln ($ REC $)$ & \begin{tabular}{|l} 
Transformação da \\
variável
\end{tabular} & $\begin{array}{l}\text { Shaoul (1997); Lin, Liu e } \\
\text { Chu (2005); Cerqueira, } \\
\text { Soares e David (2009); } \\
\text { Buccini (2012); Bekana e } \\
\text { Abitie (2012); Delen, Kuzey } \\
\text { e Uyar (2013); Reynaud e } \\
\text { Thomas (2013); Guzella e } \\
\text { Rodrigues (2015). }\end{array}$ & Lnrec \\
\hline $\begin{array}{l}\text { Investimento }= \\
\frac{\text { Investimento (CAPEX) }}{\text { Depreciação/Amortização }}\end{array}$ & $\mid \begin{array}{llr}\text { Relação } & \text { entre } & \text { a } \\
\text { composição } & & \\
\text { investimentos } & & \\
\text { (avaliados } & & \text { pelos } \\
\text { CAPEX } & - & \text { Capital } \\
\text { Expenditure }) & \text { e } & \text { a } \\
\text { depreciação } & & \text { e } \\
\text { amortização } & & \text { dos } \\
\text { ativos: o valor } & \text { de } \\
\text { investimento } & \text { sobre } & \text { o } \\
\text { valor que depreciou. }\end{array}$ & $\begin{array}{l}\text { Shaoul (1997); De Lima et } \\
\text { al (2009); Pereira e Martins } \\
(2012) \text {. }\end{array}$ & Capexdepamort \\
\hline $\begin{array}{l}\text { Governança: Dummy de Governança } \\
\text {-Variável Binária }\end{array}$ & $\begin{array}{l}\text { Para o segmento N2 e } \\
\text { Novo Mercado, é } \\
\text { igual a } 1 \text {. Para N1 e } \\
\text { tradicional, é igual a } \\
0 .\end{array}$ & $\begin{array}{l}\text { Black, Carvalho e Gorga } \\
\text { (2012); Funchal e Monte- } \\
\text { Mor (2016). }\end{array}$ & Gov \\
\hline
\end{tabular}




\begin{tabular}{|l|l|l|l|}
\hline \multicolumn{1}{|c|}{ Variável } & Definição & \multicolumn{1}{|c|}{ Autores } & Sigla \\
\hline Adesão à Medida: Dummy de & $\begin{array}{l}\text { Indica a adesão ou } \\
\text { não à MP579/2012. } \\
\text { Se for igual a 1, indica (2013). } \\
\text { Adesão - Variável Binária }\end{array}$ & $\begin{array}{l}\text { que empresa aderiu } \\
\text { à medida. }\end{array}$ & DID \\
\hline
\end{tabular}

Quadro 5 - Variáveis de Mercado

\begin{tabular}{|c|c|c|c|}
\hline Variável & Definição & Autores & Sigla \\
\hline $\begin{array}{l}\text { Valor de Mercado = o preço } \\
\text { da ação multiplicado pelo } \\
\text { número de ações da empresa }\end{array}$ & $\begin{array}{l}\text { Valor de mercado da } \\
\text { empresa, medido pelo preço } \\
\text { atual da ação, com alguns } \\
\text { valores contábeis. Avaliam } \\
\text { risco e retorno sob a } \\
\text { percepção dos analistas de } \\
\text { mercado. }\end{array}$ & $\begin{array}{l}\text { Da Costa Jr. e Neves (2000); } \\
\text { Nagano, Merlo e Silva } \\
\text { Freguete, Nossa } \\
(2015)\end{array}$ & Valormerc \\
\hline $\begin{array}{l}\text { Enterprise Value/Ebitda }= \\
\qquad \frac{\text { Enterprise Value }}{\text { EBITDA }}\end{array}$ & $\begin{array}{l}\text { Medida indicativa do valor } \\
\text { de sua empresa em relação } \\
\text { ao lucro gerado por sua } \\
\text { operação, comparável com } \\
\text { transações de mercado. O } \\
\text { Enterprise Value é } \\
\text { calculado pelo Valor de } \\
\text { Mercado somado à Dívida } \\
\text { Total Líquida somado à } \\
\text { Participação dos Acionistas } \\
\text { Minoritários. }\end{array}$ & $\begin{array}{l}\text { Altman (1968); Altman (1993); } \\
\text { Shaoul (1997); Cerqueira, Soares } \\
\text { e David (2009); Pereira e Martins } \\
(2012) .\end{array}$ & Evebitda \\
\hline $\begin{array}{l}\text { Cotação de Fechamento = } \\
\text { Proxy do Retorno do Ativo }\end{array}$ & $\begin{array}{l}\text { Indicador técnica de } \\
\text { Oscilação. (1 - (cotação de } \\
\text { fechamento da data } \times \text { } / \\
\text { cotação de fechamento da } \\
\text { data x-1)) x 100. }\end{array}$ & Pereira e Martins (2012). & Cfech \\
\hline
\end{tabular}




\begin{tabular}{|c|c|c|c|}
\hline Variável & Definição & Autores & Sigla \\
\hline Dividendo Pago por Ação & $\begin{array}{l}\text { Consiste no pagamento de } \\
\text { dividendos sobre a forma de } \\
\text { ações aos proprietários } \\
\text { existentes. }\end{array}$ & $\begin{array}{l}\text { Fama e Schwert (1977); } \\
\text { Campbell (1987); Shaoul (1997); } \\
\text { Sirtaine et a al (2005); Cerqueira, } \\
\text { Soares e David (2009); De Lima } \\
\text { et al (2009); Demirgüç-Kunt e } \\
\text { Huizinga (2010); Buccini (2012); } \\
\text { Guzella e Rodrigues (2015). }\end{array}$ & Divacao \\
\hline Coeficiente Beta & $\begin{array}{l}\text { Medida de Risco. Relativo à } \\
\text { sensibilidade dos retornos } \\
\text { da ação em relação aos } \\
\text { retornos do índice de } \\
\text { mercado }\end{array}$ & $\begin{array}{l}\text { Da Costa Jr. e Neves (2000); } \\
\text { Nagano, Merlo e Silva (2003); } \\
\text { Minardi et al (2007); De Lima et } \\
\text { al (2009). }\end{array}$ & Beta5anos \\
\hline $\begin{array}{l}\text { Volatilidade }=\text { sqrt }((\text { sum } \\
\left.\left.\left((\mathrm{Si}-\mathrm{Sm})^{\wedge} 2\right)\right) / \mathrm{n} * \text { PPA }\right) \mathrm{x} \\
100\end{array}$ & $\begin{array}{l}\text { Trata-se de uma medida de } \\
\text { dispersão dos retornos de } \\
\text { um título ou índice de } \\
\text { mercado. É uma medida de } \\
\text { risco. }\end{array}$ & $\begin{array}{l}\text { French, Schwert e Stambaugh } \\
\text { (1987); Goyal e Santa Clara, } \\
\text { (2003); Sirtaine et al (2005); } \\
\text { Minardi et al (2007); Barnea e } \\
\text { Rubin (2010); Pereira e Martins } \\
(2012) \text {. }\end{array}$ & Vol5anos \\
\hline $\begin{array}{l}\text { Retorno do IBOV: Proxy do } \\
\text { Retorno de Mercado }\end{array}$ & $\begin{array}{l}\text { É o cálculo da diferença do } \\
\text { logaritmo natural do índice } \\
\text { Ibovespa multiplicado por } \\
100 \text { para obter o valor em } \\
\text { porcentagem. }\end{array}$ & $\begin{array}{l}\text { Taffarel, da Silva e Clemente } \\
\text { (2013); Pereira e Chicoli (2016). }\end{array}$ & Retornoibov \\
\hline
\end{tabular}

Nota: 1.0 cálculo da Volatilidade de $n$ dias usa uma série de cotações de fechamento de $\mathrm{n}+1$ dias: $\mathrm{d} 0$, $\mathrm{d} 1$, $\mathrm{d} 2, \mathrm{~d} 3, \mathrm{dn}$, onde sqrt $=$ desvio padrão, $\mathrm{Si}=$ logaritmo neperiano de $(\mathrm{di} / \mathrm{di}-1) \quad \mathrm{i}=1 \ldots \mathrm{n}, \mathrm{Sm}=$ média de $\mathrm{S} 1$, S2, S3,Sn. PPA significa Períodos por Ano. Fonte: Economática.

Quadro 6 - Variáveis Econômicas

\begin{tabular}{|l|l|l|l|}
\hline \multicolumn{1}{|c|}{ Variável } & \multicolumn{1}{|c|}{ Definição } & \multicolumn{1}{|c|}{ Autores } & \multicolumn{1}{|c|}{ Sigla } \\
\hline $\begin{array}{l}\text { Oferta Interna de Energia } \\
\text { Elétrica/População } \\
\text { Residente }\end{array}$ & Medida em KWh/hab & $\begin{array}{l}\text { Fonte: Balanço Energético } \\
\text { Nacional }\end{array}$ & OIEEPOP \\
\hline $\begin{array}{l}\text { Consumo Final } \\
\text { Energético/PIB }\end{array}$ & $\begin{array}{l}\text { Consumo Final Energético } \\
\text { Com Residencial. Unidade } \\
\text { de Medida: tep/106 US\$. }\end{array}$ & $\begin{array}{l}\text { Fonte: Balanço Energético } \\
\text { Nacional. Ribeiro, Macedo e } \\
\text { Marques (2012); Montoya, Lopes } \\
\text { e Guilhoto (2014). }\end{array}$ & CONSRESPIB \\
\hline
\end{tabular}




\begin{tabular}{|c|c|c|c|}
\hline Variável & Definição & Autores & Sigla \\
\hline $\begin{array}{l}\text { Preços Médios ao } \\
\text { Consumidor com Impostos } \\
\text { - Industrial }\end{array}$ & 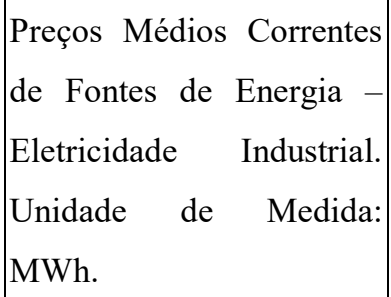 & $\begin{array}{l}\text { Fonte: Balanço Energético } \\
\text { Nacional }\end{array}$ & PIND \\
\hline $\begin{array}{l}\text { Preços Médios ao } \\
\text { Consumidor com Impostos } \\
\text { - Residencial }\end{array}$ & $\begin{array}{l}\text { Preços Médios } \\
\text { de }\end{array}$ & $\begin{array}{l}\text { Fonte: Balanço Energético } \\
\text { Nacional }\end{array}$ & PRES \\
\hline $\begin{array}{l}\text { Variação Percentual Real } \\
\text { do PIB - Produto Interno } \\
\text { Bruto = [(PIB Ano Anterior } \\
-(\text { PIB Ano Atual })-1] \text { x } 100\end{array}$ & $\begin{array}{l}\text { Crescimento do PIB. É a } \\
\text { forma mais tradicional de } \\
\text { se medir o crescimento } \\
\text { econômico de um país. }\end{array}$ & $\begin{array}{l}\text { Fonte: IBGE. Demirgüç-Kunt e } \\
\text { Huizinga (2010); Reynaud e } \\
\text { Thomas (2013). }\end{array}$ & $V A R P I B$ \\
\hline $\begin{array}{l}\text { Taxa de Investimento em \% } \\
\text { do PIB = Formação Bruta } \\
\text { de Capital Fixo* / PIB a } \\
\text { Preços Correntes x } 100\end{array}$ & $\begin{array}{l}\text { Parcela representada pelo } \\
\text { investimento no total da } \\
\text { produção nacional. }\end{array}$ & Fonte: IPEADATA. & INVEST \\
\hline $\begin{array}{l}\text { Taxa de Câmbio Comercial } \\
\text { para Compra Fim Período }= \\
\text { real }(\mathrm{R} \$) \text { / dólar americano } \\
(\mathrm{US} \$)\end{array}$ & $\begin{array}{l}\text { Taxa de câmbio em reais } \\
\text { por dólar compra em fim } \\
\text { de período. }\end{array}$ & $\begin{array}{l}\text { Fonte: IPEADATA. Pereira e } \\
\text { Chicoli (2016). }\end{array}$ & $C M B$ \\
\hline $\begin{array}{l}\text { Taxa SELIC = Média } \\
\text { ponderada pelo volume das } \\
\text { operações compromissadas } \\
\text { realizadas em determinado } \\
\text { dia, tomando como base a } \\
\text { forma anual de } 252 \text { dias } \\
\text { úteis x } 100\end{array}$ & 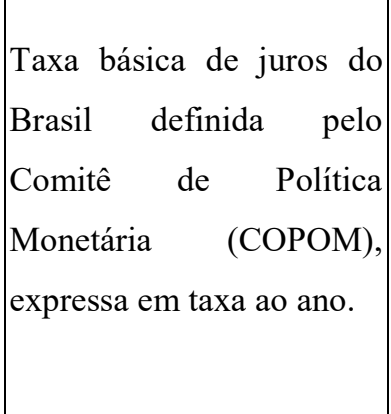 & $\begin{array}{l}\text { Fonte: Banco Central do Brasil. } \\
\text { Cerqueira, Soares e David } \\
\text { (2009); Pereira e Chicoli (2016). }\end{array}$ & SELIC \\
\hline
\end{tabular}

Nota: *Formação Bruta de Capital Fixo: Mede o quanto as empresas aumentaram seus bens de capital, isto é, sua capacidade produtiva.

Elencadas as variáveis do estudo, se faz necessário o detalhamento dos métodos aplicados na pesquisa, conforme segue. 


\subsection{Métodos}

A fim de cumprir os objetivos desta pesquisa, tornou-se necessária a utilização de modelos econométricos que proporcionassem a operacionalização das variáveis dependentes $R O E$, ROA e Retorno da Ação com as variáveis explicativas já mencionadas nos Quadros (3) a (6).

O primeiro passo foi realizar uma análise descritiva dos dados, a fim de compreender as tendências que estes assumem e verificar a possível exclusão de valores fora do escopo da pesquisa.

Após esta análise, o próximo passo abrange a verificação do modelo de dados em painel mais adequado a ser estimado, bem como o modelo diff-in-diff.

Os métodos empregados foram reproduzidos no software Stata versão 14 e estão detalhados nas seções 3.4.1 e 3.4.2.

\subsubsection{Estatística Descritiva}

O passo anterior à aplicação das técnicas econométrica é a elaboração de uma análise descritiva da amostra, contendo a média, mediana, desvio padrão, coeficiente de variação, máximo e mínimo das variáveis de estudo, conforme detalhadas na sequência. Para este trabalho, as bases de dados trimestral e a anual foram tratadas em análises separadas.

- A média é uma medida de posição central dos dados, e para a amostra é calculada por:

$$
\bar{x}=\frac{\sum x_{i}}{n}
$$

Onde: $\bar{x}$ é a média amostral; $\sum x_{i}$ é o somatório da $i$-ésima observação; $n=$ soma dos valores das $n$ observações (Sweeney, Williams \& Anderson, 2014).

- A mediana é também uma medida de posição central e trata-se do valor central quando os dados estão organizados em ordem crescente. Se o número de observações for ímpar, a mediana assume o valor que ocupa a posição central. Se o número de observações for par, a mediana é a média dos dois valores centrais (Sweeney, Williams \& Anderson, 2014).

- O desvio padrão é uma medida de variabilidade e se apresenta como a raiz quadrada da variância. O cálculo da variância amostral é dado por: 


$$
s^{2}=\frac{\sum\left(x_{i}-\bar{x}\right)^{2}}{n-1}
$$

Onde: $s^{2}$ representa a variância amostral; $\sum\left(x_{i}-\bar{x}\right)^{2}$ é o somatório dos desvios quadráticos em torno da média; e $n$ é o número de observações da amostra (Sweeney, Williams \& Anderson, 2014).

- O coeficiente de variação é uma estatística descritiva que indica qual é a magnitude do desvio padrão em relação à média e é dado por:

$$
\mathrm{CV}=\left(\frac{\text { Desvio Padrão }}{\text { Média }}\right) \times 100
$$

Os valores mínimo e máximo são medidas de posição, sendo que o mínimo é a menor observação da amostra e o máximo, a maior observação (Sweeney, Williams \& Anderson, 2014).

\subsubsection{Técnicas de Análise de Dados}

As técnicas para análise dos dados da pesquisa selecionadas foram a Regressão Linear Múltipla com Dados em Painel e a Técnica Differences-in-Differences, que serão detalhadas na sequência.

\section{Regressão Linear Múltipla com Dados em Painel}

A técnica adotada para verificar os determinantes do desempenho das empresas do setor elétrico no Brasil no período compreendido entre 2010 e 2015 é a Regressão Linear Múltipla com Dados em Painel.

A modelagem de dados em painel se apresenta como dados longitudinais com medidas repetidas em diferentes pontos no tempo em uma mesma unidade, que no caso deste estudo, tratam-se de empresas. As regressões em painel podem capturar tanto a variação ao longo das unidades (como acontece em dados em uma cross-section), quanto a variação ao longo do tempo (Cameron \& Triveldi, 2010).

O modelo linear de Regressão Linear Múltipla para Dados em Painel se apresenta, tradicionalmente, das formas: 
(i) Individual-effects Model representado na equação (4):

$$
\mathrm{Y}_{\mathrm{it}}=\alpha_{\mathrm{i}}+x_{i t}^{\prime} \beta+\varepsilon_{\mathrm{it}}
$$

Onde: $x_{i t}$ são os regressores, $\propto_{i}$ são os efeitos aleatórios do indivíduo-específico e $\varepsilon_{i t}$ é o erro idiossincrático (Cameron \& Trivedi, 2010).

(ii) Modelo de efeitos fixos (Fixed-effects Model), $\alpha_{i}$ pode ser correlacionado com os regressores $x_{i t}$, o que permite certa endogeneidade (ocorre quando um dos regressores do modelo é correlacionacionado com o erro). $\mathrm{O}$ modelo de efeitos fixos implica que $E\left(y_{i t} \mid \alpha_{i}, x_{i t}\right)=\alpha_{i}+x_{i t}^{\prime} \beta$, assumindo que $E\left(y_{i t} \mid \alpha_{i}, x_{i t}\right)=0$. Então, $\beta_{j}=\partial E\left(y_{i t} \mid \alpha_{i}, x_{i t}\right) / \partial x_{j, i t}$. A vantagem do modelo de efeitos fixos é que se pode obter um estimador consistente do efeito marginal do $j$ th regressor no termo $E\left(y_{i t} \mid \alpha_{i}, x_{i t}\right)$ fornecendo $x_{j, i t}$ é o tempo variando, mesmo que os regressores sejam endógenos (Cameron \& Trivedi, 2010).

(iii) Modelo de efeitos aleatórios, Cameron e Trivedi (2010) afirmam que este assume que, na equação (1) o termo $\alpha_{i}$ é puramente aleatório e que uma hipótese mais forte implica que $\alpha_{i}$ não é correlacionado com os regressores. De acordo com os autores, as vantagens do modelo de efeitos aleatórios são que ele é gerador de estimativas de todos os coeficientes e os efeitos marginais resultantes, mesmo dos regressores invariantes no tempo, e que o termo $E\left(y_{i t} \mid x_{i t}\right)^{2}$ pode ser estimado.

Para definição do modelo mais adequado de dados em painel, são realizados os testes de Chow, Breush-Pagan e Hausman.

- O teste de Chow é utilizado para definição entre o modelo Pooled OLS e o modelo de efeitos fixos; representa um teste F para determinar se os parâmetros de suas funções de regressão múltipla diferem entre si e verifica mudanças no intercepto e de alteração dos coeficientes de inclinação ao longo do tempo. Suas hipóteses nula e alternativa são: $\mathrm{H}_{0}$ : os interceptos são iguais para todas as cross-sections POLS. $\mathrm{H}_{1}$ : os interceptos são diferentes para todas as cross-sections - efeitos fixos (Gujarati, 2006; Wooldridge, 2010).

\footnotetext{
${ }^{2} E\left(y_{i t} \mid x_{i t}=E\left(\alpha_{i} \mid x_{i t}\right)+x_{i t}^{\prime} \beta\right.$ (Cameron \& Trivedi, 2010).
} 
- O teste LM (Lagrange Multiplier) de Breusch-Pagan é empregado para definição entre o POLS e o modelo de efeitos aleatórios. Avalia a adequação de efeitos aleatórios com base na análise dos resíduos do modelo estimado por mínimos quadrados ordinários -POLS, sob a hipótese nula de que a variância dos resíduos seja igual a zero. O teste deriva uma estatística usando o princípio multiplicador Lagrange em um cenário de probabilidade. Suas hipóteses são: $\mathrm{H}_{0}$ : a variância dos resíduos que refletem diferenças individuais é igual a zero -POLS. $\mathrm{H}_{1}$ : a variância dos resíduos que refletem diferenças individuais é diferente de zero efeitos aleatórios (Gujarati, 2006; Cameron \& Trivedi, 2010; Wooldridge, 2010).

- O teste de Hausman é utilizado para definição entre o modelo de efeitos fixos e o de efeitos aleatórios. Suas hipóteses são: $\mathrm{H}_{0}$ : modelo de correção dos erros é adequado - efeitos aleatórios. $\mathrm{H}_{1}$ : modelo de correção dos erros não é adequado efeitos fixos (Gujarati, 2006; Cameron \& Trivedi, 2010; Wooldridge, 2010).

\section{Differences-in-Differences}

Em finanças, está se tornando mais comum o uso de técnicas do chamado "quaseexperimento", que conseguem capturar o efeito de crises financeiras, mudanças em políticas econômicas, dentre outros. Apesar da existência de outros métodos plausíveis baseados na disponibilidade de dados para a inferência causal quase-experimental, como métodos de correspondência, uso de variáveis instrumentais, regressão de descontinuidade, as estimativas DID - Differences-in-Differences oferecem uma alternativa controlando as características não observadas e combinando-as com informações observadas ou complementares (Villa, 2012).

$\mathrm{O}$ teste conhecido como differences-in-differences refere-se a um experimento natural que pode ser usado quando ocorre algum evento exógeno. O procedimento consiste inicialmente na divisão da amostra em quatro grupos: (i) um grupo de controle antes da mudança, (ii) grupo de controle depois da mudança, (iii) grupo de tratamento antes da mudança e (iv) grupo de tratamento depois da mudança. Na sequência, o diff-in-diff faz a comparação dos participantes e não participantes antes e depois do efeito do fator exógeno de mudança (Torres-Reyna, 2015).

A metodologia diff-in-diff, portanto, foi utilizada nesta pesquisa para capturar o efeito da implantação da MP nº 579/2012 nas empresas com relação às empresas do grupo de 
controle. Destaca-se que ambos os grupos vinham de empresas reagindo de forma similar a todo e qualquer fator que afeta a variável de interesse antes da intervenção, no caso a edição da Medida Provisória em 2012.

Pode ser representado matematicamente pela equação:

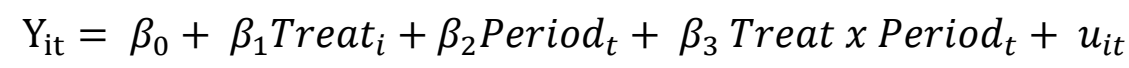

Onde: Treat $_{i}$ e Period $_{t}$ são variáveis binárias: Treat $_{i}=1$ indica se tratado e Period $_{t}=1$ depois do tratamento. $\beta_{0}$ captura o patamar base não tratada antes do tratamento; $\beta_{1}$ captura diferenças básicas, não observadas e fixas entre os dois grupos antes do tratamento (assumindo que permaneçam os mesmos após o tratamento); $\beta_{2}$ compreende controles gerais, tendências comuns que afetam os resultados, mesmo na ausência de um tratamento (assumindo ser o mesmo para ambos os grupos); $\beta_{3}$ estima o efeito do tratamento (quando ocorre, no grupo tratado) (Campello, 2015).

\subsection{Modelo Econométrico}

Apresentados os modelos em suas formas gerais e estabelecidos os testes adequados, é possível construir os modelos econométricos da pesquisa, conforme ordem: primeiro estudo, segundo estudo e terceiro estudo.

\subsubsection{Primeiro Estudo: Desempenho e Variáveis Contábeis, de Governança e de Mercado}

A primeira abordagem da pesquisa refere-se à avaliação do desempenho do setor elétrico no Brasil com dados trimestrais compreendendo o primeiro trimestre de 2010 ao quarto trimestre de 2015, alinhado com o objetivo geral da pesquisa e com as hipóteses H1 e H2 de pesquisa.

H1: Os indicadores contábeis explicam o desempenho.

H2: Os indicadores de mercado explicam o desempenho.

Como resultado dessa primeira análise, pode-se estabelecer que, se pelo menos um beta (parâmetro estimado) for estatisticamente diferente de zero, as hipóteses $\mathrm{H} 1$ e $\mathrm{H} 2$ podem ser aceitas. 
A análise para examinar os determinantes do desempenho se deu através de indicadores contábeis e de governança e de mercado, separadamente.

Para a análise com variáveis contábeis como explicativas, o estudo fez uso de duas variáveis dependentes: ROE e ROA.

Estudos de Shaoul (1997); Lin, Liu e Chu (2005); Sirtaine et al (2005); Rocha, Camacho e Bragança (2007); Matarazzo (2008), Cerqueira, Soares e David (2009); De Lima et al (2009); Szuster et al (2011), Buccini (2012); Bekana e Abitie (2012); Ribeiro, Macedo e Marques (2012); Delen, Kuzey e Uyar (2013); Reynaud e Thomas (2013); Assaf Neto (2014); Curcino, Lemes e Botinha (2014) utilizaram a variável ROE como dependente.

Sendo assim, estabeleceu-se o modelo de variáveis contábeis com a variável ROE como dependente, conforme segue.

$$
\begin{aligned}
\text { ROE }=\alpha_{i}+ & \beta_{1} \text { Divbrat }_{i t}+\beta_{2} \text { Divliqebitda }_{i t}+\beta_{3} \text { Invpl }_{i t}+\beta_{4} \text { Liqcor }_{i t} \\
& +\beta_{5} \text { Capgir }_{i t}+\beta_{6} \text { Mliq }_{i t}+\beta_{7} \text { Lnrec }_{i t}+\beta_{8} \text { CapexDepAmort }_{i t} \\
& +\beta_{9} \text { GOV }_{i t}+\varepsilon_{i t}
\end{aligned}
$$

Onde: ROE: Retorno sobre o Patrimônio Líquido; (1) Divbrat: Dívida Bruta sobre o Ativo; (2) Divliqebitda: Dívida Líquida sobre Ebitda; (3) Invpl: Investimento sobre o Patrimônio Líquido; (4) Liqcor: Liquidez Corrente; (5) Capgir: Capital de Giro; (6) Mliq: Margem Líquida; (7) Lnrec: Logaritmo Natural da Receita; (8) CapexDepAmort: Investimento -CAPEX sobre Depreciação e Amortização; (9) GOV: Dummy de Governança.

Estudos de Shaoul (1997); Lin, Liu e Chu (2005); Minardi et al (2007); Matarazzo (2008); Cohen e Zarowin (2010); Demirgüç-Kunt e Huizinga (2010); Szuster et al (2011); Bekana e Abitie (2012); Ribeiro, Macedo e Marques (2012); Delen, Kuzey e Uyar (2013); Assaf Neto (2014) utilizaram ROA como variável dependente.

Estabeleceu-se, portanto, o modelo de variáveis contábeis com a variável ROA como dependente, conforme segue.

$$
\begin{aligned}
\text { ROA }=\alpha_{i}+ & \beta_{1} \text { Divbrat }_{i t}+\beta_{2} \text { Divliqebitda }_{i t}+\beta_{3} \text { Invpl }_{i t}+\beta_{4} \text { Liqcor }_{i t} \\
& +\beta_{5} \text { Capgir }_{i t}+\beta_{6} \text { Mliq }_{i t}+\beta_{7} \text { Lnrec }_{i t}+\beta_{8} \text { CapexDepAmort }_{i t} \\
& +\beta_{9} \text { GOV }_{i t}+\varepsilon_{i t}
\end{aligned}
$$


Onde: ROA: Retorno sobre o Ativo; (1) Divbrat: Dívida Bruta sobre o Ativo; (2) Divliqebitda: Dívida Líquida sobre Ebitda; (3) Invpl: Investimento sobre o Patrimônio Líquido; (4) Liqcor: Liquidez Corrente; (5) Capgir: Capital de Giro; (6) Mliq: Margem Líquida; (7) Lnrec: Logaritmo Natural da Receita; (8) CapexDepAmort: Investimento CAPEX sobre Depreciação e Amortização; (9) GOV: Dummy de Governança.

Para a análise com variáveis de mercado como explicativas, se fez uso da variável Retorno da Ação como dependente. Estudos de Nagano, Merlo e Silva (2003); Mellone Junior e Saito (2004); Acharya e Schnabl (2010); Demirgüç-Kunt e Huizinga (2010); Edmans (2011); Assaf Neto (2014); Bragança, Pessoa e Rocha (2015) utilizaram a variável Retorno da Ação como dependente.

Com isso, tornou-se possível estabelecer o modelo de variáveis de mercado com a variável Retorno da Ação como dependente, conforme segue.

$$
\begin{aligned}
& \text { RetAcao }=\alpha_{i}+\beta_{1} \text { Valormerc }_{i t}+\beta_{2} \text { Evebitda }_{i t}+\beta_{3} \text { Cfech }_{i t}+\beta_{4} \text { Divacao }_{i t} \\
& +\beta_{5} \text { Beta5anos }_{i t}+\beta_{6} \text { Desvpad5anos }_{i t}+\beta_{7} \text { Vol5anos }_{i t} \\
& +\beta_{8} \text { Retornolbov } i t+\varepsilon_{i t}
\end{aligned}
$$

Onde: RetAcao: Retorno da Ação; (1) Valormerc: Valor de Mercado; (2) Evebitda: Enterprise Value sobre o Ebitda; (3) Cfech: Cotação de Fechamento; (4) Divacao: Dividendo por Ação; (5) Beta5anos: Beta para 5 Anos; (6) Desvpad5anos: Desvio Padrão para 5 anos; (7) Vol5anos: Volatilidade para 5 anos; (8) RetornoIbov: Retorno do Ibovespa.

\subsubsection{Segundo Estudo: Desempenho e Variáveis Econômicas}

Na sequência, desenvolve-se o estudo referente à avaliação do desempenho do setor elétrico no Brasil de janeiro de 2010 a dezembro de 2015, com dados anuais, alinhado com a hipótese $\mathrm{H} 3$ de pesquisa.

H3: O ambiente macroeconômico afetou a rentabilidade das empresas

Estudos de Cerqueira, Soares e David (2009); Demirgüç-Kunt e Huizinga (2010); Reynaud e Thomas (2013) e Pereira e Chicoli (2016) empregaram variáveis econômicas na análise.

Da mesma maneira que o estudo com as variáveis contábeis e de governança como explicativas, se fez uso de duas variáveis dependentes no estudo: ROE e ROA. 
Com base nesse apoio da literatura, foi possível estabelecer o modelo para a variável dependente ROE, a saber:

$$
\begin{aligned}
\text { ROE }=\alpha_{i}+ & \beta_{1} \text { Divbrat }_{i t}+\beta_{2} \text { Divliqebitda }_{i t}+\beta_{3} \text { Invpl }_{i t}+\beta_{4} \text { Liqcor }_{i t} \\
& +\beta_{5} \text { Capgir }_{i t}+\beta_{6} \text { Mliq }_{i t}+\beta_{7} \text { Lnrec }_{i t}+\beta_{8} \text { CapexDepAmort }_{i t} \\
& +\beta_{9} \text { GOV }_{i t}+\beta_{10} \text { Valormerc }_{i t}+\beta_{11} \text { Evebitda }_{i t}+\beta_{12} \text { Cfech }_{i t} \\
& +\beta_{13} \text { Divacao }_{i t}+\beta_{14}{\text { Beta } 5 \text { anos }_{i t}+\beta_{15} \text { Vol5anos }_{i t}} \\
& +\beta_{16} \text { RetornoIbov }_{i t}+\beta_{17} \text { OIEEPOP }_{i t}+\beta_{18} \text { CONSRESPIB }_{i t} \\
& +\beta_{19} \text { PIND }_{i t}+\beta_{20} \text { PRES }_{i t}+\beta_{21} \text { VARPIB }_{i t}+\beta_{22} \text { INVEST }_{i t} \\
& +\beta_{23} \text { CMB }_{i t}+\beta_{24} \text { SELIC }_{i t}+\varepsilon_{i t}
\end{aligned}
$$

Onde: ROE: Retorno sobre o Patrimônio Líquido; (1) Divbrat: Dívida Bruta sobre o Ativo; (2) Divliqebitda: Dívida Líquida sobre Ebitda; (3) Invpl: Investimento sobre o Patrimônio Líquido; (4) Liqcor: Liquidez Corrente; (5) Capgir: Capital de Giro; (6) Mliq: Margem Líquida; (7) Lnrec: Logaritmo Natural da Receita; (8) CapexDepAmort: Investimento - CAPEX sobre Depreciação e Amortização; (9) GOV: Dummy de Governança; (10) Valormerc: Valor de Mercado; (11) Evebitda: Enterprise Value sobre o Ebitda; (12) Cfech: Cotação de Fechamento; (13) Divacao: Dividendo por Ação; (14) Beta5anos: Beta para 5 Anos; (15) Vol5anos: Volatilidade para 5 anos; (16) RetornoIbov: Retorno do Ibovespa; (17) OIEEPOP: Oferta Interna de Energia Elétrica sobre População; (18) CONSRESPIB: Consumo Final Energético sobre o PIB; (19) PIND: Preços Médios ao Consumidor - Industrial; (20) PRES: Preços Médios aos Consumidor - Residencial; (21) VARPIB: Crescimento do PIB; (22) INVEST: Taxa de Investimento; (23) CMB: Taxa de Câmbio; (24) SELIC: Taxa Selic. 
Com base na literatura, foi possível estabelecer também o modelo para a variável dependente ROA, a saber:

$$
\begin{aligned}
\text { ROA }=\alpha_{i}+ & \beta_{1} \text { Divbrat }_{i t}+\beta_{2} \text { Divliqebitda }_{i t}+\beta_{3} \text { Invpl }_{i t}+\beta_{4} \text { Liqcor }_{i t} \\
& +\beta_{5} \text { Capgir }_{i t}+\beta_{6} \text { Mliq }_{i t}+\beta_{7} \text { Lnrec }_{i t}+\beta_{8} \text { CapexDepAmort }_{i t} \\
& +\beta_{9} \text { GOV }_{i t}+\beta_{10} \text { Valormerc }_{i t}+\beta_{11} \text { Evebitda }_{i t}+\beta_{12} \text { Cfech }_{i t} \\
& +\beta_{13} \text { Divacao }_{i t}+\beta_{14} \text { Beta5anos }_{i t}+\beta_{15} \text { Vol5anos }_{i t} \\
& +\beta_{16} \text { RetornoIbov }_{i t}+\beta_{17} \text { OIEEPOP }_{i t}+\beta_{18} \text { CONSRESPIB }_{i t} \\
& +\beta_{19} \text { PIND }_{i t}+\beta_{20} \text { PRES }_{i t}+\beta_{21} \text { VARPIB }_{i t}+\beta_{22} \text { INVEST }_{i t} \\
& +\beta_{23} \text { CMB }_{i t}+\beta_{24} \text { SELIC }_{i t}+\varepsilon_{i t}
\end{aligned}
$$

Onde: ROA: Retorno sobre o Ativo; (1) Divbrat: Dívida Bruta sobre o Ativo; (2) Divliqebitda: Dívida Líquida sobre Ebitda; (3) Invpl: Investimento sobre o Patrimônio Líquido; (4) Liqcor: Liquidez Corrente; (5) Capgir: Capital de Giro; (6) Mliq: Margem Líquida; (7) Lnrec: Logaritmo Natural da Receita; (8) CapexDepAmort: Investimento CAPEX sobre Depreciação e Amortização; (9) GOV: Dummy de Governança; (10) Valormerc: Valor de Mercado; (11) Evebitda: Enterprise Value sobre o Ebitda; (12) Cfech: Cotação de Fechamento; (13) Divacao: Dividendo por Ação; (14) Beta5anos: Beta para 5 Anos; (15) Vol5anos: Volatilidade para 5 anos; (16) RetornoIbov: Retorno do Ibovespa; (17) OIEEPOP: Oferta Interna de Energia Elétrica sobre População; (18) CONSRESPIB: Consumo Final Energético sobre o PIB; (19) PIND: Preços Médios ao Consumidor - Industrial; (20) PRES: Preços Médios aos Consumidor - Residencial; (21) VARPIB: Crescimento do PIB; (22) INVEST: Taxa de Investimento; (23) CMB: Taxa de Câmbio; (24) SELIC: Taxa Selic.

\subsubsection{Terceiro Estudo: Impacto da MP nº 579/2012}

A terceira abordagem da pesquisa refere-se à avaliação do impacto da MP n ${ }^{\circ}$ 579/2012 na rentabilidade das empresas do setor elétrico no Brasil. Com isso, foram utilizados dados anuais para o período de 2010 a 2015 e aplicado o teste diff-in-diff, alinhado com a hipótese $\mathrm{H} 4$ de pesquisa.

H4: A edição da MP579 afetou negativamente a rentabilidade das empresas do setor elétrico no Brasil. 
O primeiro passo foi realizar a separação dos dados para os períodos pré e pós a edição da MP $n^{\circ}$. 579/2012. Para isso, foi criada uma dummy de tempo nomeada time: para $\mathrm{t}<2012=0$ (grupo de controle antes da mudança) e para $\mathrm{t}>2012=1$ (grupo de controle depois da mudança).

Em seguida, foi gerada a dummy de tratamento denominada treated: para $\mathrm{id}<3=0$ (grupo de tratamento antes da mudança e para id $>3=1$ (grupo de tratamento depois da mudança). Esta dummy reflete a adesão à medida por parte das empresas da amostra. $\mathrm{O}$ grupo de tratamento anterior à mudança compreende as empresas que não aderiram à $\mathrm{MP} \mathrm{n}^{\circ}$. 579/2012, ordenadas de 1 a 3 no banco de dados, a saber: 1 - Cemig; 2 - Cesp e 3 Copel. E as demais empresas, 4 a 24 são as que aderiram à Medida. A identificação das empresas consta no Apêndice 1.2.

Ainda, foi gerada a dummy de interação entre o tempo e o tratamento, identificada por $D I D$, para comparação das empresas participantes e não participantes antes e depois da edição da Medida.

E, por fim, foi realizada a aplicação do Teste Differences-in-Differences para verificar se a adesão à Medida provocou efeitos na rentabilidade das empresas, bem como a regressão com as variáveis contábeis, de mercado, de governança, econômicas e as dummies de tempo, tratamento e a interação geradas, conforme equação (11) e equação (12).

$$
\begin{aligned}
\text { ROE }_{i t}=\beta_{0}+ & \beta_{1} \text { Divbrat }_{i t}+\beta_{2} \text { Divliqebitda }_{i t}+\beta_{3} \text { Invpl }_{i t}+\beta_{4} \text { Liqcor }_{i t} \\
& +\beta_{5} \text { Capgir }_{i t}+\beta_{6} \text { Mliq }_{i t}+\beta_{7} \text { Lnrec }_{i t}+\beta_{8} \text { CapexDepAmort }_{i t} \\
& +\beta_{9} \text { GOV }_{i t}+\beta_{10} \text { Valormerc }_{i t}+\beta_{11} \text { Evebitda }_{i t}+\beta_{12} \text { Cfech }_{i t} \\
& +\beta_{13} \text { Divacao }_{i t}+\beta_{14} \text { Beta5anos }_{i t}+\beta_{15} \text { Vol5anos }_{i t} \\
& +\beta_{16} \text { RetornoIbov }_{i t}+\beta_{17} \text { OIEEPOP }_{i t}+\beta_{18} \text { CONSRESPIB }_{i t} \\
& +\beta_{19} \text { PIND }_{i t}+\beta_{20} \text { PRES }_{i t}+\beta_{21} \text { VARPIB }_{i t}+\beta_{22} \text { INVEST }_{i t} \\
& +\beta_{23} \text { CMB }_{i t}+\beta_{24} \text { SELIC }_{i t}+\beta_{25} \text { Time }_{i}+\beta_{26} \text { Treated }_{t}+\beta_{27} \text { DID }_{t} \\
& +u_{i t}
\end{aligned}
$$

Onde: ROE: Retorno sobre o Patrimônio Líquido; (1) Divbrat: Dívida Bruta sobre o Ativo; (2) Divliqebitda: Dívida Líquida sobre Ebitda; (3) Invpl: Investimento sobre o Patrimônio Líquido; (4) Liqcor: Liquidez Corrente; (5) Capgir: Capital de Giro; (6) Mliq: Margem Líquida; (7) Lnrec: Logaritmo Natural da Receita; (8) CapexDepAmort: Investimento - CAPEX sobre Depreciação e Amortização; (9) GOV: Dummy de 
Governança; (10) Valormerc: Valor de Mercado; (11) Evebitda: Enterprise Value sobre o Ebitda; (12) Cfech: Cotação de Fechamento; (13) Divacao: Dividendo por Ação; (14) Beta5anos: Beta para 5 Anos; (15) Vol5anos: Volatilidade para 5 anos; (16) RetornoIbov: Retorno do Ibovespa; (17) OIEEPOP: Oferta Interna de Energia Elétrica sobre População; (18) CONSRESPIB: Consumo Final Energético sobre o PIB; (19) PIND: Preços Médios ao Consumidor - Industrial; (20) PRES: Preços Médios aos Consumidor - Residencial; (21) VARPIB: Crescimento do PIB; (22) INVEST: Taxa de Investimento; (23) CMB: Taxa de Câmbio; (24) SELIC: Taxa Selic; (25) Time: dummy de tempo; (26) Treated: dummy de tratamento; (27) DID: dummy de interação.

$$
\begin{aligned}
\text { ROA }_{i t}=\beta_{0}+ & \beta_{1} \text { Divbrat }_{i t}+\beta_{2} \text { Divliqebitda }_{i t}+\beta_{3} \text { Invpl }_{i t}+\beta_{4} \text { Liqcor }_{i t} \\
& +\beta_{5} \text { Capgir }_{i t}+\beta_{6} \text { Mliq }_{i t}+\beta_{7} \text { Lnrec }_{i t}+\beta_{8} \text { CapexDepAmort }_{i t} \\
& +\beta_{9} \text { GOV }_{i t}+\beta_{10} \text { Valormerc }_{i t}+\beta_{11} \text { Evebitda }_{i t}+\beta_{12} \text { Cfech }_{i t} \\
& +\beta_{13} \text { Divacao }_{i t}+\beta_{14} \text { Beta5anos }_{i t}+\beta_{15} \text { Vol5anos }_{i t} \\
& +\beta_{16} \text { RetornoIbov }_{i t}+\beta_{17} \text { OIEEPOP }_{i t}+\beta_{18} \text { CONSRESPIB }_{i t} \\
& +\beta_{19} \text { PIND }_{i t}+\beta_{20} \text { PRES }_{i t}+\beta_{21} \text { VARPIB }_{i t}+\beta_{22} \text { INVEST }_{i t} \\
& +\beta_{23} \text { CMB }_{i t}+\beta_{24} \text { SELIC }_{i t}+\beta_{25} \text { Time }_{i}+\beta_{26} \text { Treated }_{t}+\beta_{27} \text { DID }_{t} \\
& +u_{i t}
\end{aligned}
$$

Onde: ROA: Retorno sobre o Ativo; (1) Divbrat: Dívida Bruta sobre o Ativo; (2) Divliqebitda: Dívida Líquida sobre Ebitda; (3) Invpl: Investimento sobre o Patrimônio Líquido; (4) Liqcor: Liquidez Corrente; (5) Capgir: Capital de Giro; (6) Mliq: Margem Líquida; (7) Lnrec: Logaritmo Natural da Receita; (8) CapexDepAmort: Investimento CAPEX sobre Depreciação e Amortização; (9) GOV: Dummy de Governança; (10) Valormerc: Valor de Mercado; (11) Evebitda: Enterprise Value sobre o Ebitda; (12) Cfech: Cotação de Fechamento; (13) Divacao: Dividendo por Ação; (14) Beta5anos: Beta para 5 Anos; (15) Vol5anos: Volatilidade para 5 anos; (16) RetornoIbov: Retorno do Ibovespa; (17) OIEEPOP: Oferta Interna de Energia Elétrica sobre População; (18) CONSRESPIB: Consumo Final Energético sobre o PIB; (19) PIND: Preços Médios ao Consumidor - Industrial; (20) PRES: Preços Médios aos Consumidor - Residencial; (21) VARPIB: Crescimento do PIB; (22) INVEST: Taxa de Investimento; (23) CMB: Taxa de Câmbio; (24) SELIC: Taxa Selic; (25) Time: dummy de tempo; (26) Treated: dummy de tratamento; (27) DID: dummy de interação. 


\section{RESULTADOS}

Estabelecida a abordagem metodológica da pesquisa, seguem os resultados obtidos com a estatística descritiva, os testes para escolha do melhor modelo de painel; as regressões com dados em painel e o teste diff-in-diff.

\subsection{Estatística Descritiva}

A amostra constituída inicialmente por 43 empresas de capital aberto do setor elétrico no Brasil resultou, após a retirada de holdings em 24 empresas. Com o intuito de compreender melhor o comportamento dessas empresas e variáveis estudadas, foi realizada uma análise descritiva das mesmas. Para o primeiro estudo foi utilizada a base de dados trimestrais e para o segundo e o terceiro estudo foi utilizada a base de dados anual, por isso a análise descritiva foi realizada de forma separada, conforme segue.

\subsubsection{Dados Trimestrais}

Para o período estudado, do primeiro trimestre de 2010 ao quarto trimestre de 2015, são 24 trimestres no total. A amostra final possui 24 empresas. Portanto, são 576 observações. A Tabela 2 apresenta a estatística descritiva para as variáveis contábeis, bem como as variáveis resposta ROE e ROA.

Tabela 2 - Estatística Descritiva das Variáveis Contábeis

\begin{tabular}{l|c|c|c|c|c|c|c}
\hline \multicolumn{1}{c|}{ Variável } & N & Mínimo & Máximo & Média & Mediana & DP & CV \\
\hline ROE & 524 & $-290,51$ & 77,38 & 1,16 & 3,21 & 19,29 & 16,62 \\
ROA & 533 & $-19,95$ & 13,51 & 1,34 & 1,45 & 2,74 & 2,05 \\
Divbrat & 531 & 0 & 75,93 & 28,44 & 29,60 & 15,04 & 0,53 \\
Divliqebitda & 524 & $-792,47$ & 5394 & 13,24 & 5,18 & 243,73 & 18,41 \\
Invpl & 421 & $-13,18$ & 75,86 & 5,05 & 0 & 14,21 & 2,81 \\
Liqcor & 534 & 0 & 53,24 & 2,19 & 1,15 & 5,41 & 2,47 \\
Capgir & 534 & -4438105 & 4104948 & 148486 & 87885 & 878517 & 5,92 \\
Mliq & 532 & $-730,44$ & 471,95 & 4,08 & 11,35 & 63,90 & 15,66 \\
Lnrec & 531 & 8,28 & 15,64 & 13,07 & 13,47 & 1,61 & 0,12 \\
Capexdepamort & 499 & -74879 & 132706 & 1230 & 214,63 & 9326 & 7,58 \\
Gov & 576 & 0 & 1 & 0,21 & 0 & 0,41 & 1,95 \\
\hline
\end{tabular}

Nota. Siglas: $\mathrm{N}=$ Número de Observações; DP = Desvio Padrão; CV = Coeficiente de Variação. Onde: roe: retorno sobre o patrimônio líquido; roa: retorno sobre o ativo; divbrat: dívida bruta/ativo; divliqebitda: 
dívida líquida/ebitda; invpl: investimento/patrimônio líquido; liqcor: liquidez corrente; capgir: capital de giro; mliq: margem líquida; lnrec: logaritmo natural da receita; capexdepamort: capex/depreciação e amortização; gov: dummy de governança.

Com relação às variáveis dependentes ROE a ROA, ambas apresentaram alta variabilidade em relação à média, expressa pelo coeficiente de variação.

A variável dependente ROE varia em torno $1,16 \%$ e a variável dependente ROA em $1,34 \%$.

A variável ROE se destacou por demonstrar média de 1,16, mediana de 3,21, desvio padrão de 19,29 , valor mínimo de $-290,51$ e valor máximo de 77,38, indicando uma amostra heterogênea.

A Tabela 3Tabela 3 apresenta a estatística descritiva para as variáveis de mercado, bem como a variável resposta Retorno da Ação.

Tabela 3 - Estatística Descritiva das Variáveis de Mercado

\begin{tabular}{l|c|c|c|c|c|c|c}
\hline \multicolumn{1}{c|}{ Variável } & $\mathbf{N}$ & Mínimo & Máximo & Média & Mediana & DP & CV \\
\hline Retacao & 415 & $-53,33$ & 58,77 & 0,30 & 0 & 17,59 & 58,63 \\
Valormercado & 522 & 0 & 0 & 4781158 & 3089455 & 5507457 & 0,12 \\
Evebitda & 469 & $-874,09$ & 267066 & 3763 & 26,72 & 22523 & 5,98 \\
Cfech & 452 & -913 & 3198 & 131,83 & 23,30 & 450,03 & 3,41 \\
Divacao & 408 & 0 & 237,88 & 3,59 & 0,99 & 14,41 & 4,01 \\
Beta5anos & 382 & $-0,90$ & 4,94 & 0,43 & 0,39 & 0,51 & 1,19 \\
Vol5anos & 382 & 4,48 & 131,06 & 37,13 & 30,63 & 18,67 & 0,50 \\
Retornoibov & 552 & $-16,15$ & 13,94 & $-1,63$ & $-1,04$ & 9,38 & $-5,75$ \\
\hline
\end{tabular}

Nota. Siglas: N = Número de Observações; DP = Desvio Padrão; CV = Coeficiente de Variação. Onde: retacao: retorno da ação; valormercado: valor de mercado; evebitda: enterprise value/ebitda; cfech: cotação de fechamento; divacao: dividendo por ação; beta5anos: beta para 5 anos; vol5anos: volatilidade para 5 anos; retornoibov: retorno do Ibovespa.

A variável dependente Retorno da Ação mostrou variabilidade alta em relação à média (58,63\%). A variável explicativa Retorno do Ibovespa apresentou coeficiente de variação negativo, indicando média negativa.

A variável dependente Retorno da Ação varia em torno 0,30\% representando a menor média entre as demais variáveis apresentadas. 


\subsubsection{Dados Anuais}

Para o período estudado, de janeiro de 2010 a dezembro de 2015, são seis anos no total. A amostra final possui 24 empresas. Portanto, são 144 observações.

A Tabela 4 apresenta a estatística descritiva para as variáveis contábeis, bem como as variáveis resposta ROE e ROA.

Tabela 4 - Estatística Descritiva das Variáveis Contábeis

\begin{tabular}{l|c|c|c|c|c|c|c}
\hline \multicolumn{1}{c|}{ Variável } & $\mathbf{N}$ & Mínimo & Máximo & Média & Mediana & DP & CV \\
\hline ROE & 129 & $-225,94$ & 61,51 & 8,38 & 14,51 & 33,06 & 3,95 \\
ROA & 134 & $-22,10$ & 23,31 & 5,22 & 5,58 & 8,17 & 1,57 \\
Divbrat & 134 & 0 & 73,39 & 28,58 & 30,12 & 15,67 & 0,55 \\
Divliqebitda & 131 & $-67,46$ & 18,45 & 0,38 & 1,48 & 8,11 & 21,34 \\
Invpl & 102 & 0 & 75,14 & 5,25 & 0 & 14,92 & 2,84 \\
Liqcor & 134 & 0,25 & 21,18 & 1,81 & 1,18 & 2,80 & 1,55 \\
Capgir & 134 & -3708772 & 2144279 & 81000 & 103329 & 894028 & 11,04 \\
Mliq & 134 & $-259,63$ & 66,11 & 5,22 & 10,26 & 39,08 & 7,49 \\
Lnrec & 134 & 2,72 & 16,87 & 13,79 & 14,78 & 2,98 & 0,22 \\
Capexdepamort & 125 & $-2,97$ & 833,04 & 16,84 & 2,32 & 89,74 & 5,33 \\
Gov & 144 & 0 & 1 & 0,20 & 0 & 0,40 & 2 \\
\hline
\end{tabular}

Nota. Siglas: $\mathrm{N}=$ Número de Observações; $\mathrm{DP}=$ Desvio Padrão; $\mathrm{CV}$ = Coeficiente de Variação. Onde: roe: retorno sobre o patrimônio líquido; roa: retorno sobre o ativo; divbrat: dívida bruta/ativo; divliqebitda: dívida líquida/ebitda; invpl: investimento/patrimônio líquido; liqcor: liquidez corrente; capgir: capital de giro; mliq: margem líquida; lnrec: logaritmo natural da receita; capexdepamort: capex/depreciação e amortização; gov: dummy de governança.

As variáveis ROE e ROA apresentam baixa variabilidade em relação à média, expressas pelos coeficientes de variação (3, 95 e 1,57 respectivamente). Na média, ROE variou $8,38 \%$ e ROA 5,22\%. As variáveis capital de giro e capex sobre depreciação e amortização apresentaram os valores mais discrepantes de mínimo, máximo, média, mediana e desvio padrão. Os maiores coeficientes de variação são das variáveis capital de giro (11,04\%) e Dívida Líquida sobre Ebitda (21,34\%). 
Tabela 5 apresenta a estatística descritiva para as variáveis de mercado.

Tabela 5 - Estatística Descritiva das Variáveis de Mercado

\begin{tabular}{l|c|c|c|c|c|c|c}
\hline \multicolumn{1}{c|}{ Variável } & $\mathbf{N}$ & Mínimo & Máximo & Média & Mediana & DP & CV \\
\hline Valormercado & 130 & 60778 & 0 & 4741682 & 3277379 & 5330788 & 1,12 \\
Evebitda & 117 & $-293,40$ & 67,33 & 2,98 & 6,51 & 31,26 & 10,49 \\
Cfech & 120 & 0,43 & 682,41 & 39,4 & 18,79 & 89,74 & 2,28 \\
Divacao & 105 & 0 & 10,48 & 1,39 & 0,68 & 1,92 & 1,38 \\
Beta5anos & 102 & $-2,54$ & 2,39 & 0,26 & 0,34 & 0,94 & 3,62 \\
Vol5anos & 102 & 4,87 & 108,26 & 32,63 & 26,35 & 21,99 & 0,67 \\
Retornoibov & 120 & $-18,11$ & 7,40 & $-8,49$ & $-13,31$ & 9,51 & $-1,12$ \\
\hline
\end{tabular}

Nota. Siglas: $\mathrm{N}=$ Número de Observações; $\mathrm{DP}=$ Desvio Padrão; $\mathrm{CV}$ = Coeficiente de Variação. Onde: valormercado: valor de mercado; evebitda: enterprise value/ebitda; cfech: cotação de fechamento; divacao: dividendo por ação; beta5anos: beta para 5 anos; vol5anos: volatilidade para 5 anos; retornoibov: retorno do Ibovespa.

A variável enterprise value sobre ebitda apresentou a maior variabilidade em relação à média $(10,49 \%)$ e o Retorno do Ibovespa apresentou variação negativa $(-1,12 \%)$.

A Tabela 6 apresenta a estatística descritiva para as variáveis econômicas.

Tabela 6- Estatística Descritiva das Variáveis Econômicas

\begin{tabular}{l|c|c|c|c|c|c|c}
\hline \multicolumn{1}{c|}{ Variável } & $\mathbf{N}$ & Mínimo & Máximo & Média & Mediana & DP & CV \\
\hline OIEEPOP & 144 & 2802 & 3066 & 2953 & 2981 & 93,13 & 0,03 \\
CONSRESPIB & 144 & 78,61 & 83,37 & 80,43 & 79,73 & 1,59 & 0,02 \\
PIND & 144 & 153,85 & 180,01 & 166,26 & 167,18 & 8,97 & 0,05 \\
PRES & 144 & 200,45 & 257,80 & 224,80 & 224,46 & 19,82 & 0,09 \\
VARPIB & 144 & $-3,85$ & 7,53 & 2,10 & 2,47 & 3,50 & 1,67 \\
INVEST & 144 & 18,16 & 20,18 & 18,91 & 18,74 & 0,79 & 0,04 \\
CMB & 144 & 1,67 & 3,90 & 2,41 & 2,19 & 0,74 & 0,31 \\
SELIC & 144 & 7,14 & 14,15 & 10,73 & 10,78 & 2,1 & 0,20 \\
\hline
\end{tabular}

Nota. Siglas: $\mathrm{N}=$ Número de Observações; $\mathrm{DP}=$ Desvio Padrão; $\mathrm{CV}=$ Coeficiente de Variação. Onde: OIEEPOP: oferta interna de energia/População; CONSRESPIB: consumo final energético residencial; PIND: preços médios ao consumidor - industrial; PRES: preços médios ao consumidor - residencial; VARPIB: variação percentual real do PIB; INVEST: taxa de investimento; CMB: taxa de câmbio; SELIC: taxa Selic.

Em relação às variáveis econômicas empregadas no estudo, estas possuem baixa variabilidade em relação à média, apresentando uma amostra bem homogênea. O número de observações é o mesmo para todas as variáveis, não apresentando, portanto, missing values. 


\subsection{Primeiro Estudo: Análise de Dados em Painel - Desempenho e Variáveis Contábeis, de Governança e de Mercado}

As empresas estão identificadas por número, de 1 a 24 , por ordem alfabética, conforme consta na Tabela do Apêndice 1.1. Os dados são trimestrais. As seções 4.21, 4.2.2 e 4.2.3 trazem as análises com as variáveis dependentes ROE, ROA e Retorno da Ação separadamente.

\subsubsection{Primeiro Painel: Desempenho e Variáveis Contábeis e de Governança com a Variável Dependente ROE}

Nesta etapa, é realizada a aplicação do modelo de Regressão Linear Múltipla com Dados em Painel, tendo como dependente a variável ROE para avaliar desempenho financeiro e variáveis contábeis e de Governança como explicativas.

O painel se apresenta desbalanceado, pois o número de observações por variável é distinto. O número total de períodos para cada empresa é de 24 trimestres.

Mediante a possibilidade de escolha do modelo para dados em painel, primeiramente foi aplicado o Teste de Hausman, que indicou p-valor de 0,0003, indicando que o melhor modelo é o de efeitos fixos e rejeitando a hipótese nula do teste.

$\mathrm{Na}$ sequência, foi realizado o Teste de Chow para identificar qual o modelo mais adequado entre o modelo de Efeitos Fixos e o Modelo Pooled.

A estatística do teste $\mathrm{F}(21,356)=4,49$, bem como seu respectivo $p$-valor (Prob $>F=$ 0,0077) indicaram que o modelo de efeitos fixos se sobrepõe à estimação do modelo Pooled, rejeitando a hipótese nula do teste, corroborando para a estimação de efeitos fixos encontrada pelos resultados do Teste de Hausman.

Desta maneira, estimou-se o modelo de Efeitos Fixos com erro-padrão robusto, conforme evidencia a Tabela 7. 
Tabela 7 - Estimação com Erro-Padrão Robusto por Efeitos Fixos para a Variável ROE

\begin{tabular}{l|c|c|c|c|c|c}
\hline \multicolumn{1}{c|}{ ROE } & Coef. & DP & $\mathbf{t}$ & $\mathbf{P}>|\mathbf{t}|$ & \multicolumn{2}{c}{ IC - 95\% } \\
\hline Divbrat & $-0,333$ & 0,276 & $-1,2$ & 0,242 & $-0,907$ & 0,242 \\
Divliqebitda & $-0,001$ & 0,002 & $-0,81$ & 0,429 & $-0,004$ & 0,002 \\
Invpl & $-0,048$ & 0,059 & $-0,8$ & 0,431 & $-0,171$ & 0,076 \\
Liqcor & $-1,126^{* *}$ & 0,506 & $-2,23$ & 0,037 & $-2,178$ & $-0,074$ \\
Capgir & 0 & 0 & 1,23 & 0,234 & 0 & 0 \\
Mliq & $0,074^{* * *}$ & 0,021 & 3,52 & 0,002 & 0,030 & 0,118 \\
Lnrec & $-3,52$ & 3,789 & $-0,93$ & 0,364 & $-11,395$ & 4,360 \\
Capexdepamort & -0 & 0,0003 & $-1,04$ & 0,311 & 0 & 0 \\
cons & 58,234 & 47,076 & 1,24 & 0,23 & $-39,665$ & 156,134 \\
\hline
\end{tabular}

Nota: Siglas: Coef:: coeficientes; $D P$ : desvio-padrão; $t$ : estatística t de student; $P>|t|:$-valor da estatística t; IC-95\%: intervalo de confiança de 95\%. Fixed-effects (within) regression. Variável gov omitida colinearidade. 386 observações. 22 grupos. $R$-squared: variação within $=0,0563$; variação between $=$ 0,0081 ; variação overall $=0,0225$. Corr $\left(\mathrm{u} \_\mathrm{i}, \mathrm{Xb}\right)=-0,4646$. $\mathrm{F}(8,21)=31,27$. Prob $>\mathrm{F}=0,0000$. Sigma_u $=12,879$; sigma $\mathrm{e}=19,38$; rho $=0,306$. Inferencia: $* * *$ Significante a $1 \% * *$ Significante a $5 \%$ *Significante a $10 \%$. Onde: roe: retorno sobre o patrimônio líquido; divbrat: dívida bruta/ativo; divliqebitda: dívida líquida/ebitda; invpl: investimento/patrimônio líquido; liqcor: liquidez corrente; capgir: capital de giro; mliq: margem líquida; lnrec: logaritmo natural da receita; capexdepamort: capex/depreciação e amortização.

Como resultado para essa primeira análise, ao nível de 5\% de significância, as variáveis liquidez corrente e margem líquida se apresentaram significantes, sendo que estas podem explicar o desempenho financeiro das empresas do setor elétrico com a variável dependente Retorno sobre o Patrimônio Líquido para dados trimestrais de janeiro de 2010 a dezembro de 2015 .

A margem líquida mede a eficiência e a viabilidade da empresa. Uma margem alta reflete bom desempenho. É a variável de menor controle pela empresa pelo fato de o setor ser altamente regulado e o preço ser determinado pelo Governo, que, com suas medidas, pode jogar a margem para cima ou para baixo e é representativa para o resultado das empresas. Seu coeficiente foi positivo nesse caso indicando que uma melhor margem implica em melhor desempenho financeiro.

Em relação à liquidez corrente, se as empresas gerarem muito caixa e, no entanto, investir o valor todo de uma vez, elas tornam-se pouco líquidas. Isto pode ser explicado pelo sinal negativo do coeficiente. Pelo lado do custo, pois a demanda de energia é relativamente inelástica e o valor da tarifa é exógeno à empresa, o fato da empresa ser endividada não é relevante, mas sim o fato de ela gerar caixa (ter liquidez). Se a empresa gerar muito caixa e investir tudo de uma vez, ela torna-se pouco líquida.

O estudo de Bekana e Abitie (2012) apontou a variável liquidez corrente como significativa para explicar a rentabilidade dos bancos e que apresenta um padrão 
decrescente nesse setor. Ribeiro, Macedo e Marques (2012) encontraram evidências de que o ROE é indicador relevante para explicar o desempenho financeiro no setor de distribuição de energia elétrica no Brasil. Reynauld e Thomas (2013) encontraram que a margem líquida e o ROE são forte e positivamente correlacionados para o setor de utilities em países desenvolvidos e emergentes.

Em relação aos coeficientes, pelo menos um beta se mostrou estatisticamente diferente de zero e, com isso, não há evidências que levem a rejeição da hipótese de pesquisa H1, de que os indicadores contábeis explicam o desempenho.

\subsubsection{Segundo Painel: Desempenho e Variáveis Contábeis e de Governança com a Variável Dependente ROA}

Na sequência, é realizada a aplicação do modelo de Regressão Linear Múltipla com Dados em Painel, tendo como dependente a variável ROA para avaliar desempenho operacional e variáveis contábeis e de Governança como explicativas.

O painel se apresenta desbalanceado, pois o número de observações por variável é distinto. O número total de períodos para cada empresa é de 24 trimestres.

Mediante a possibilidade de escolha do modelo para dados em painel, primeiramente foi aplicado o Teste de Hausman, cujos resultados evidenciaram, através do p-valor de 0,0463 que o melhor modelo é o de efeitos fixos, rejeitando a hipótese nula do teste.

Com isso, foi realizada a estimação feita por Efeitos Fixos para a variável dependente ROA, com a aplicação do Teste de Chow para identificar qual o modelo mais adequado entre o modelo de Efeitos Fixos e o Modelo Pooled. A estatística do teste F $(21,360)=$ 11,90, bem como seu respectivo $\mathrm{p}$-valor ( $\mathrm{Prob}>\mathrm{F}=0,0000)$, indicaram que o modelo de efeitos fixos se sobrepõe à estimação do modelo Pooled, rejeitando a hipótese nula do teste, reforçando os resultados do Teste de Hausman.

Sendo assim, foi realizada a estimação do modelo de Efeitos Fixos com erro-padrão robusto, conforme apresenta a Tabela 8 . 
Tabela 8 - Estimação com Erro-Padrão Robusto por Efeitos Fixos para a Variável ROA

\begin{tabular}{l|c|c|c|c|c|c}
\hline \multicolumn{1}{c|}{ ROA } & Coef. & DP & $\mathbf{t}$ & $\mathbf{P}>|\mathbf{t}|$ & \multicolumn{2}{c}{ IC -95\% } \\
\hline Divbrat & $-0,07 * * *$ & 0,017 & $-4,31$ & 0 & $-0,108$ & $-0,038$ \\
Divliqebitda & 0 & 0,0001 & $-0,7$ & 0,49 & $-0,0002$ & 0,0001 \\
Invpl & $-0,02662$ & 0,016 & $-1,64$ & 0,116 & $-0,060$ & 0,007 \\
Liqcor & $-0,21564 * * *$ & 0,067 & $-3,24$ & 0,004 & $-0,354$ & $-0,077$ \\
Capgir & 0 & 0 & 1,33 & 0,199 & 0 & 0 \\
Mliq & $0,020 * * *$ & 0,004 & 4,87 & 0 & 0,012 & 0,029 \\
Lnrec & $-0,291$ & 0,388 & $-0,75$ & 0,461 & $-1,099$ & 0,516 \\
Capexdepamort & 0 & 0 & $-1,67$ & 0,109 & 0 & 0 \\
cons & 7,422 & 5,205 & 1,43 & 0,169 & $-3,402$ & 18,246 \\
\hline
\end{tabular}

Nota: Siglas: Coef:: coeficientes; $D P$ : desvio-padrão; $t$ : estatística t de student; $P>|t|:$-valor da estatística t; IC-95\%: intervalo de confiança de 95\%. Fixed-effects (within) regression. Variável gov omitida colinearidade. 390 observações. 22 grupos. $R$-squared: variação within $=0,3480$; variação between $=$ 0,1436 ; variação overall $=0,2397$. Corr $\left(\mathrm{u} \_\mathrm{i}, \mathrm{Xb}\right)=-0,4390$. F $(8,21)=62,01$. Prob $>\mathrm{F}=0,0000$. Sigma_u $=1,974 ;$ sigma $\mathrm{e}=1,696 ;$ rho $=0,575$. Inferência: $* * *$ Significante a $1 \% * *$ Significante a $5 \% *$ Significante a $10 \%$. Onde: roa: retorno sobre o ativo; divbrat: dívida bruta/ativo; divliqebitda: dívida líquida/ebitda; invpl: investimento/patrimônio líquido; liqcor: liquidez corrente; capgir: capital de giro; mliq: margem líquida; lnrec: logaritmo natural da receita; capexdepamort: capex/depreciação e amortização.

Como resultado para a análise com a variável ROA como dependente, ao nível de 5\% de significância, as variáveis dívida bruta sobre ativo, liquidez corrente e margem líquida se apresentaram significantes, sendo que estas podem explicar o desempenho operacional das empresas do setor elétrico para o período compreendido entre janeiro de 2010 a dezembro de 2015.

A variável de destaque para a análise com o ROA é a dívida bruta/ativo. Para o ROA, o fato de ser mais ou menos endividado é significativo. O sinal do coeficiente nesse caso é negativo apontando que quanto menor a dívida, maior o ROA. Se a empresa tiver que pagar muito juro, compromete a margem e também o ROA (margem x giro).

Minardi et al (2007) encontraram em seu estudo para empresas americanas do setor industrial, que as variáveis dívida bruta/ativo total e ROA são significativas. Quanto maior o desempenho operacional, melhor o rating de crédito para essas empresas. Cohen e Zarowin (2010) avaliaram desempenho através do ROA e seus resultados apontaram desempenho semelhante ao longo do tempo para o estudo das SEOs (Seasoned Equity Offerings).

Em relação aos coeficientes, pelo menos um beta se mostrou estatisticamente diferente de zero e, com isso, não há evidências que levem a rejeição da hipótese de pesquisa $\mathrm{H} 1$, de que os indicadores contábeis explicam o desempenho. 


\subsubsection{Terceiro Painel: Desempenho e Variáveis de Mercado com a Variável Dependente Retorno da Ação}

A terceira parte do primeiro estudo trata da aplicação do modelo de Regressão Linear Múltipla com Dados em Painel, tendo como dependente a variável Retorno da Ação e variáveis de mercado como explicativas para verificar desempenho a nível de mercado. O painel se apresentou desbalanceado, devido ao fato de que o número de observações por variável difere. O número total de períodos para cada empresa é de 24 trimestres.

Mediante a possibilidade de escolha do modelo para dados em painel, primeiramente foi aplicado o Teste de Hausman, cujas evidências através do p-valor de 0,0002 apontaram que o melhor modelo é o de efeitos fixos, rejeitando a hipótese nula do teste.

Desse modo, foi elaborado o Teste de Chow para verificação do melhor modelo a ser estimado entre Efeitos Fixos e Pooled. O teste apresentou a estatística F $(17,257)=3,29$ e seu p-valor (Prob > F) de 0,0000, o que indicou sobreposição do modelo de efeitos fixos ao modelo Pooled, rejeitando a hipótese nula do teste, e correspondendo aos resultados do Teste de Hausman.

Isto posto, realizou-se a estimação modelo de Efeitos Fixos com erro-padrão robusto, conforme apresenta a Tabela 9.

Tabela 9 - Estimação com Erro-Padrão Robusto por Efeitos Fixos para a Variável RetAcao

\begin{tabular}{l|c|c|c|c|c|c}
\hline \multicolumn{1}{c|}{ Retacao } & Coef. & DP & $\mathbf{t}$ & $\mathbf{P}>|\mathbf{t}|$ & \multicolumn{2}{c}{ IC - 95\% } \\
\hline Valormerc & $0 * * *$ & 0 & 6,41 & 0 & 0 & 0 \\
Evebitda & $0,0002 *$ & 0,0001 & 1,9 & 0,075 & $-0,00002$ & 0,0005 \\
Cfech & 0,006 & 0,007 & 1 & 0,329 & $-0,007$ & 0,020 \\
Divacao & 0,416 & 0,496 & 0,84 & 0,413 & $-0,623$ & 1,462 \\
Beta5anos & 3,302 & 2,280 & 1,45 & 0,166 & $-1,509$ & 8,114 \\
Vol5anos & $-0,011$ & 0,097 & $-0,11$ & 0,913 & $-0,216$ & 0,194 \\
Retornoibov & $0,140^{*}$ & 0,075 & 1,86 & 0,08 & $-0,018$ & 0,299 \\
cons & $-19,392$ & 2,453 & $-7,91$ & 0 & $-24,566$ & $-14,217$ \\
\hline
\end{tabular}

Nota: Siglas: Coef:: coeficientes; $D P$ : desvio-padrão; $t$ : estatística t de student; $P>|t|:$ p-valor da estatística $t$; IC-95\%: intervalo de confiança de 95\%. Fixed-effects (within) regression. 282 observações. 18 grupos. $R$-squared: variação within $=0,1243$; variação between $=0,0851$; variação overall $=0,0260$. Corr $(\mathrm{u} \mathrm{i}, \mathrm{Xb})$ $=-0,8981 . \mathrm{F}(7,17)=98,48$. Prob $>\mathrm{F}=0,0000$. Sigma $u=16,837$; sigma e $=15,403$; rho $=0,544$. Inferência: ***Significante a $1 \% * *$ Significante a $5 \%$ *Significante a $10 \%$. Onde: retacao: retorno da ação; valormercado: valor de mercado; evebitda: enterprise value/ebitda; cfech: cotação de fechamento; divacao: dividendo por ação; beta 5 anos: beta para 5 anos; vol5anos: volatilidade para 5 anos; retornoibov: retorno do Ibovespa. 
Como resultado para a análise com a variável RetAcao como dependente, ao nível de 5\% de significância, a variável valor de Mercado. Ao nível de $10 \%$, evebitda e retorno do Ibovespa se apresentaram significantes, sendo que estas podem explicar o desempenho das empresas do setor elétrico sob a ótica de variáveis de mercado.

O valor de mercado, é o próprio retorno da ação. Em relação ao evebitda, o impacto é baixo. Se a empresa possuir um múltiplo compatível com a situação da companhia, observa-se que ele contribui pra a melhoria do retorno. Se estiver baixo, compromete o retorno. As empresas do setor elétrico precisam ter o ebitda bem alinhado. Sua participação no coeficiente é baixa para o retorno, nesse caso. Quanto ao retorno do Ibovespa, o setor elétrico é um setor que está alinhado com o mercado e a economia e portanto acompanha o Ibovespa. Se pensar como uma proxy de crescimento, estão alinhados (0,14 e positivo).

Acharya e Schnabl (2010) também utilizaram a variável dependente retorno da ação, porém para compreender o impacto do papel comercial com garantia de ativos no início da crise financeira de 2008, porém encontraram outras variáveis significativas: exposição e dívida de curto prazo. Da Costa Jr. e Neves (2000) encontraram uma relação negativa entre desempenho e valor de mercado para as carteiras criadas no estudo. Pereira e Martins (2012) encontraram também a variável enterprise value como significativa, proem para medir o valor de mercado de empresas norte e latino-americanas do setor de construção. Taffarel, da Silva e Clemente (2013) utilizaram o retorno do Ibovespa como proxy do retorno de mercado, da mesma forma, e encontraram evidências de que esta variável é significativa para apurar os eventos regulatórios sobre os retornos das ações do setor elétrico brasileiro, corroborando os achados desta pesquisa.

Em relação aos coeficientes, pelo menos um beta se mostrou estatisticamente diferente de zero e, por isso, não há evidências que levem à rejeição da hipótese de pesquisa H2, de que os indicadores de mercado explicam o desempenho com dados trimestrais para o período de janeiro de 2010 a dezembro de 2015. 


\subsection{Segundo Estudo: Análise de Dados em Painel - Desempenho, Variáveis Contábeis, de Governança e de Mercado e Variáveis Econômicas}

Nesta etapa é realizada a aplicação do modelo de Regressão de Dados em Painel para as variáveis ROE e ROA como dependentes e variáveis contábeis, de mercado e macroeconômicas históricas como explicativas.

As empresas estão identificadas por número, de 1 a 24, por ordem alfabética, conforme consta na Tabela do Apêndice 1.1. Os dados são anuais.

\subsubsection{Primeiro Painel: Desempenho, Variáveis Contábeis e de Governança, Variáveis de Mercado e Variáveis Econômicas com a Variável Dependente ROE}

O primeiro painel do segundo estudo utiliza a variável ROE como dependente para avaliar desempenho financeiro e as variáveis de contábeis e de governança, de mercado e econômicas como explicativas no modelo para o período de 2010 a 2015 .

O painel apresentou-se fortemente balanceado, com seis períodos para cada empresa, 24 empresas, totalizando 144 observações para cada variável explicativa.

Atendendo a possibilidade de escolha do melhor modelo para dados em painel, primeiramente foi aplicado o Teste de Hausman, que indicou através do p-valor de 0,0134 que o melhor modelo é o de efeitos fixos, rejeitando a hipótese nula do teste.

A seguir, foi realizado o Teste de Chow para identificar qual o modelo mais adequado entre o modelo de Efeitos Fixos e o Modelo Pooled. A estatística do teste F $(14,19)=$ 7,95, bem como seu respectivo p-valor (Prob $>F$ ) de 0,0000 indicaram que o modelo de efeitos fixos se sobrepõe à estimação do modelo Pooled, rejeitando a hipótese nula do teste, em conformidade com a estimação de efeitos fixos resultante do Teste de Hausman. Desta forma, estimou-se o modelo de Efeitos Fixos com erro-padrão robusto, conforme mostra Tabela 10. 
Tabela 10 - Estimação com Erro-Padrão Robusto por Efeitos Fixos para a Variável ROE

\begin{tabular}{l|c|c|c|c|c|c}
\hline \multicolumn{1}{c|}{ roe } & Coef. & DP & $\mathbf{t}$ & $\mathbf{P}>|\mathbf{t}|$ & \multicolumn{2}{c}{ IC - 95\% } \\
\hline divbrat & 0,039 & 0,188 & 0,21 & 0,835 & $-0,364$ & 0,444 \\
divliqebitda & $4,732 * * *$ & 1,079 & 4,39 & 0,001 & 2,418 & 7,047 \\
invpl & 0,076 & 0,089 & 0,86 & 0,405 & $-0,114$ & 0,266 \\
liqcor & 2,817 & 3,023 & 0,93 & 0,367 & $-3,666$ & 9,300 \\
capgir & 0 & 0 & 0,28 & 0,781 & 0 & 0 \\
mliq & $0,633 * * *$ & 0,089 & 7,12 & 0 & 0,442 & 0,824 \\
lnrec & $-7,4 *$ & 4,139 & $-1,79$ & 0,095 & $-16,277$ & 1,479 \\
capexdepamort & $-0,174 * * *$ & 0,028 & $-6,2$ & 0 & $-0,234$ & 0,114 \\
gov & 2,439 & 1,591 & 1,53 & 0,148 & $-0,973$ & 5,851 \\
valormerc & 0 & 0 & 0,87 & 0,398 & 0 & 0 \\
evebitda & $-2,687 * * *$ & 0,696 & $-3,86$ & 0,002 & $-4,179$ & $-1,195$ \\
cfech & $0,148 * * *$ & 0,031 & 4,82 & 0 & 0,082 & 0,213 \\
divacao & 2,148 & 1,356 & 1,58 & 0,136 & $-0,761$ & 5,057 \\
beta5anos & $4,352 * *$ & 1,740 & 2,5 & 0,025 & 0,619 & 8,084 \\
vol5anos & 0,041 & 0,125 & 0,33 & 0,747 & $-0,226$ & 0,308 \\
retornoibov & 0,086 & 0,144 & 0,6 & 0,559 & $-0,222$ & 0,394 \\
OIEEPOP & $-0,165$ & 0,136 & $-1,21$ & 0,245 & $-0,458$ & 0,127 \\
CONSRESPIB & 4,028 & 2,561 & 1,57 & 0,138 & $-1,465$ & 9,519 \\
PIND & $-0,846$ & 0,762 & $-1,11$ & 0,286 & $-2,481$ & 0,789 \\
cons & 407,348 & 356,366 & 1,14 & 0,272 & $-356,981$ & 1171,677 \\
\hline
\end{tabular}

Nota: Siglas: Coef:: coeficientes; $D P$ : desvio-padrão; $t$ : estatística t de student; $P>|t|:$ p-valor da estatística $t$; IC-95\%: intervalo de confiança de 95\%. Fixed-effects (within) regression. Variáveis PRES; VARPIB; INVEST; CMB; SELIC omitidas por colinearidade. 53 observações. 15 grupos. $R$-squared: variação within $=0,9542$; variação between $=0,0837$; variação overall $=0,2911$. corr $(\mathrm{u}$ i, $\mathrm{Xb})=-0,8313$. $\mathrm{F}(11,14)=-$. Prob $>\mathrm{F}=-$. Sigma_u $=31,691$; sigma_e $=4,497$; rho $=0,98$. Inferência: $* * *$ Significante a $1 \%$

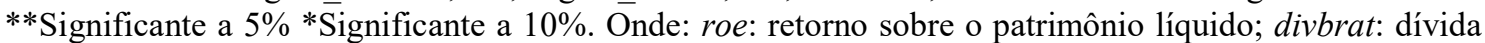
bruta/ativo; divliqebitda: dívida líquida/ebitda; invpl: investimento/patrimônio líquido; liqcor: liquidez corrente; capgir: capital de giro; mliq: margem líquida; lnrec: logaritmo natural da receita; capexdepamort: capex/depreciação e amortização; gov: dummy de governança; valormercado: valor de mercado; evebitda: enterprise value/ebitda; cfech: cotação de fechamento; divacao: dividendo por ação; beta5anos: beta para 5 anos; vol5anos: volatilidade para 5 anos; retornoibov: retorno do Ibovespa; OIEEPOP: oferta interna de energia/População; CONSRESPIB: consumo final energético residencial; PIND: preços médios ao consumidor - industrial.

Como resultado para essa primeira análise, ao nível de 5\% de significância, as variáveis dívida líquida/ebitda, margem líquida, capex/depreciação e amortização, enterprise value/ebitda, cotação de fechamento e beta5anos se apresentaram significantes, sendo que estas podem explicar o desempenho financeiro das empresas do setor elétrico com a variável dependente Retorno sobre o Patrimônio Líquido.

A margem líquida nesse caso se apresentou bastante forte (coeficiente 0,6). $\mathrm{O}$ capex/depreciação apresentou coeficiente negativo. Uma explicação é que se investe até 
a depreciação, ele é nulo. Se investe após a depreciação, é negativo. As empresas do setor elétrico investem altos montantes sobre o que deprecia.

Para a variável enterprise value/ebitda, o sinal do coeficiente é negativo. Um enterprise value muito alto sobre o ebitda torna o retorno baixo e significa que o valor pelo qual a empresa está sendo negociada está muito alto e, portanto, ela está supervalorizada. Para o investidor, o retorno fica menor. Quanto à cotação de fechamento, é proxy do retorno do ativo e seu coeficiente positivo. O coeficiente beta fortemente positivo, com índice 4, expressa o risco. O beta normalmente precisa ser baixo, menor que 1 para relativa estabilidade. Nesse caso, tem efeito forte no retorno. A dívida líquida/ebitda é um múltiplo para avaliar endividamento (o custo da dívida). É um balizador da liquidez. Variáveis econômicas não tiveram significância estatística.

Esses resultados corroboram os estudos de Pereira e Martins (2012) que encontraram que variáveis de mercado conseguem explicar o valor de mercado da empresa, para o setor de construção, Minardi et al (2007) apresentou que através de variáveis contábeis e de mercado é possível determinar uma precisão dos ratings de crédito de empresas, de Lima et al (2009) fez um estudo de caso da empresa AES Tietê com análise contábil, financeira e prospectiva. Estes estudos utilizaram amostras, períodos e testes econométricos diferentes, porém fizeram uso de algumas variáveis utilizadas neste trabalho, e estas também foram significativas em suas pesquisas.

Com relação ao atendimento da hipótese $\mathrm{H} 3$ de pesquisa, as variáveis de conjuntura econômica: crescimento do PIB, taxa de investimento, taxa de câmbio e taxa Selic foram omitidas na regressão por apresentarem colinearidade. Com isso, não houveram evidências para afirmar que o ambiente macroeconômico afetou negativamente a rentabilidade das empresas.

\subsubsection{Segundo Painel: Desempenho, Variáveis Contábeis e de Governança, Variáveis de Mercado, de Governança e Variáveis Econômicas com a Variável Dependente ROA}

O segundo painel estimado para o segundo estudo utilizou a variável dependente ROA para avaliar desempenho operacional com variáveis contábeis e de governança, de mercado e econômicas como independentes para os anos de 2010 a 2015. 
O painel se configurou como fortemente balanceado, com seis períodos para cada empresa, 24 empresas, totalizando 144 observações para cada uma das variáveis independentes.

Para a escolha do modelo mais adequado para dados em painel, primeiramente foi aplicado o Teste de Hausman, que indicou, por meio do p-valor de 0,0110 que o melhor modelo é o de efeitos fixos, rejeitando a hipótese nula do teste.

Em seguida, foi realizado o Teste de Chow para identificar qual o modelo mais adequado entre o modelo de Efeitos Fixos e o Modelo Pooled. A estatística do teste F $(15,21)=$ 7,39, bem como seu respectivo p-valor (Prob $>F)$ de 0,0000 indicaram que o modelo de efeitos fixos se sobrepõe à estimação do modelo Pooled, rejeitando a hipótese nula do teste, em conformidade com os resultados do Teste de Hausman.

Com isso, estimou-se o modelo de Efeitos Fixos com erro-padrão robusto, de acordo com a Tabela 11.

Tabela 11 - Estimação com Erro-Padrão Robusto por Efeitos Fixos para a Variável ROA

\begin{tabular}{l|c|c|c|c|c|c}
\hline \multicolumn{1}{c|}{ roa } & Coef. & DP & $\mathbf{t}$ & $\mathbf{P}>|\mathbf{t}|$ & \multicolumn{2}{|c}{ IC $-\mathbf{9 5 \%}$} \\
\hline divbrat & 0,028 & 0,083 & 0,34 & 0,739 & $-0,149$ & 0,206 \\
divliqebitda & $0,673^{* *}$ & 0,270 & 2,49 & 0,025 & 0,097 & 1,249 \\
invpl & $0,093^{* * *}$ & 0,028 & 3,28 & 0,005 & 0,033 & 0,154 \\
liqcor & $2,707 * *$ & 0,989 & 2,74 & 0,015 & 0,599 & 4,815 \\
capgir & 0 & 0 & 0,11 & 0,915 & 0 & 0 \\
mliq & $0,296^{* * *}$ & 0,022 & 13,5 & 0,000 & 0,249 & 0,343 \\
lnrec & 3,430 & 2,165 & 1,58 & 0,134 & $-1,184$ & 8,045 \\
capexdepamort & 0,009 & 0,017 & 0,56 & 0,583 & $-0,027$ & 0,046 \\
gov & $-0,978$ & 0,827 & $-1,18$ & 0,255 & $-2,739$ & 0,784 \\
valormerc & 0 & 0 & 0,9 & 0,383 & 0 & 0 \\
evebitda & $-0,419 * *$ & 0,186 & $-2,26$ & 0,039 & $-0,816$ & $-0,023$ \\
cfech & 0,016 & 0,018 & 0,91 & 0,375 & $-0,022$ & 0,055 \\
divacao & $0,815^{* *}$ & 0,327 & 2,5 & 0,025 & 0,119 & 1,512 \\
beta5anos & $1,413 * *$ & 0,528 & 2,68 & 0,017 & 0,288 & 2,539 \\
vol5anos & $-0,068$ & 0,048 & $-1,41$ & 0,18 & $-0,171$ & 0,035 \\
retornoibov & 0,018 & 0,029 & 0,62 & 0,544 & $-0,043$ & 0,078 \\
OIEEPOP & $-0,028$ & 0,033 & $-0,87$ & 0,398 & $-0,098$ & 0,041 \\
CONSRESPIB & 0,029 & 0,521 & 0,06 & 0,956 & $-1,081$ & 1,139 \\
PIND & $-0,091$ & 0,177 & $-0,51$ & 0,615 & $-0,467$ & 0,286 \\
cons & 48,259 & 85,462 & 0,56 & 0,581 & $-133,899$ & 230,417 \\
\hline
\end{tabular}

Nota: Siglas: Coef.: coeficientes; $D P$ : desvio-padrão; $t$ : estatística t de student; $P>|t|:$ p-valor da estatística $t$; IC-95\%: intervalo de confiança de 95\%. Fixed-effects (within) regression. Variáveis PRES; VARPIB; INVEST; CMB; SELIC omitidas por colinearidade. 56 observações. 16 grupos. $R$-squared: variação within $=0,9431$; variação between $=0,0628$; variação overall $=0,0947$. corr $\left(\mathrm{u} \_\mathrm{i}, \mathrm{Xb}\right)=-0,8401$. F $(13,15)=-$. 
Prob $>\mathrm{F}=$-. Sigma_u $=12,663 ;$ sigma_e $=1,643 ;$ rho $=0,983$. Inferência: $* * *$ Significante a $1 \%$ **Significante a $5 \%{ }^{*}$ Significante a $10 \%$. Onde: roa: retorno sobre o ativo; divbrat: dívida bruta/ativo; divliqebitda: dívida líquida/ebitda; invpl: investimento/patrimônio líquido; liqcor: liquidez corrente; capgir: capital de giro; mliq: margem líquida; lnrec: logaritmo natural da receita; capexdepamort: capex/depreciação e amortização; gov: dummy de governança; valormercado: valor de mercado; evebitda: enterprise value/ebitda; cfech: cotação de fechamento; divacao: dividendo por ação; beta5anos: beta para 5 anos; vol5anos: volatilidade para 5 anos; retornoibov: retorno do Ibovespa; OIEEPOP: oferta interna de energia/População; CONSRESPIB: consumo final energético residencial; PIND: preços médios ao consumidor - industrial.

Como resultado para esta análise, ao nível de 5\% de significância, as variáveis dívida líquida/ebitda, investimento/patrimônio líquido, liquidez corrente, margem líquida, enterprise value/ebitda, dividendo pago por ação e beta5anos se apresentaram significantes, sendo que estas podem explicar o desempenho operacional das empresas do setor elétrico com a variável dependente Retorno sobre o Ativo.

As variáveis de destaque para a análise com ROA foram o investimento sobre o patrimônio líquido, que é o grau de alavancagem, quanto mais investimentos, maior o retorno e implica em ter ativos mais novos e mais eficientes; e o dividendo pago por ação, que teve coeficiente baixo e sinal positivo, indicando que quanto melhor o retorno, melhor a política de dividendos das empresas.

Assim como para a variável ROE, os estudos de Pereira e Martins (2012), Minardi et al (2007) e de Lima et al (2009) encontraram resultados semelhantes em relação às variáveis estatisticamente significantes.

Em relação à hipótese $\mathrm{H} 3$ de pesquisa, neste caso as variáveis de conjuntura econômica: crescimento do PIB, taxa de investimento, taxa de câmbio e taxa Selic também foram omitidas na regressão por apresentarem colinearidade, assim como para a variável dependente ROE. Desta forma, não houveram evidências para afirmar que o ambiente macroeconômico afetou negativamente a rentabilidade das empresas.

\subsection{Terceiro Estudo: Teste Diff-in-Diff e a Análise do Impacto da MP nº 579/2012}

O Terceiro estudo compreende a análise do impacto da edição da MP579 sobre a rentabilidade das empresas do setor elétrico brasileiro para os anos de 2010 a 2015 com o recorte temporal de três anos anteriores e três anos posteriores à Medida.

Para elaborar o teste, a amostra foi particionada e as empresas estão identificadas por número, de 1 a 24, conforme consta na Tabela do Apêndice 1.2. As empresas de 1 a 3 são aquelas que não aderiram à Medida, a saber: Cemig, Cesp e Copel - variável treated. A 
base de dados é anual e foi dividida em 2010/2011/2012 e 2013/2014/2015 - variável time para avaliar o efeito da Medida - variável DID. Foram empregadas duas variáveis dependentes para avaliar o desempenho: ROE e ROA. As análises constam na sequência.

\subsubsection{Estimador diff-in-diff para as variáveis ROE e ROA}

Primeiramente foi gerado o estimador de diferenças para as duas variáveis dependentes, a saber: ROE e ROA a fim de verificar o impacto do experimento natural sobre a variável estudada, neste caso a política exógena - a edição da MP 579. A Tabela 12 apresenta o estimador diff-in-diff para a variável dependente ROE, que avalia o aspecto financeiro do desempenho.

Tabela 12 - Estimador diff-in-diff para Variável Dependente ROE

\begin{tabular}{r|c|c|c|c|c|c}
\hline roe & Coef. & DP & $\mathbf{t}$ & $\mathbf{P}>|\mathbf{t}|$ & \multicolumn{2}{|c}{$\mathbf{I C}-\mathbf{9 5 \%}$} \\
\hline time & $-0,433$ & 5,029 & $-0,09$ & 0,932 & $-10,387$ & 9,521 \\
treated & $-0,917$ & 6,561 & $-0,14$ & 0,889 & $-13,902$ & 12,068 \\
DID & $-5,616$ & 8,465 & $-0,66$ & 0,508 & $-22,369$ & 11,137 \\
cons & 11,876 & 3,782 & 3,14 & 0,002 & 4,391 & 19,362 \\
\hline
\end{tabular}

Nota: Siglas: Coef:: coeficientes; $D P$ : desvio-padrão; $t$ : estatística t de student; $P>|t|:$ p-valor da estatística t; IC-95\%: intervalo de confiança de 95\%. Linear Regression. 129 observações. F $(3,125)=0,65$. Prob > $\mathrm{F}=0,5869$. $R$-squared $=0,0089$. Root $M S E=33,304$. Inferência: $* * *$ Significante a $1 \% * *$ Significante a $5 \%$ * Significante a $10 \%$.

Os resultados apontados na Tabela 12 evidenciam que o estimador DID possui sinal negativo no coeficiente, o que indica impacto negativo no desempenho das empresas. Este efeito já era esperado, de acordo com a literatura que indica que a edição da MP579 ocasionou reação negativa do mercado e das empresas de energia elétrica (Assis, 2013; De Castro et al, 2013).

Isto posto, verifica-se o estimador diff-in-diff para a variável dependente ROA, que avalia o aspecto operacional do desempenho, conforme Tabela 13.

Tabela 13 - Estimador diff-in-diff para Variável Dependente ROA

\begin{tabular}{r|c|c|c|c|c|c}
\hline roa & Coef. & DP & $\mathbf{t}$ & $\mathbf{P}>|\mathbf{t}|$ & \multicolumn{2}{|c}{$\mathbf{I C - 9 5 \%}$} \\
\hline time & 0,107 & 1,639 & 0,07 & 0,948 & $-3,136$ & 3,349 \\
treated & 2,529 & 1,637 & 1,55 & 0,125 & $-0,709$ & 5,769 \\
DID & $-3,496$ & 2,294 & $-1,52$ & 0,130 & $-8,035$ & 1,042 \\
cons & 4,541 & 1,095 & 4,15 & 0 & 2,375 & 6,708 \\
\hline
\end{tabular}

Nota: Siglas: Coef:: coeficientes; $D P$ : desvio-padrão; $t$ : estatística t de student; $P>|t|:$ p-valor da estatística t; IC-95\%: intervalo de confiança de 95\%. Linear Regression. 134 observações. F $(3,130)=1,56$. Prob > $\mathrm{F}=\quad 0,2021$. R-squared $=0,0384$. Root $M S E=8,1059$. Inferência: ***Significante a $1 \% * *$ Significante a $5 \% *$ Significante a $10 \%$. 
Os resultados apontados na Tabela 13 evidenciam efeito negativo no desempenho demonstrado por meio do sinal do coeficiente do estimador $D I D$, da mesma maneira que os resultados que se apresentaram para a variável ROE.

Sendo assim, foi realizada regressão com a presença das variáveis dummies geradas para a aplicação do teste diff-in-diff. Isto porque, após verificar o estimador DID, é necessário realizar controle por outros fatores relevantes na regressão, pois a seleção dos grupos de controle não é aleatória. Antes de alegar que DID fornece o impacto da política exógena, é preciso descobrir e isolar o efeito de todas as outras variáveis de controle relevantes na regressão, para evitar que efeitos de outras variáveis produzam vieses na estimação. Através da regressão, portanto, é possível determinar o efeito puro do experimento natural sobre a variável a ser estudada, neste caso o desempenho.

\subsubsection{Estimação Differences-in-Differences e Análise do Impacto da MP $\mathbf{n}^{\circ}$ 579/2012 através do estimador DID}

Nesta etapa, foi elaborada regressão em painel com as variáveis dependentes ROE e ROA e as variáveis explicativas contábeis, de governança, de mercado e macroeconômicas, com a inclusão das dummies de tempo, tratamento e o estimador de diferenças - DID a fim de verificar o impacto da MP579 na rentabilidade das empresas no período estudado. Desta forma, a Tabela 14 apresenta os resultados para a variável dependente ROE. 
Tabela 14 - Resultados da Regressão com Erro-Padrão Robusto para Variável Dependente ROE

\begin{tabular}{l|c|c|c|c|c|c}
\hline \multicolumn{1}{c|}{ roe } & Coef. & DP & $\mathbf{t}$ & $\mathbf{P}>|\mathbf{t}|$ & \multicolumn{2}{|c}{ IC - 95\% } \\
\hline divbrat & $0,391^{*}$ & 0,225 & 1,73 & 0,093 & $-0,069$ & 0,850 \\
divliqebitda & 0,449 & 0,929 & 0,48 & 0,632 & $-1,445$ & 2,345 \\
invpl & $-0,159$ & 0,147 & $-1,08$ & 0,287 & $-0,458$ & 0,140 \\
liqcor & 1,765 & 7,095 & 0,25 & 0,805 & $-12,706$ & 16,235 \\
capgir & 0 & 0 & $-0,43$ & 0,673 & 0 & 0 \\
mliq & $0,944^{* * *}$ & 0,232 & 4,07 & 0 & 0,471 & 1,417 \\
lnrec & 0,482 & 1,166 & 0,41 & 0,682 & $-1,895$ & 2,859 \\
capexdepamort & 0,003 & 0,065 & 0,05 & 0,964 & $-0,130$ & 0,136 \\
gov & $-6,202$ & 6,121 & $-1,01$ & 0,319 & $-18,686$ & 6,282 \\
valormerc & 0 & 0 & 0,95 & 0,351 & 0 & 0 \\
evebitda & 0,072 & 0,546 & 0,13 & 0,896 & $-1,041$ & 1,185 \\
cfech & 0,058 & 0,069 & 0,84 & 0,409 & $-0,083$ & 0,199 \\
divacao & $-0,357$ & 1,523 & $-0,23$ & 0,816 & $-3,462$ & 2,749 \\
beta5anos & $5,072 * * *$ & 1,563 & 3,24 & 0,003 & 1,884 & 8,259 \\
vol5anos & 0,187 & 0,163 & 1,15 & 0,258 & $-0,145$ & 0,519 \\
retornoibov & $-0,594 *$ & 0,316 & $-1,88$ & 0,069 & $-1,238$ & 0,050 \\
OIEEPOP & $0,224 *$ & 0,112 & 2 & 0,055 & $-0,005$ & 0,452 \\
PIND & $-0,097$ & 0,405 & $-0,24$ & 0,812 & $-0,922$ & 0,728 \\
PRES & $0,524 *$ & 0,275 & 1,91 & 0,066 & $-0,036$ & 1,084 \\
treated & 6,070 & 10,553 & 0,58 & 0,569 & $-15,454$ & 27,594 \\
did & $-7,725$ & 9,507 & $-0,81$ & 0,423 & $-27,116$ & 11,665 \\
cons & $-801,649$ & 419,475 & $-1,91$ & 0,065 & $-1657,175$ & 53,876 \\
\hline Sid
\end{tabular}

Nota: Siglas: Coef.: coeficientes; $D P$ : desvio-padrão; $t$ : estatística t de student; $P>|t|:$ p-valor da estatística $t$; IC-95\%: intervalo de confiança de 95\%. Linear Regression. 53 observações. F $(21,31)=118,12$. Prob > $\mathrm{F}=0,0000 . R$-squared $=0,8873$. Root $M S E=9,1291$. Variáveis Omitidas por colinearidade: CONRESPIB; VARPIB; INVEST; CMB; SELIC; TIME. Inferência: ***Significante a $1 \%$ **Significante a $5 \%$ *Significante a 10\%. Onde: roe: retorno sobre o patrimônio líquido; divbrat: dívida bruta/ativo; divliqebitda: dívida líquida/ebitda; invpl: investimento/patrimônio líquido; liqcor: liquidez corrente; capgir: capital de giro; mliq: margem líquida; lnrec: logaritmo natural da receita; capexdepamort: capex/depreciação e amortização; gov: dummy de governança; valormercado: valor de mercado; evebitda: enterprise value/ebitda; cfech: cotação de fechamento; divacao: dividendo por ação; beta5anos: beta para 5 anos; vol5anos: volatilidade para 5 anos; retornoibov: retorno do Ibovespa; OIEEPOP: oferta interna de energia/população; PIND: preços médios indústria; PRES: preços médios residencial; treated: dummy de tratamento; did: estimador de diferenças.

Os resultados evidenciados na Tabela 14 mostram que o modelo teve um bom ajuste (88\%) para explicar a variação do desempenho financeiro a partir das 21 variáveis explicativas. Ao nível de $10 \%$ de significância, as variáveis dívida bruta sobre o ativo, margem líquida, beta para 5 anos, retorno do ibovespa, oferta interna de energia sobre população residente e preços médios - residencial foram significativas com a variável dependente ROE. 
Após a separação da amostra houve mudança para as variáveis: dívida bruta sobre ativo, retorno do Ibovespa, oferta interna de energia/população residente e preços médios residencial. Variáveis econômicas se mostraram determinantes nesse caso.

A inferência dos efeitos da Medida, na regressão, não obteve significância estatística nas variáveis de tratamento e no estimador de diferenças - DID. A variável DID apresentou sinal negativo no coeficiente estimado pela regressão, isto é, a interferência da Medida nos anos posteriores a 2012 foi negativa em relação à rentabilidade, considerando o desempenho financeiro.

A Tabela 15 apresenta os resultados da regressão para a variável dependente ROA.

Tabela 15 - Resultados da Regressão para Variável Dependente ROA

\begin{tabular}{l|c|c|c|c|c|c}
\hline \multicolumn{1}{c|}{ roa } & Coef. & DP & $\mathbf{t}$ & $\mathbf{P}>|\mathbf{t}|$ & \multicolumn{2}{c}{ IC - 95\% } \\
\hline divbrat & 0,104 & 0,064 & 1,62 & 0,115 & $-0,027$ & 0,235 \\
divliqebitda & $-0,273$ & 0,326 & $-0,84$ & 0,409 & $-0,936$ & 0,390 \\
invpl & $-0,005$ & 0,045 & $-0,11$ & 0,912 & $-0,096$ & 0,086 \\
liqcor & 2,845 & 1,875 & 1,52 & 0,138 & $-0,965$ & 6,656 \\
capgir & 0 & 0 & $-1,03$ & 0,311 & 0 & 0 \\
mliq & $0,310^{* * *}$ & 0,055 & 5,6 & 0 & 0,198 & 0,422 \\
lnrec & $-0,326$ & 0,399 & $-0,82$ & 0,42 & $-1,139$ & 0,486 \\
capexdepamort & 0,011 & 0,0198 & 0,54 & 0,595 & $-0,029$ & 0,051 \\
gov & $-1,671$ & 2,32 & $-0,72$ & 0,477 & $-6,387$ & 3,046 \\
valormerc & 0 & 0 & $-0,44$ & 0,664 & 0 & 0 \\
evebitda & 0,263 & 0,189 & 1,39 & 0,172 & $-0,121$ & 0,647 \\
cfech & 0,020 & 0,019 & 1,04 & 0,304 & $-0,019$ & 0,059 \\
divacao & 0,192 & 0,459 & 0,42 & 0,678 & $-0,741$ & 1,125 \\
beta5anos & $1,216 * *$ & 0,591 & 2,06 & 0,047 & 0,016 & 2,417 \\
vol5anos & 0,061 & 0,040 & 1,51 & 0,141 & $-0,021$ & 0,143 \\
retornoibov & $-0,140$ & 0,100 & $-1,4$ & 0,169 & $-0,344$ & 0,063 \\
OIEEPOP & 0,019 & 0,043 & 0,44 & 0,659 & $-0,068$ & 0,106 \\
PIND & $-0,209$ & 0,159 & $-1,31$ & 0,199 & $-0,532$ & 0,115 \\
PRES & 0,094 & 0,113 & 0,83 & 0,413 & $-0,136$ & 0,323 \\
treated & 0,307 & 3,148 & 0,1 & 0,923 & $-6,089$ & 6,704 \\
did & $-3,312$ & 2,785 & $-1,19$ & 0,243 & $-8,972$ & 2,349 \\
cons & $-45,35$ & 164,23 & $-0,28$ & 0,784 & $-379,09$ & 288,40 \\
\hline Sig
\end{tabular}

Nota: Siglas: Coef:: coeficientes; $D P$ : desvio-padrão; $t$ : estatística t de student; $P>|t|: \mathrm{p}$-valor da estatística $t$; IC-95\%: intervalo de confiança de 95\%. Linear Regression. 56 observações. $\mathrm{F}(21,34)=65,36$. Prob $>\mathrm{F}$ $=0,0000 . R$-squared $=0,9010$. Root MSE $=3,1659$. Variáveis Omitidas por colinearidade: CONRESPIB; VARPIB; INVEST; CMB; SELIC; TIME. Inferência: ***Significante a $1 \% * *$ Significante a $5 \%$ *Significante a $10 \%$.Onde: roa: retorno sobre o ativo; divbrat: dívida bruta/ativo; divliqebitda: dívida líquida/ebitda; invpl: investimento/patrimônio líquido; liqcor: liquidez corrente; capgir: capital de giro; mliq: margem líquida; lnrec: logaritmo natural da receita; capexdepamort: capex/depreciação e amortização; gov: dummy de governança; valormercado: valor de mercado; evebitda: enterprise value/ebitda; cfech: cotação de fechamento; divacao: dividendo por ação; beta5anos: beta para 5 anos; 
vol5anos: volatilidade para 5 anos; retornoibov: retorno do Ibovespa; OIEEPOP: oferta interna de energia/população; PIND: preços médios indústria; PRES: preços médios residencial; treated: dummy de tratamento; did: estimador de diferenças.

Os resultados evidenciados na Tabela 15 demonstraram que o modelo teve um bom ajuste (90\%) para explicar a variação do desempenho operacional a partir das 21 variáveis explicativas, ajuste melhor se comparado à regressão com ROE. Ao nível de 5\% de significância, apenas as variáveis margem líquida e beta5anos foram significativas. A variável de interação - DID não apresentou significância estatística e o sinal do coeficiente estimado se apresentou negativo indicando que a Medida afetou de forma negativa a rentabilidade das empresas nos anos posteriores a 2012, considerando o desempenho operacional.

Em relação à hipótese $\mathrm{H} 4$ de pesquisa levantada, com base nos sinais dos coeficientes da variável DID em ambas as regressões - ROE e ROA - que se apresentaram negativos, pode-se constatar que não há evidências de rejeição para a hipótese $\mathrm{H} 4$ de pesquisa e a edição da MP $n^{\circ}$ 579/2012 afetou negativamente a rentabilidade das empresas do setor elétrico no Brasil no período compreendido entre os anos de 2013 a 2015. 


\section{CONSIDERAÇÕES FINAIS}

O objetivo principal do trabalho era encontrar os fatores determinantes do desempenho para o setor elétrico no Brasil. Para isso, foram elencadas variáveis contábeis e de Governança, variáveis de mercado e variáveis econômicas. Para análise do desempenho, dois estudos foram realizados, através de regressões com dados em painel e em todos os casos o painel elaborado foi de Efeitos Fixos com erro-padrão robusto e, assim, algumas variáveis foram identificadas como determinantes para avaliar o desempenho financeiro, operacional e de mercado do setor elétrico no período compreendido entre 2010 a 2015. Em relação ao primeiro estudo, para os dados trimestrais, a regressão com a variável dependente ROE, as variáveis liquidez corrente e margem líquida se mostraram significativas para avaliar o desempenho financeiro do setor. A regressão com a variável dependente ROA apontou como relevantes as variáveis dívida bruta sobre ativo, liquidez corrente e margem líquida para explicar o comportamento do desempenho operacional. A regressão com a variável dependente Retorno da Ação apresentou as variáveis valor de mercado, enterprise value/ebitda e o retorno do Ibovespa como significantes para avaliar o desempenho de mercado do setor elétrico no período estudado.

Para o segundo estudo, com dados anuais, o primeiro painel com a variável dependente ROE indicou as variáveis dívida líquida/ebitda, margem líquida, capex/depreciação e amortização, enterprise value/ebitda, cotação de fechamento e beta5anos para explicar o comportamento do desempenho financeiro das empresas da amostra e o segundo painel, com a variável dependente ROA, apontou dívida líquida/ebitda, investimento/patrimônio líquido, liquidez corrente, margem líquida, enterprise value/ebitda, dividendo pago por ação e beta5anos como relevantes para avaliar o desempenho operacional do setor elétrico.

Para avaliar as mudanças regulatórias recentes, a exemplo da edição da MP579 em 2012, foi realizado o terceiro estudo. Foi empregado o teste diff-in-diff que compara períodos anteriores e posteriores ao choque exógeno e indica seu efeito para os indivíduos ou empresas estudadas. Neste caso, o teste revelou, tanto para a regressão com a variável ROE quanto para a variável ROA que a edição da MP579 por parte do Governo em 2012 afetou de forma negativa a rentabilidade das empresas de capital aberto do setor elétrico. Portanto, esta pesquisa avaliou o desempenho das empresas de energia elétrica no Brasil e atendeu ao objetivo principal de encontrar os fatores que podem determinar este 
desempenho de forma significativa. Apontou que a variável de Governança Corporativa não impactou no desempenho das empresas durante o período estudado. Evidenciou que os indicadores contábeis e os indicadores de mercado podem explicar o desempenho das empresas, conforme proposto pelas hipóteses $\mathrm{H} 1$ e $\mathrm{H} 2$ de pesquisa. Analisou o impacto da MP579 e verificou que a edição desta Medida impactou negativamente na rentabilidade das empresas que aderiram à MP579, atendendo à hipótese H4 de pesquisa formulada para o trabalho. Para o ambiente macroeconômico, não foi possível ter evidências dos efeitos de suas variações no desempenho das empresas do setor elétrico no período estudado. Por isso, o contexto econômico acabou afetando todas as empresas igualmente.

A contribuição fundamental deste trabalho para a literatura são as variáveis testadas, a janela temporal abordada e os testes econométricos que não foram encontrados de forma semelhante na literatura. Alguns estudos utilizaram as variáveis ROE e ROA para aferir desempenho, no entanto, através de técnicas distintas e um número menor de variáveis e/ou o conjunto de variáveis diferentes das utilizadas neste estudo. Outro aspecto que merece destaque é a aplicação do teste diferences-in-differences, utilizado por autores internacionais para estudar outros fenômenos, em sua maioria intervenções regulatórias do Governo nos mais variados setores, principalmente de infraestrutura. No entanto, para analisar o impacto da MP579 no setor de energia através da perspectiva de avaliação da rentabilidade das empresas, não foram encontrados trabalhos na literatura. Algumas teses utilizam o teste e o impacto da MP579, no entanto, para avaliar outros efeitos, como a intervenção do Governo na estrutura societária dessas empresas, por exemplo, como a tese de Loch (2016).

A sugestão para estudos futuros se centra na realização de uma pesquisa somente com as variáveis econômicas e a verificação de seu impacto no desempenho através de mais medidas além do ROE e ROA, ou até mesmo modelos de previsão com variáveis macroeconômicas históricas. 


\section{REFERÊNCIAS}

Acharya, V. V., \& Schnabl, P. (2010). Do global banks spread global imbalances? Assetbacked commercial paper during the financial crisis of 2007-09. IMF Economic Review, 58(1), 37-73.

Altman, E.I. (1968) Financial ratios, discriminant analysis and the prediction of corporate bankruptcy, The Journal of Finance, Vol.4, 589-609.

Altman, E. I. (1993). Corporate financial distress and bankruptcy: A complete guide to predicting and avoiding distress and profiting from bankruptcy. John Wiley \& Sons. Inc., New York.

Aneel. (2015). Atlas. Parte 1 - Energia no Brasil e no Mundo. Recuperado em: http://www2.aneel.gov.br/arquivos/pdf/atlas_par1_cap1.pdf.

Assis, J. de M. (2013). Uma análise dos determinantes das decisões das empresas do setor elétrico brasileiro afetadas pela medida provisória $n^{0} 579$. Monografia defendida ao Departamento de Economia da Pontifícia Universidade Católica do Rio de Janeiro.

Assunção, T. N., Takamatsu, R. T., \& Bressan, V. G. F. (2015). Os impactos da medida provisória 579 nos retornos das ações de companhias de energia elétrica. Revista de Gestão, Finanças e Contabilidade, 5(2), 38.

Barnea, A., \& Rubin, A. (2010). Corporate social responsibility as a conflict between shareholders. Journal of business ethics, 97(1), 71-86.

Beaver, W. (1966) Financial ratios as predictors of failure, Journal of Accounting Research, Vol. 4, 71-102.

Bernardino, F. F. M., Peixoto, F. M., \& do Nascimento Ferreira, R. (2015). Governança e eficiência em empresas do setor elétrico brasileiro. Revista Pretexto, 16(1), 36-51.

Bernstein, L.A. (1988). Financial statement analysis, theory, application, and interpretation, Journal of Accounting Research, Vol. 3, 61-80.

Black, B. S., De Carvalho, A. G., \& Gorga, É. (2012). What matters and for which firms for corporate governance in emerging markets? Evidence from Brazil (and other BRIK countries). Journal of Corporate Finance, 18(4), 934-952.

Bragança, G. G., Pessoa, M. D. S., \& Rocha, K. (2015). Intervenção Regulatória nos Setores de Telecomunicações e Elétrico em 2012: um estudo de eventos com modelo de precificação multifatorial.

Brambilla, P. H. M., \& Mueller, B. M. P. (2015). Impacto da energia elétrica no crescimento econômico. Revista de Ciências Jurídicas e Empresariais, 5(1).

Bressan, V. G. F. (2009). Seguro depósito e moral Hazard nas cooperativas de crédito brasileiras. 
Buccini, A. R. A. (2012). Avaliação de empresas de prestação de serviço público (Public Utilities) no Brasil: um estudo dos direcionadores de valor através da análise das demonstrações financeiras.

Camacho, F., Rocha, K., \& Bragança, G. (2006). Custo de capital de distribuição de energia elétrica: revisão tarifária 2007/2009.

Cameron, A. C., \& Trivedi, P. K. (2010). Microeconometrics using stata (Vol. 5). College Station, TX: Stata press. Revised Edition.

Campbell, J. Y. (1987). Stock returns and the term structure. Journal of financial economics, 18(2), 373-399.

Campello, M. (2015). Econometric Approaches to Causal Estimation Using Observational Data. Material Distributed in the Presentation at FEA-USP.

Casey, C. J. (1980). The usefulness of accounting ratios for subjects' predictions of corporate failure: Replication and extensions. Journal of Accounting Research, 603-613.

Cerqueira, J. E. A., Soares, T. M., \& David, M. V. (2009). Novas evidências sobre a relação entre a geração de valor ao acionista e o valor de mercado das ações: uma análise em painel comparando o EVA ${ }^{\circledR}$ e o MVA ${ }^{\circledR}$ no mercado brasileiro. Revista Pesquisa Operacional para o Desenvolvimento-PODES, 1(2), 178-196.

Cohen, D. A., \& Zarowin, P. (2010). Accrual-based and real earnings management activities around seasoned equity offerings. Journal of Accounting and Economics, 50(1), 2-19.

Costellini, C., \& Hollanda, L. (2014). Setor Elétrico: da MP 579 ao pacote financeiro.

Cuberos, F. L. (2008). Novo modelo institucional do setor elétrico brasileiro: análise dos mecanismos de mitigação de riscos de mercado das distribuidoras (Doctoral dissertation, Universidade de São Paulo).

Curcino, G. M., Lemes, S., \& Botinha, R. A. (2014). Efeito do resultado Abrangente nos Indicadores de desempenho das Companhias Abertas brasileiras. Revista Evidenciação Contábil \& Finanças, 2(3), 24-40.

Da Costa Jr, N. C., \& Neves, M. B. (2000). Variáveis fundamentalistas e os retornos das ações. Revista Brasileira de Economia, 54(1), 123-137.

Deakin, E. B. (1972). A discriminant analysis of predictors of business failure. Journal of accounting research, 167-179.

Deakin, E. B. (1977). Business failure prediction: an empirical analysis. Chapter, 4, 7288 . 
De Castro, N. J., Brandão, R., Dantas, G., \& Rosental, R. (2013). O processo de reestruturação do setor elétrico brasileiro e os impactos da MP 579.

Demirgüç-Kunt, A., \& Huizinga, H. (2010). Bank activity and funding strategies: The impact on risk and returns. Journal of Financial Economics, 98(3), 626-650.

Delen, D., Kuzey, C., \& Uyar, A. (2013). Measuring firm performance using financial ratios: A decision tree approach. Expert Systems with Applications,40(10), 3970-3983.

De Lima, V. S., Ilha, H. F., Scalzer, R. S., \& Galdi, F. C. (2009). Análise fundamentalista sob a perspectiva do analista de mercado: um estudo de caso na AES TIETÊ comparando os modelos de fluxo de caixa descontado e AEG Ohlson (1995). In $6^{\circ}$ Congresso Usp Iniciação Científica Em Contabilidade (Vol. 6, pp. 1-15).

De Souza, G. H. S., Lima, N. C., Barbosa, F. B., Coutinho, A. C. \& de Albuquerque, A. A. (2015). Corporate Governance and performance of the stocks of companies from the Brazilian electricity sector listed in Bovespa. Revista de Negócios, 20(1), 13-28.

Edmans, A. (2011). Does the stock market fully value intangibles? Employee satisfaction and equity prices. Journal of Financial Economics, 101(3), 621-640.

Edmister, R. O. (1972). An empirical test of financial ratio analysis for small business failure prediction. Journal of Financial and Quantitative analysis, 7(02), 1477-1493.

Fama, E. F., \& Schwert, G. W. (1977). Asset returns and inflation. Journal of financial economics, 5(2), 115-146.

Feng, C.M. and Wang, R.T. (2000) Performance evaluation for airlines including the consideration of financial ratios, Journal of Air Transport Management, Vol. 6, 133-142.

Ferreira, c. d., \& Silva, g. c. (2016). Governança corporativa e valor: um estudo no setor elétrico do brasil. caderno de administração, 24(2), 1-13.

Freguete, L. M., Nossa, V., \& Funchal, B. (2015). Responsabilidade Social Corporativa e Desempenho Financeiro das Empresas Brasileiras na Crise de 2008/Corporate Social Responsibility and Brazilian Firms' Financial Performance. Revista de Administração Contemporânea, 19(2), 232.

French, K. R., Schwert, G. W., \& Stambaugh, R. F. (1987). Expected stock returns and volatility. Journal of financial Economics, 19(1), 3-29.

Funchal, B., \& Monte $\square$ Mor, D. S. (2016). Corporate Governance and Credit Access in Brazil: The Sarbanes $\square$ Oxley Act as a Natural Experiment.Corporate Governance: An International Review.

Gomes, P. P. \& Vieira, M. M. F. (2009). O campo da energia elétrica no Brasil de 1880 a 2002. RapRio de Janeiro, 43(2), 295-321.

Goyal, A., \& Santa $\square$ Clara, P. (2003). Idiosyncratic risk matters!. The Journal of Finance, 58(3), 975-1007. 
Gujarati, Damodar N. Econometria Básica. 4. Ed. 5. Tiragem. Tradução de Maria J. Cyhlar. Rio de Janeiro: Elsevier, 2006.

Guzella, M., \& Rodrigues, A. (2015, September). Avaliação do Poder Preditivo do Desempenho Operacional a Partir da Situação Econômico-Financeira das Distribuidoras Brasileiras de Energia Elétrica. In VI Congresso Nacional de Administração e Contabilidade-AdCont 2015.

Hoffman, R.; Vieira, S. (1998). Análise de Regressão: Uma Introdução à Econometria. Hucitec. 3. Ed: São Paulo.

Klagsbrunn, V. H., de Castro, N. J., Sales, S., Brandão, R. (2011). Análise Conjuntural da Economia Brasileira: Dinâmica Macroeconômica e Setor de Energia Elétrica Setembro de 2011. Texto de Discussão do Setor Elétrico no ${ }^{\circ}$ 41. Grupo de Estudos do Setor Elétrico - UFRJ. Rio de Janeiro.

Kmenta, Jan. Elementos de Econometria: Teoria Estatística Básica. 3. Ed. São Paulo: Atlas, 1990.

Lin, W. C., Liu, C. F., \& Chu, C. W. (2005). Performance efficiency evaluation of the Taiwan's shipping industry: an application of data envelopment analysis. In Proceedings of the Eastern Asia Society for Transportation Studies (Vol. 5, pp. 467-476).

Loch, M. (2016). A influência do governo como regulador e acionista no desempenho das empresas brasileiras de distribuição de energia elétrica. Tese defendida ao Departamento de Administração e Turismo da Universidade do Vale do Itajaí.

Malko, J. R., \& Skinner, R. (2011). Selecting a Capital Structure for a Regulated Electric Utility: Some Issues and Directions. The Electricity Journal, 24(7), 49-56.

Mamo Bekana, D., \& Abitie, A. (2012). Evaluation of financial performance of banking enterprises; the case of construction and business bank of ethiopia. Young Economists Journal/Revista Tinerilor Economisti, 9(18).

Martins, E., Diniz, J. A., \& Miranda, G. J. (2012). Análise avançada das demonstrações contábeis: uma abordagem crítica. São Paulo: Atlas.

Matarazzo, D. C. Análise financeira de balanços: abordagem básica e gerencial. 6. Ed. São Paulo: Atlas, 2008.

Medeiros, F. D. S. (2014). Eficiência em concessões de infraestrutura: Benchmarking, Price-cap e o fator " $\mathrm{x}$ ".

Mellone Junior, G. M., \& Saito, R. (2004). Monitoramento interno e desempenho da empresa: determinantes de substituição de executivos em empresas de capital aberto no Brasil. Revista de Administração/Faculdade de Economia, Administração e Contabilidade da Universidade de São Paulo, 39(4), 385-397. 
Merwin, C. L. (1942). Financing small corporations in five manufacturing industries, 1926-36. NBER Books.

Minardi, A. M. F., Sanvicente, A. Z., Artes, R., Pereira, A. P. P., \& Zausner, F. W. (2007). Estimação do custo de capital de terceiros a valor de mercado para companhias fechadas no Brasil visando uma melhor gestão estratégica de projetos. Insper, São Paulo/SP.

Montoya, M. A., Lopes, R. L., \& Guilhoto, J. J. M. (2014). Desagregação setorial do balanço energético nacional a partir dos dados da matriz insumo-produto: uma avaliação metodológica. Economia Aplicada, 18(3), 379-419.

Nagano, M. S., Merlo, E. M., \& SILVA, M. D. (2003). As variáveis fundamentalistas e seus impactos na taxa de retorno de ações no Brasil. Revista FAE, Curitiba, 6(2), 13-28.

Neely, A., Gregory, M., \& Platts, K. (1995). Performance measurement system design: a literature review and research agenda. International journal of operations \& production management, 15(4), 80-116.

Neely, A. (1998). Measuring business performance.

Neto, A. A. Finanças corporativas e valor. 7. Ed. Atlas: São Paulo, 2014.

Ohlson J. A. (1980) Financial ratios and the probabilitistic prediction of bankruptcy, Journal of Accounting Research, Vol. 19, No. 1, 61-80.

Parker, D. (1997). Price cap regulation, profitability and returns to investors in the UK regulated industries. Utilities Policy, 6(4), 303-315.

Pereira, J. R. D. L. M., \& da Silva Chicoli, R. (2016). Como Alterações na Taxa de Câmbio Afetam o Retorno do Índice Ibovespa. Finanças Públicas: o Difícil Caminho das Metas Fiscais, 44.

Pereira, V. S., \& Martins, V. F. (2012). Informações Contábeis e Não-Contábeis para Prever o Valor de Mercado das Empresas Norte e Latino Americanas do Setor de Construção. RIC - Revista de Informação Contábil, 5(4), 104-123.

Pires, J. C. L. (2000). Desafios da reestruturação do setor elétrico brasileiro (Vol. 76). BNDES, Área de Planejamento, Departamento Econômico-DEPEC.

Pires, J. C. L., Giambiagi, F., \& Sales, A. F. (2002). As perspectivas do setor elétrico após o racionamento. BNDES, Área de Planejamento, Gerência Executiva de Análise Econômica-GEANE.

Pires, J. C. L., \& Piccinini, M. S. (1998). Modelos de regulação tarifária do setor elétrico. Revista do BNDES, 9(6).

Prado Jr, F. A. de Almeida, \& da Silva, A. L. R. (2013). Sobre reformas e concessões no setor elétrico brasileiro: uma análise crítica. Revista Estratégica, 11(2). 
Reynaud, A., \& Thomas, A. (2013). Firm's profitability and regulation in water and network industries: An empirical analysis. Utilities Policy, 24, 48-58.

Ribeiro, M. G. C., da Silva Macedo, M. Á., \& da Costa Marques, J. A. V. (2012). Análise da relevância de indicadores financeiros e não financeiros na avaliação de desempenho organizacional: um estudo exploratório no setor brasileiro de distribuição de energia elétrica. Revista de Contabilidade e Organizações, 6(15), 60.

Rocha, K., Camacho, F., \& Braganca, G. (2007). Return on capital of Brazilian electricity distributors: A comparative analysis. Energy Policy, 35(4), 2526-2537.

Rose, P. S., \& Giroux, G. A. (1984). Predicting corporate bankruptcy: an analytical and empirical evaluation. Review of Financial Economics, 19(2), 1.

Scalabrin, I., \& Alves, T. W. (2003). Os indicadores contábeis podem prever a geração de valor. XXVII ENANPAD.

Shaoul, J. (1997). A Critical Financial Analysis of the Performance of Privatised Industries: The Case of the Water Industry in England and Wales.Critical Perspectives on Accounting, 8(5), 479-505.

Sirtaine, S., Pinglo, M. E., Guasch, J. L., \& Foster, V. (2005). How profitable are private infrastructure concessions in Latin America?: Empirical evidence and regulatory implications. The Quarterly Review of Economics and Finance, 45(2), 380-402.

Szuster, N., Cardoso, R. L., Szuster, F. R., Szuster, F. R., \& Szuster, F. R. Contabilidade Geral: introdução à contabilidade societária. 3. Ed. São Paulo: Atlas, 2011.

Sweeney, D. J., Williams, T. A., \& Anderson, D. R. (2014). Estatística aplicada à administração e economia. São Paulo, Cengage Learning.

Taffarel, M., da Silva, W. V., \& Clemente, A. (2013). Risco regulatório e reação do Mercado: análise do setor de energia elétrica brasileiro. Revista Universo Contábil, 9(1), 121.

Takahashi, K. e Kurokawa, Y. (1985) Corporate bankruptcy prediction in Japan. Journal of Banking and Finance, 8, 230-247.

Tolmasquim, M. T., Guerreiro, A., \& Gorini, R. (2007). Matriz energética brasileira: uma prospectiva. Novos estudos-CEBRAP, (79), 47-69.

Tolmasquim, M. T. (2012). Perspectivas e planejamento do setor energético no Brasil. Estudos Avançados, 26(74), 247-260.

Torres-Reyna, O. (2015). Differences-in-Differences (using Stata).

Vieira, M. R. (2015). O impacto da medida provisória 579. 
Villa, J. M. (2012). Simplifying the estimation of difference in differences treatment effects with Stata.

Winakor, A., \& Smith, R. F. (1935). Changes in financial structure of unsuccessful industrial companies. Bureau of Business Research, Bulletin, 51.

Wooldridge, J. M. (2010). Econometric analysis of cross section and panel data. MIT press. 


\section{APÊNDICES}

Apêndice 1 - Classificação das Empresas da Amostra no Stata

Apêndice 1.1 - Classificação para as Regressões de Dados em Painel

\begin{tabular}{l|c}
\multicolumn{1}{c|}{ Nome } & id \\
\hline AES Tiete E & 1 \\
Afluente & 2 \\
Afluente T & 3 \\
Ampla Energ & 4 \\
Ceee-D & 5 \\
Ceee-Gt & 6 \\
Celpa & 7 \\
Celpe & 8 \\
Cemar & 9 \\
Cemig & 10 \\
Cesp & 11 \\
Coelba & 12 \\
Coelce & 13 \\
Copel & 14 \\
Cosern & 15 \\
Elektro & 16 \\
Eletropaulo & 17 \\
Emae & 18 \\
Energisa Mt & 19 \\
Eneva & 20 \\
Engie Brasil & 21 \\
Ger Paranap & 22 \\
Renova & 23 \\
Tran Paulist & 24
\end{tabular}


Apêndice 1.2 - Classificação para as Análises do Teste Diff-in-Diff

\begin{tabular}{l|c}
\multicolumn{1}{c|}{ Nome } & id \\
\hline Cemig & 1 \\
Cesp & 2 \\
Copel & 3 \\
AES Tiete E & 4 \\
Afluente & 5 \\
Afluente T & 6 \\
Ampla Energ & 7 \\
Ceee-D & 8 \\
Ceee-Gt & 9 \\
Celpa & 10 \\
Celpe & 11 \\
Cemar & 12 \\
Coelba & 13 \\
Coelce & 14 \\
Cosern & 15 \\
Elektro & 16 \\
Eletropaulo & 17 \\
Emae & 18 \\
Energisa Mt & 19 \\
Eneva & 20 \\
Engie Brasil & 21 \\
Ger Paranap & 22 \\
Renova & 23 \\
Tran Paulist & 24
\end{tabular}


Apêndice 2 - Análise das Variáveis - Dados Trimestrais

Apêndice 2.1 - Descrição do Banco de Dados

\begin{tabular}{|c|c|c|c|c|}
\hline $\begin{array}{l}\text { Contains data } \\
\text { obs: } \\
\text { vars: } \\
\text { size: }\end{array}$ & $\begin{array}{r}579 \\
22 \\
94,377\end{array}$ & & & \\
\hline variable name & $\begin{array}{l}\text { storage } \\
\text { type }\end{array}$ & $\begin{array}{l}\text { display } \\
\text { format }\end{array}$ & $\begin{array}{l}\text { value } \\
\text { label }\end{array}$ & variable label \\
\hline $\begin{array}{l}\text { Nome } \\
\text { id } \\
t \\
\text { roe } \\
\text { roa } \\
\text { divbrat } \\
\text { divliqebitda } \\
\text { invpl } \\
\text { liqcor } \\
\text { capgir } \\
\text { mliq } \\
\text { lnrec } \\
\text { capexdepamort } \\
\text { gov } \\
\text { retacao } \\
\text { valormerc } \\
\text { evebitda } \\
\text { cfech } \\
\text { divacao } \\
\text { beta5anos } \\
\text { vol5anos } \\
\text { retornoibov }\end{array}$ & $\begin{array}{l}\text { str13 } \\
\text { byte } \\
\text { long } \\
\text { double } \\
\text { double } \\
\text { double } \\
\text { double } \\
\text { double } \\
\text { double } \\
\text { double } \\
\text { double } \\
\text { double } \\
\text { double } \\
\text { byte } \\
\text { double } \\
\text { double } \\
\text { double } \\
\text { double } \\
\text { double } \\
\text { double } \\
\text { double } \\
\text { double }\end{array}$ & $\begin{array}{l}\% 13 \mathrm{~s} \\
\% 10.0 \mathrm{~g} \\
\% 10.0 \mathrm{~g} \\
\% 10.0 \mathrm{~g} \\
\% 10.0 \mathrm{~g} \\
\% 10.0 \mathrm{~g} \\
\% 10.0 \mathrm{~g} \\
\% 10.0 \mathrm{~g} \\
\% 10.0 \mathrm{~g} \\
\% 10.0 \mathrm{~g} \\
\% 10.0 \mathrm{~g} \\
\% 10.0 \mathrm{~g} \\
\% 10.0 \mathrm{~g} \\
\% 10.0 \mathrm{~g} \\
\% 14.2 \mathrm{fc} \\
\% 10.0 \mathrm{~g} \\
\% 10.0 \mathrm{~g} \\
\% 10.0 \mathrm{~g} \\
\% 10.0 \mathrm{~g} \\
\% 14.2 \mathrm{fc} \\
\% 14.2 \mathrm{fc} \\
\% 14.2 \mathrm{fc}\end{array}$ & & $\begin{array}{l}\text { Nome } \\
\text { empresa } \\
\text { trimestre } \\
\text { rentabilidade sobre o patrimonio liquido } \\
\text { rentabilidade sobre o ativo } \\
\text { divida bruta sobre o ativo } \\
\text { divida liquida sobre o ebitda } \\
\text { investimento sobre o patrimonio liquido } \\
\text { liquidez corrente } \\
\text { capital de giro } \\
\text { margem liquida } \\
\text { logaritmo natural da receital } \\
\text { capex sobre depreciacao e amortizacao } \\
\text { dummy de governanca } \\
\text { retorno da acao } \\
\text { valor de mercado } \\
\text { enterprise value sobre ebitda } \\
\text { cotacao de fechamento } \\
\text { dividendo pago por acao } \\
\text { beta para } 5 \text { anos } \\
\text { volatilidade para } 5 \text { anos } \\
\text { retorno do ibovespa }\end{array}$ \\
\hline
\end{tabular}

Apêndice 2.2 - Estatísticas descritivas das variáveis contábeis e de governança

. tabstat roe roa divbrat divliqebitda invpl liqcor capgir mliq Inrec capexdepamort gov, statistics( mean median sd max cv min )

\begin{tabular}{|c|c|c|c|c|c|c|c|c|c|c|c|}
\hline stats | & roe & roa & divbrat & divliq a & invpl & liqcor & capgir & mliq & lnrec & capexd t & gov \\
\hline p50 & 3.214225 & 1.44733 & 29. & 5.1 & $\theta$ & 1.151283 & 87885 & 11.34863 & 13.47167 & 28 & \\
\hline $\max$ & 77.37899 & 13.50752 & 75.92971 & 5394.074 & 75.86289 & 53.24185 & 4104948 & 471.9503 & 15.64154 & 6.1 & \\
\hline $\mathrm{cV}$ & 16.62479 & 2.050416 & .5287179 & 18.40609 & 2.812084 & 2.466351 & 5.916469 & 15.67499 & .1232312 & 7.580282 & 1.95 \\
\hline $\min$ & -290.512 & -19.94562 & 0 & -792.4738 & -13.18182 & 0 & -4438105 & -730.4374 & 8.282989 & -74879.74 & \\
\hline
\end{tabular}

Apêndice 2.3 - Estatísticas descritivas das variáveis de mercado

. tabstat retacao valormerc evebitda cfech divacao beta5anos vol5anos retornoibov, statistics( mean median sd max cv min )

\begin{tabular}{r|rrrrrrrr} 
stats | retacao valorm c evebitda & cfech & divacao beta5a s vol5anos retorn v \\
mean | & .2957905 & 4781158 & 3763.994 & 131.8303 & 3.586726 & .4325418 & 37.12888 & -1.632223 \\
p50 | & 0 & 3089455 & 26.72343 & 23.29958 & .9868181 & .3873971 & 30.63105 & -1.036015 \\
sd | & 17.58894 & 5507457 & 22523.7 & 450.0341 & 14.41307 & .512107 & 18.66595 & 9.384305 \\
max | & 58.76993 & $2.99 \mathrm{e}+07$ & 267066.4 & 3198 & 237.8792 & 4.939051 & 131.0558 & 13.93944 \\
cv | & 59.46417 & 1.151909 & 5.983988 & 3.413738 & 4.018447 & 1.183948 & .5027339 & -5.7494 \\
$\min \mid$ & -53.33333 & -35.40587 & -874.0956 & -913 & 0 & -.9034396 & 4.475646 & -16.15147
\end{tabular}


Apêndice 3 - Análise das Variáveis - Dados Anuais

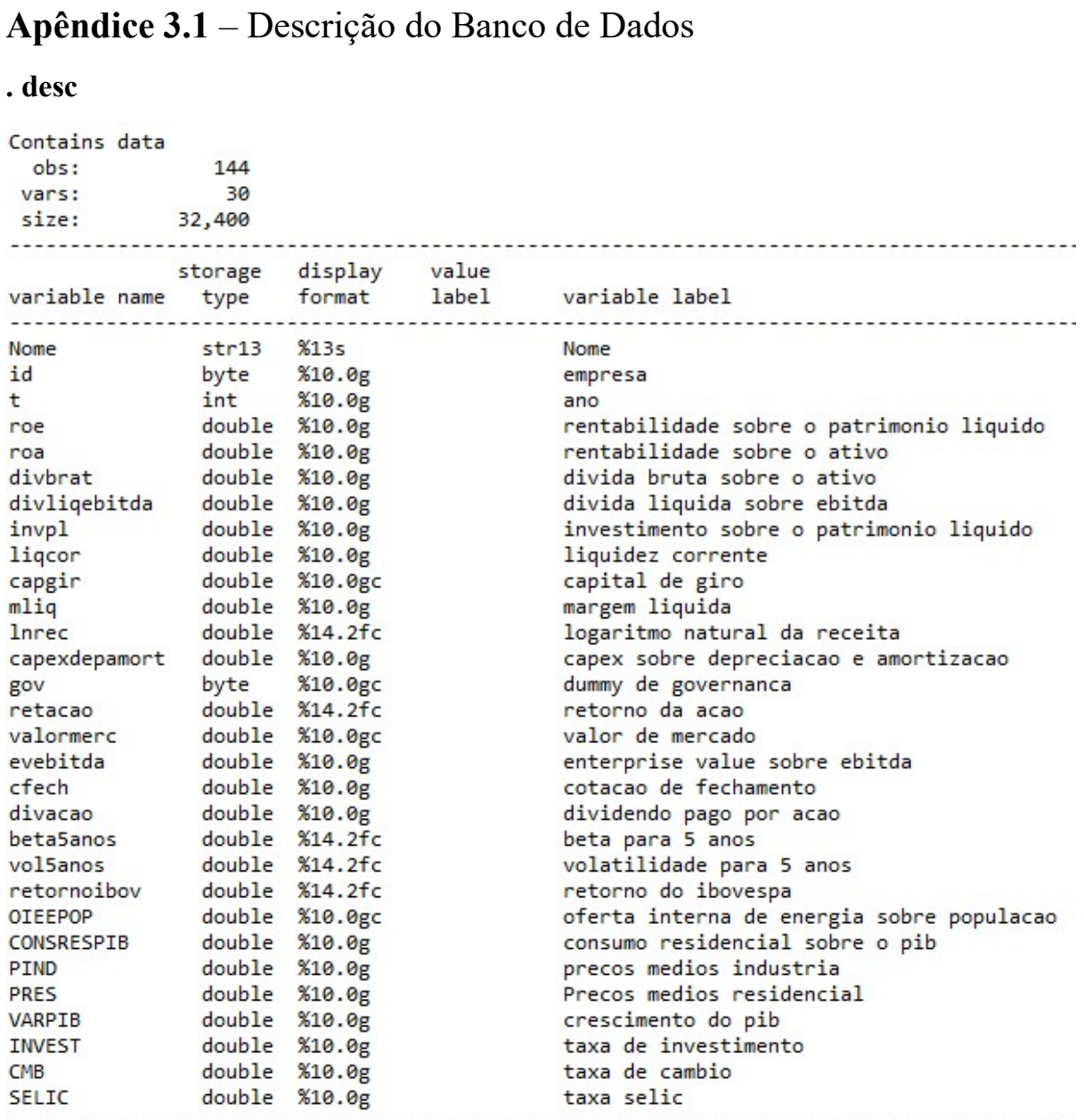

Apêndice 3.2 - Estatísticas descritivas das variáveis contábeis e de governança

- tabstat roe roa divbrat divliqebitda invpl liqcor capgir mliq Inrec capexdepamort gov, statistics( mean median sd max cv min )

\begin{tabular}{r|rrrrrrrrr} 
stats | & roe & roa & divbrat & divliq a & invpl & liqcor & capgir & mliq & lnrec capexd t \\
gov
\end{tabular}


Apêndice 3.3 - Estatísticas descritivas das variáveis de mercado

- tabstat valormerc evebitda cfech divacao beta5anos vol5anos retornoibov, statistics( mean median sd max cv min )

\begin{tabular}{r|rrrrrrr} 
stats | valorm c evebitda & cfech & divacao beta5a s & vol5anos retorn v \\
mean | & 4741682 & 2.976527 & 39.3974 & 1.390611 & .2583975 & 32.62868 & -8.48679 \\
p50 | & 3277379 & 6.508374 & 18.78758 & .6803 & .3405566 & 26.3458 & -13.31414 \\
sd | & 5330788 & 31.25918 & 89.74171 & 1.918031 & .9422704 & 21.99576 & 9.509388 \\
max | & $2.35 \mathrm{e}+07$ & 67.32617 & 682.4073 & 10.48379 & 2.387108 & 108.2579 & 7.396835 \\
cv | & 1.12424 & 10.5019 & 2.277859 & 1.379272 & 3.646592 & .6741234 & -1.120493 \\
min | & 60778.91 & -293.3981 & .4282992 & 0 & -2.541263 & 4.870608 & -18.10862
\end{tabular}

Apêndice 3.4 - Estatísticas descritivas das variáveis econômicas

. tabstat OIEEPOP CONSRESPIB PIND PRES VARPIB INVEST CMB SELIC, statistics( mean median sd max cv min )

\begin{tabular}{r|rrrrrrrr} 
stats | & OIEEPOP & CONSRE B & PIND & PRES & VARPIB & INVEST & CMB & SELIC \\
mean | & 2953.31 & 80.42602 & 166.26 & 224.8038 & 2.104264 & 18.90651 & 2.4142 & 10.73333 \\
p50 | & 2981.132 & 79.72827 & 167.1785 & 224.4585 & 2.465791 & 18.74 & 2.19245 & 10.78 \\
sd & 93.13074 & 1.58846 & 8.972745 & 19.82438 & 3.499384 & .7864181 & .7411328 & 2.09509 \\
$\max \mid$ & 3066.247 & 83.37234 & 180.0098 & 257.8046 & 7.528226 & 20.17515 & 3.9042 & 14.15 \\
cv & .0315344 & .0197506 & .0539682 & .0881853 & 1.662997 & .0415951 & .306989 & .1951948 \\
min | & 2802.006 & 78.61455 & 153.8518 & 200.4458 & -3.847603 & 18.16 & 1.6654 & 7.14 \\
\hline
\end{tabular}


Apêndice 4 - Saídas do Stata para o primeiro estudo - desempenho e variáveis contábeis, de governança e de mercado

Apêndice 4.1 - Comando de saída do Stata para o teste de Hausman com a variável dependente roe

. qui xtreg roe divbrat divliqebitda invpl liqcor capgir mliq Inrec capexdepamort gov, fe

. estimates store fe

. qui xtreg roe divbrat divliqebitda invpl liqcor capgir mliq Inrec capexdepamort gov, re

. estimates store re

. hausman fe re, sigmamore

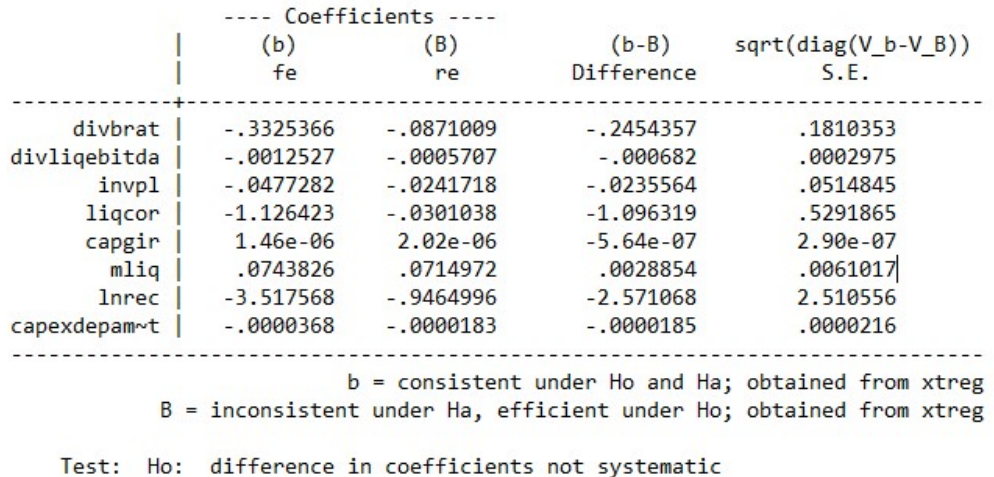

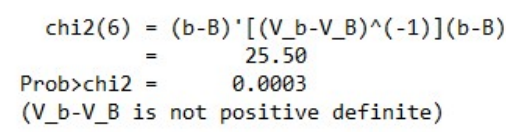

Apêndice 4.2 - Comando de saída do Stata para o teste de Chow com a variável dependente roe

. xtreg roe divbrat divliqebitda invpl liqcor capgir mliq Inrec capexdepamort gov, fe note: gov omitted because of collinearity

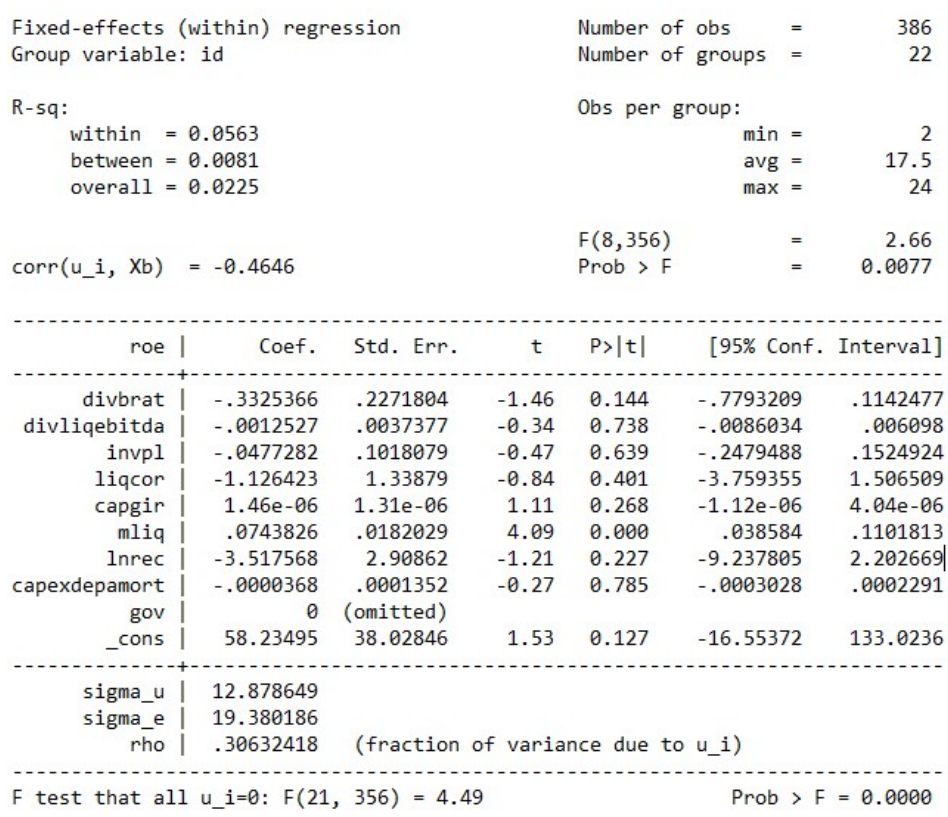


Apêndice 4.3 - Comando de saída do Stata para a estimação Efeitos Fixos com erropadrão robusto com a variável dependente roe

- xtreg roe divbrat divliqebitda invpl liqcor capgir mliq Inrec capexdepamort gov, fe robust

\begin{tabular}{|c|c|c|c|c|c|c|}
\hline \multicolumn{4}{|c|}{ Fixed-effects (within) regression } & \multicolumn{3}{|c|}{ Number of obs } \\
\hline \multicolumn{4}{|c|}{ Group variable: id } & \multicolumn{3}{|c|}{ Number of groups } \\
\hline \multicolumn{4}{|l|}{ R-sq: } & \multicolumn{3}{|c|}{ Obs per group: } \\
\hline within $=$ & $=0.0563$ & & & & $\min =$ & 2 \\
\hline between $=$ & $=0.0081$ & & & & avg $=$ & 17.5 \\
\hline \multirow[t]{2}{*}{ overall = } & $=0.0225$ & & & & $\max =$ & 24 \\
\hline & & & & $F(8,21)$ & $=$ & 31.27 \\
\hline $\operatorname{corr}\left(u_{-} i, X_{b}\right)$ & $=-0.4646$ & & & Prob $>F$ & $=$ & 0.0000 \\
\hline \multicolumn{7}{|c|}{ (Std. Err. adjusted for 22 clusters in id) } \\
\hline \multicolumn{7}{|c|}{ Robust } \\
\hline roe & Coef. & Std. Err. & $\mathrm{t}$ & $P>|t|$ & [95\% Conf. & Interval] \\
\hline \multicolumn{7}{|c|}{ 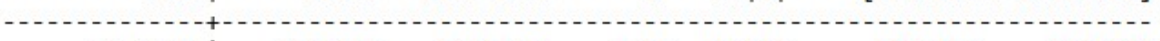 } \\
\hline divbrat & -.3325366 & .2763128 & -1.20 & 0.242 & -.9071605 & .2420874 \\
\hline divliqebitda & -.0012527 & .0015528 & -0.81 & 0.429 & -.0044818 & .0019764 \\
\hline invpl & -.0477282 & .0594219 & -0.80 & 0.431 & -.1713029 & .0758464 \\
\hline liqcor & -1.126423 & .5058964 & -2.23 & 0.037 & -2.178492 & -.0743535 \\
\hline capgir & $1.46 e-06$ & $1.19 e-06$ & 1.23 & 0.234 & $-1.01 \mathrm{e}-06$ & $3.93 e-06$ \\
\hline mliq & .0743826 & .0211385 & 3.52 & 0.002 & .0304227 & .1183426 \\
\hline lnrec & -3.517568 & 3.788088 & -0.93 & 0.364 & -11.39533 & 4.360192 \\
\hline capexdepamort & -.0000368 & .0000355 & -1.04 & 0.311 & -.0001107 & .000037 \\
\hline gov & 0 & (omitted) & & & & \\
\hline _cons & 58.23495 & 47.07579 & 1.24 & 0.230 & -39.66452 & 156.1344 \\
\hline & $\ldots$ & $-\ldots$ & & & & \\
\hline sigma_u & 12.878649 & & & & & \\
\hline sigma_e & 19.380186 & & & & & \\
\hline rho & .30632418 & (fraction & var & ce due & u_i) & \\
\hline
\end{tabular}

Apêndice 4.4 - Comando de saída do Stata para o teste de Hausman com a variável dependente roa

. qui xtreg roa divbrat divliqebitda invpl liqcor capgir mliq Inrec capexdepamort gov, fe . estimates store fe

. qui xtreg roa divbrat divliqebitda invpl liqcor capgir mliq Inrec capexdepamort gov, re

. estimates store re

. hausman fe re, sigmamore

\begin{tabular}{|c|c|c|c|c|}
\hline & $\begin{array}{l}\text { (b) } \\
\mathrm{fe}\end{array}$ & $\begin{array}{r}\text { (B) } \\
\text { re }\end{array}$ & $\begin{array}{c}(b-B) \\
\text { Difference }\end{array}$ & $\begin{array}{l}\operatorname{sqrt}\left(\operatorname{diag}_{(\mathrm{V}}\left(\mathrm{V}_{\mathrm{b}} \mathrm{b}-\mathrm{V}_{-} \mathrm{B}\right)\right) \\
\text { S.E. }\end{array}$ \\
\hline divbrat & -.0730483 & -.0235308 & -.0495176 & .0141265 \\
\hline divliqebitda & -.0000718 & -.0000441 & -.0000277 & . \\
\hline invpl & -.0266178 & -.0239574 & -.0026604 & .0033341 \\
\hline liqcor & -.2156409 & -.0932018 & -.1224391 & .0287 \\
\hline capgir & $2.65 e-07$ & $3.13 e-07$ & $-4.77 e-08$ & . \\
\hline mliq & .0202692 & .0201948 & .0000744 & .0002288 \\
\hline lnrec & -.2914486 & -.1536154 & -.1378333 & .2006537 \\
\hline capexdepam t & $-9.75 e-06$ & $-9.83 e-06$ & $8.47 e-08$ & . \\
\hline
\end{tabular}

$B=$ inconsistent under $\mathrm{Ha}$, efficient under Ho; obtained from xtreg

Test: Ho: difference in coefficients not systematic

$$
\begin{array}{rlrl}
\text { chi2 }(6) & = & (b-B)^{\prime}\left[\left(V_{-} b-V_{-} B\right)^{\wedge}(-1)\right](b-B) \\
& = & 12.80 \\
\text { Prob }>c h i 2 & = & 0.0463 \\
\text { (V_b-V_B } & \text { is } & \text { not } & \text { positive definite) }
\end{array}
$$


Apêndice 4.5 - Comando de saída do Stata para o teste de Chow com a variável dependente roa

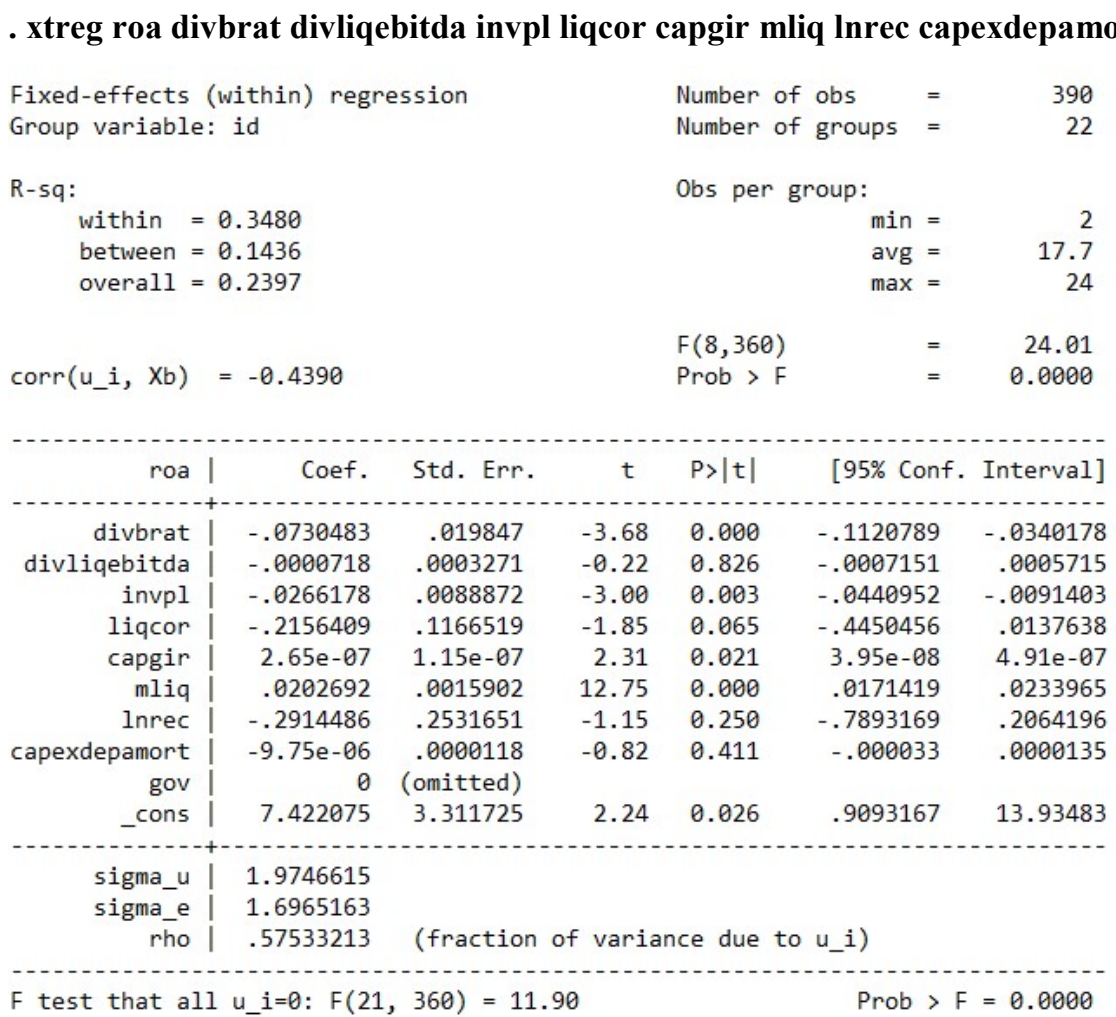

Apêndice 4.6 - Comando de saída do Stata para a estimação Efeitos Fixos com erropadrão robusto com a variável dependente roa

- xtreg roa divbrat divliqebitda invpl liqcor capgir mliq Inrec capexdepamort gov, fe robust

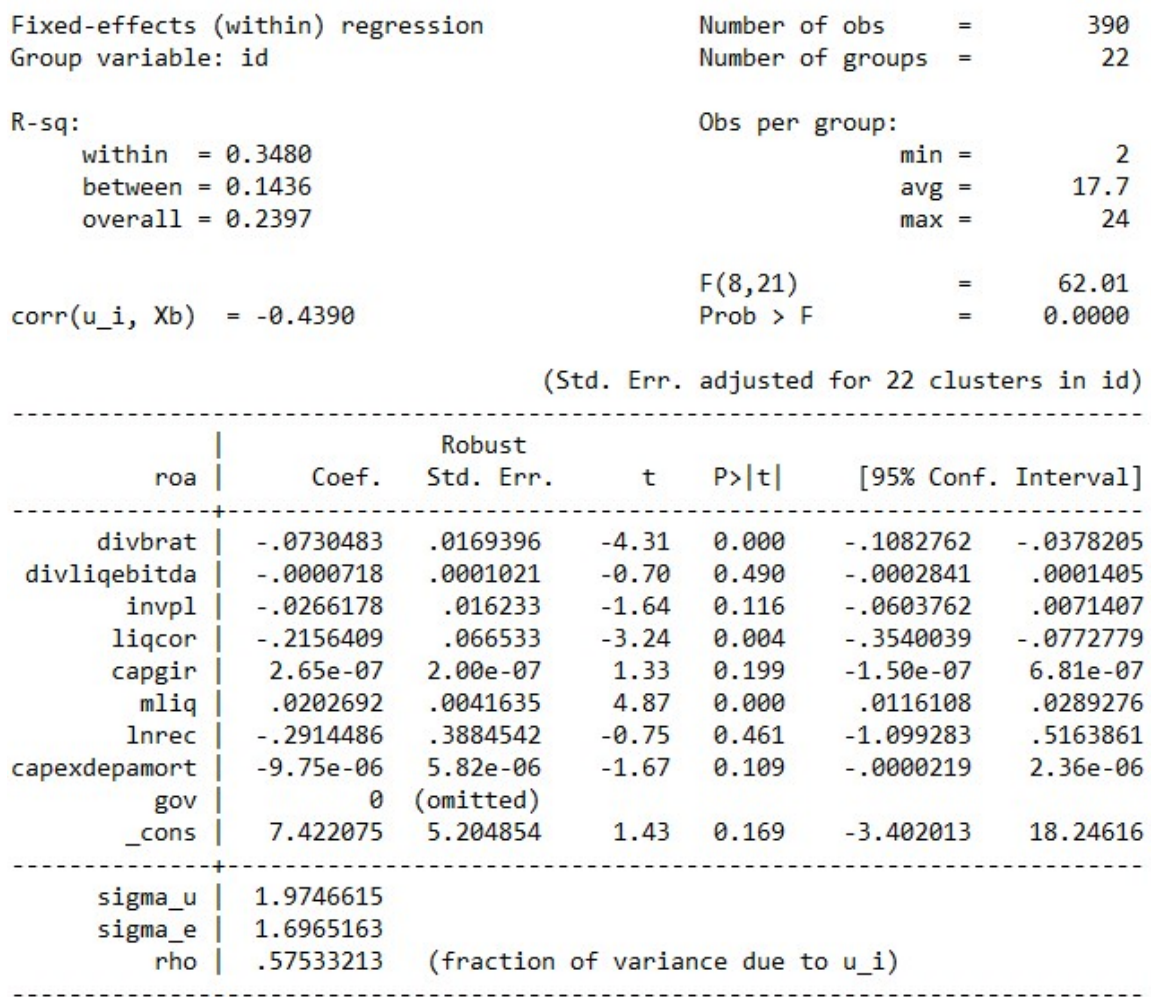


Apêndice 4.7 - Comando de saída do Stata para o teste de Hausman com a variável dependente retacao

. qui xtreg retacao valormerc evebitda cfech divacao beta5anos vol5anos retornoibov, fe . estimates store fe

. qui xtreg retacao valormerc evebitda cfech divacao beta5anos vol5anos retornoibov, re . estimates store re

. hausman fe re, sigmamore

\begin{tabular}{|c|c|c|c|c|}
\hline & $\begin{array}{l}\text { (b) } \\
\mathrm{fe}\end{array}$ & $\begin{array}{l}\text { (B) } \\
\text { re }\end{array}$ & $\begin{array}{c}(b-B) \\
\text { Difference }\end{array}$ & $\begin{array}{c}\operatorname{sqrt}\left(\operatorname{diag}_{\mathrm{S}}\left(\mathrm{V}_{-} b-\mathrm{V}_{-} \mathrm{B}\right)\right) \\
\text { S.E. }\end{array}$ \\
\hline valormerc & $2.53 e-06$ & $2.62 \mathrm{e}-07$ & $2.27 e-06$ & $5.18 e-07$ \\
\hline evebitda & .0002547 & -.0003288 & .0005836 & .000364 \\
\hline cfech & .0065737 & .0062387 & .0003349 & .0034756 \\
\hline divacao & .4162538 & .6013659 & -.1851122 & .3196039 \\
\hline beta5anos & 3.302439 & -.6646811 & 3.96712 & 1.741758 \\
\hline voltanos & -.0107666 & -.1103273 & .0995607 & .0847706 \\
\hline retornoibov & .1402298 & .1862787 & -.0460488 & . \\
\hline
\end{tabular}

$\mathrm{b}=$ consistent under $\mathrm{Ho}$ and $\mathrm{Ha}$; obtained from xtreg

$B=$ inconsistent under $\mathrm{Ha}$, efficient under Ho; obtained from xtreg

Test: Ho: difference in coefficients not systematic

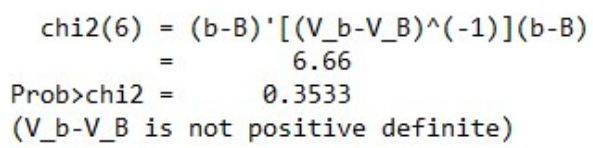

Apêndice 4.8 - Comando de saída do Stata para o teste de Chow com a variável dependente retacao

- xtreg retacao valormerc evebitda cfech divacao beta5anos vol5anos retornoibov, fe

\begin{tabular}{|c|c|c|c|c|c|c|}
\hline Fixed-effects & (within) reg & ession & & Number of & obs & 282 \\
\hline Group variable & : id & & & Number of & groups $=$ & 18 \\
\hline R-sq: & & & & Obs per gr & roup: & \\
\hline within & 0.1243 & & & & $\min =$ & \\
\hline between $=$ & 0.0851 & & & & avg $=$ & 15.7 \\
\hline overall = & 0.0260 & & & & $\max =$ & \\
\hline & & & & $F(7,257)$ & $=$ & 5.21 \\
\hline $\operatorname{corr}\left(u_{-} i, \mathrm{Xb}\right)$ & $=-0.8981$ & & & Prob $>F$ & $=$ & 0.0000 \\
\hline retacao | & Coef. & Std. Err. & $t$ & $P>|t|$ & [95\% Conf. & Interval \\
\hline - & & 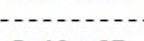 & -1 & - & - n & - \\
\hline valormerc & $2.53 e-06$ & $5.46 e-07$ & 4.63 & 0.000 & $1.45 e-06$ & $3.60 e-06$ \\
\hline evebitda & .0002547 & .0005093 & 0.50 & 0.617 & -.0007481 & .0012576 \\
\hline cfech & .0065737 & .0091203 & 0.72 & 0.472 & -.0113863 & .0245336 \\
\hline divacao & .4162538 & .6159566 & 0.68 & 0.500 & -.7967111 & 1.629219 \\
\hline beta5anos & 3.302439 & 2.794414 & 1.18 & 0.238 & -2.200427 & 8.805304 \\
\hline vol5anos & -.0107666 & .1076503 & -0.10 & 0.920 & -.2227556 & .2012225 \\
\hline retornoibov & .1402298 & .1039207 & 1.35 & 0.178 & -.0644148 & .3448744 \\
\hline _cons & -19.39145 & 4.815364 & -4.03 & 0.000 & -28.87405 & -9.908857 \\
\hline$\ldots$ & - & - & & & & \\
\hline sigma_u & 16.837865 & & & & & \\
\hline sigma_e & 15.403193 & & & & & \\
\hline rho & .54441036 & (fractio & var & e du & i) & \\
\hline
\end{tabular}

$F$ test that all u_i=0: $F(17,257)=3.29 \quad$ Prob $>F=0.0000$ 
Apêndice 4.9 - Comando de saída do Stata para a estimação Efeitos Fixos com erropadrão robusto com a variável dependente retacao

- xtreg retacao valormerc evebitda cfech divacao beta5anos vol5anos retornoibov, fe robust

\begin{tabular}{|c|c|c|c|c|c|c|}
\hline Fixed-effects & (within) reg & ession & & Number & $f$ obs & 282 \\
\hline Group variable & : id & & & Number & $f$ groups $=$ & 18 \\
\hline R-sq: & & & & Obs pe & group: & \\
\hline within $=$ & $=0.1243$ & & & & $\min =$ & 2 \\
\hline between = & $=0.0851$ & & & & avg $=$ & 15.7 \\
\hline overall = & $=0.0260$ & & & & $\max =$ & 20 \\
\hline & & & & $F(7,1)$ & $=$ & 98.48 \\
\hline $\operatorname{corr}\left(u_{-} i, X_{b}\right)$ & $=-0.8981$ & & & Prob $>$ & $=$ & 0.0000 \\
\hline & & & d. Err. & $\operatorname{adj}$ & for 18 clust & rs in id) \\
\hline & & Robust & & & & \\
\hline retacao | & Coef. & Std. Err. & $\mathrm{t}$ & $P>|t|$ & [95\% Conf. & Interval] \\
\hline valormerc & $2.53 e-06$ & $3.95 \mathrm{e}-07$ & 6.41 & a & $1700-86$ & $3.36 e_{-} 06$ \\
\hline evebitda & .0002547 & .0001343 & $\begin{array}{l}0.41 \\
1.90\end{array}$ & 0.075 & -.0000286 & .0005381 \\
\hline cfech & .0065737 & .0065442 & 1.00 & 0.329 & -.0072335 & .0203808 \\
\hline divacao & .4162538 & .4957243 & 0.84 & 0.413 & -.629633 & 1.462141 \\
\hline beta5anos & 3.302439 & 2.280326 & 1.45 & 0.166 & -1.508628 & 8.113506 \\
\hline vol5anos & -.0107666 & .0971097 & -0.11 & 0.913 & -.2156501 & .194117 \\
\hline retornoibov & .1402298 & .0752204 & 1.86 & 0.080 & -.0184714 & .298931 \\
\hline _cons & -19.39145 & 2.452595 & -7.91 & 0.000 & -24.56598 & -14.21693 \\
\hline$\cdots$ & $-\cdots$ & $\cdots$ & & & & -- \\
\hline sigma_u & 16.837865 & & & & & \\
\hline sigma_e & 15.403193 & & & & & \\
\hline rho & .54441036 & (fractio & var & ce du & u_i) & \\
\hline
\end{tabular}


Apêndice 5 - Saídas do Stata para o segundo estudo - desempenho e variáveis contábeis, de governança, de mercado e econômicas

Apêndice 5.1 - Comando de saída do Stata para o teste de Hausman com a variável dependente roe

- qui xtreg roe divbrat divliqebitda invpl liqcor capgir mliq Inrec capexdepamort gov valormerc evebitda cfech divacao beta5anos vol5anos retornoibov OIEEPOP CONSRESPIB PIND PRES VARPIB INVEST CMB SELIC, fe

. estimates store fe

- qui xtreg roe divbrat divliqebitda invpl liqcor capgir mliq Inrec capexdepamort gov valormerc evebitda cfech divacao beta5anos vol5anos retornoibov OIEEPOP CONSRESPIB PIND PRES VARPIB INVEST CMB SELIC, re

. estimates store re

. hausman fe re, sigmamore

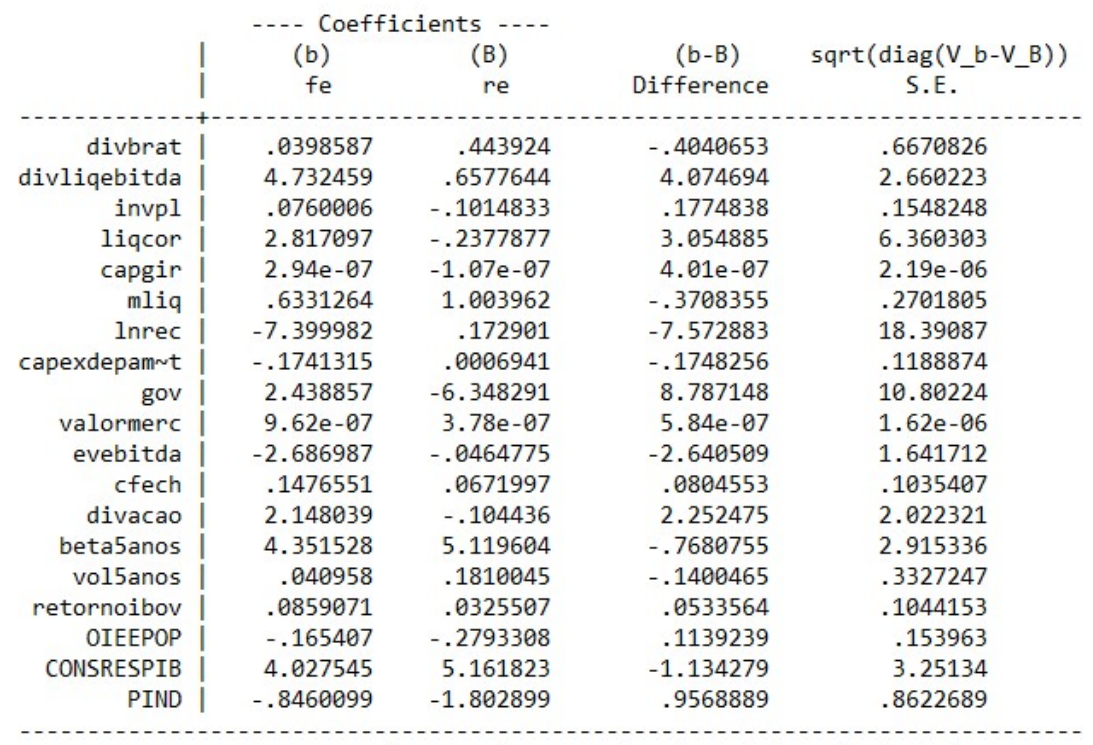

$b=$ consistent under $\mathrm{Ho}$ and $\mathrm{Ha}$; obtained from xtreg
$B=$ inconsistent under $\mathrm{Ha}$, efficient under $\mathrm{Ho}$; obtained from xtreg

Test: Ho: difference in coefficients not systematic

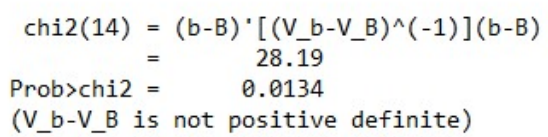

Apêndice 5.2 - Comando de saída do Stata para o teste de Chow com a variável dependente roe

- xtreg roe divbrat divliqebitda invpl liqcor capgir mliq Inrec capexdepamort gov valormerc evebitda cfech divacao beta5anos vol5anos retornoibov OIEEPOP CONSRESPIB PIND PRES VARPIB INVEST CMB SELIC, fe 


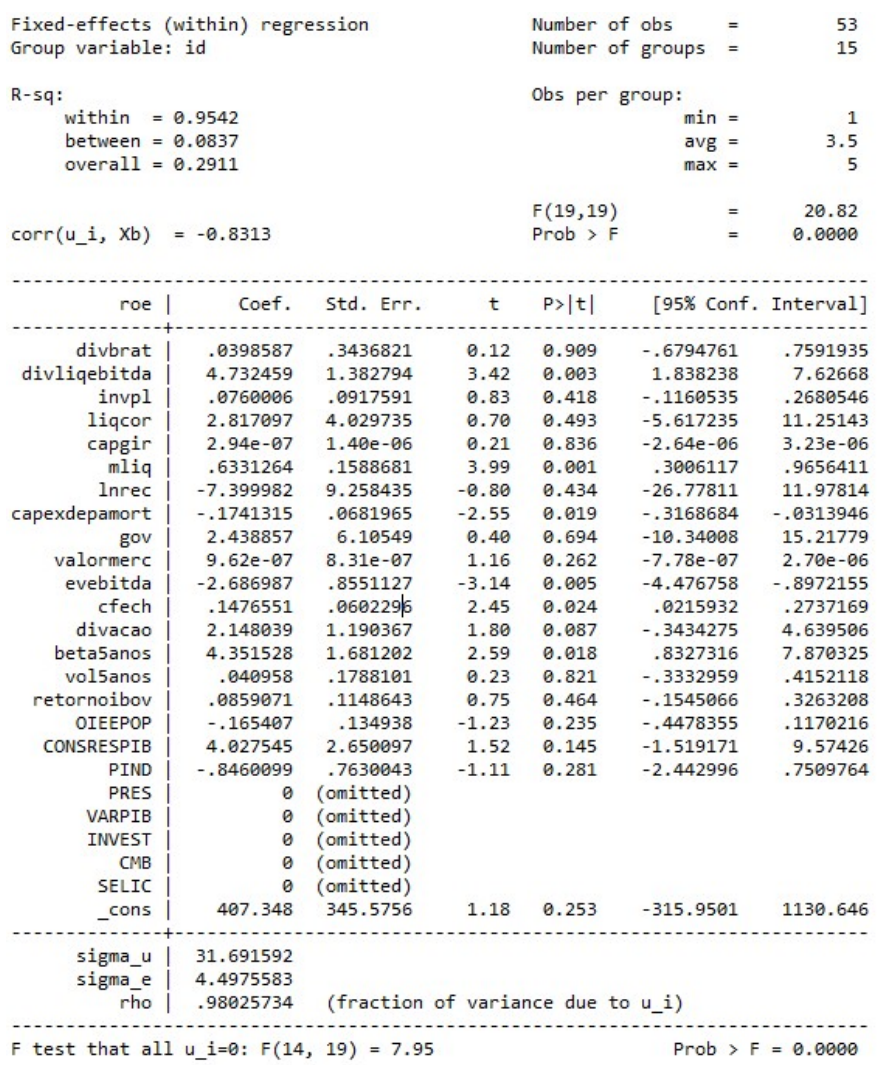

Apêndice 5.3 - Comando de saída do Stata para a estimação Efeitos Fixos com erropadrão robusto com a variável dependente roe

- xtreg roe divbrat divliqebitda invpl liqcor capgir mliq Inrec capexdepamort gov valormerc evebitda cfech divacao beta5anos vol5anos retornoibov OIEEPOP CONSRESPIB PIND PRES VARPIB INVEST CMB SELIC, fe robust 


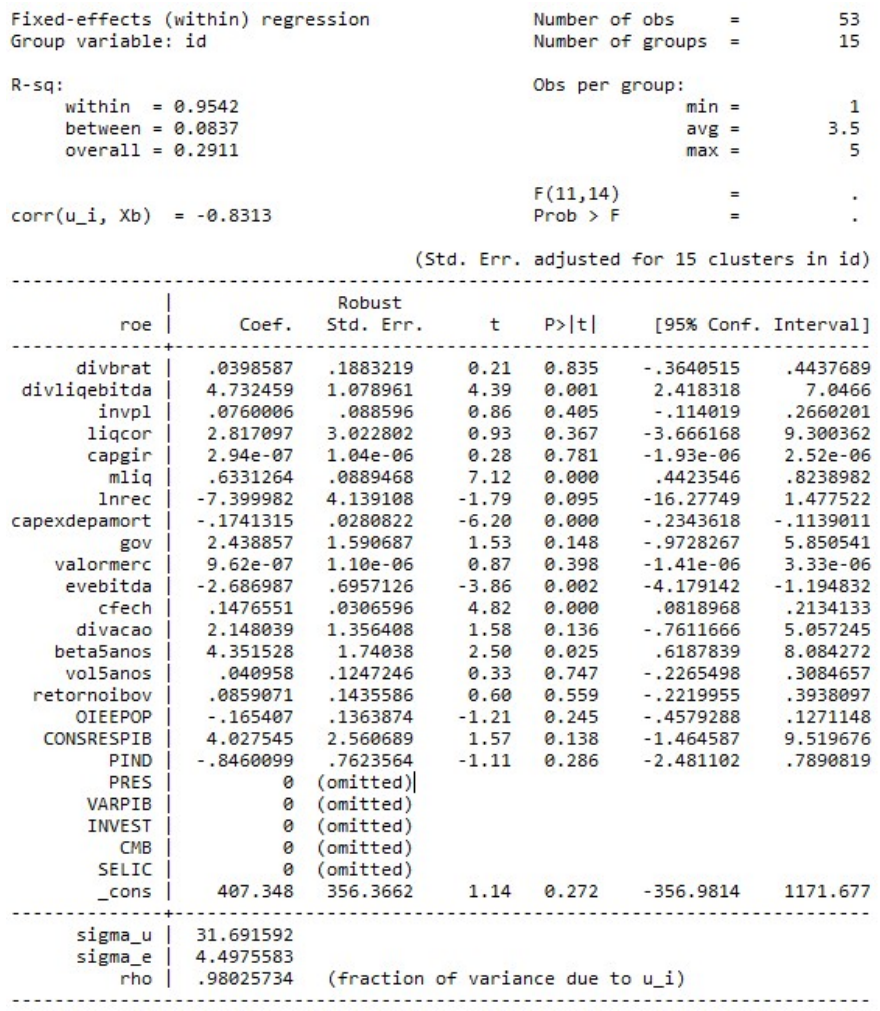

Apêndice 5.4 - Comando de saída do Stata para o teste de Hausman com a variável dependente roa

- qui xtreg roa divbrat divliqebitda invpl liqcor capgir mliq Inrec capexdepamort gov valormerc evebitda cfech divacao beta5anos vol5anos retornoibov OIEEPOP CONSRESPIB PIND PRES VARPIB INVEST CMB SELIC, fe

. estimates store fe

- qui xtreg roa divbrat divliqebitda invpl liqcor capgir mliq Inrec capexdepamort gov valormerc evebitda cfech divacao beta5anos vol5anos retornoibov OIEEPOP CONSRESPIB PIND PRES VARPIB INVEST CMB SELIC, re

. estimates store re

. hausman fe re, sigmamore 


\begin{tabular}{|c|c|c|c|c|}
\hline & $\begin{array}{c}\text { (b) Coeff } \\
\mathrm{fe}\end{array}$ & $\begin{array}{c}\text { (B) } \\
\text { re }\end{array}$ & $\begin{array}{c}(b-B) \\
\text { Difference }\end{array}$ & 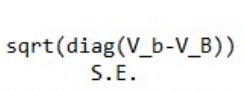 \\
\hline divbrat & .0282284 & 1080718 & -.0798433 & .2017694 \\
\hline divliqebitda & .6731906 & -.1827828 & .8559734 & .4980973 \\
\hline invpl & .093245 & .0328017 & .0604433 & .049893 \\
\hline liqcor & 2.707215 & 1.953815 & .7533999 & 2.035607 \\
\hline capgir & $3.88 e-08$ & $-1.73 e-07$ & $2.12 \mathrm{e}-07$ & $7.42 e-07$ \\
\hline mliq & .2960591 & .3351294 & -.0390703 & .0526002 \\
\hline Inrec & 3.430434 & -.2743319 & 3.704766 & 5.968003 \\
\hline capexdepam $\sim t$ & .0096484 & .0158671 & -.0062187 & .0324241 \\
\hline gov & -.9776287 & -2.075802 & 1.098174 & 3.719744 \\
\hline valormerc & $2.48 \mathrm{e}-07$ & $-5.93 e-08$ & $3.08 e-07$ & $4.89 e-07$ \\
\hline evebitda & -.4199248 & .1992901 & -.6192148 & .318698 \\
\hline cfech & .0164179 & .0176635 & -.0012455 & .0336062 \\
\hline divacao & .8153228 & .1488924 & .6664305 & .6439927 \\
\hline beta5anos & 1.413367 & 1.270928 & .1424392 & .9551536 \\
\hline vol5anos & -.0681859 & .065424 & -.1336099 & .103815 \\
\hline retornoibov & .0177603 & .0233766 & -.0056163 & .0356416 \\
\hline OIEEPOP & -.0283398 & -.0920984 & .0637586 & .045994 \\
\hline CONSRESPIB & .0290959 & .9792697 & -.9501738 & 1.072712 \\
\hline PIND & -.0907248 & -.5835873 & .4928625 & .2567166 \\
\hline
\end{tabular}

$\mathrm{b}=$ consistent under Ho and $\mathrm{Ha}$; obtained from xtreg

Test: Ho: difference in coefficients not systematic

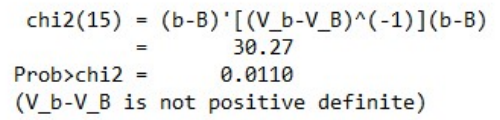

Apêndice 5.5 - Comando de saída do Stata para o teste de Chow com a variável dependente roa

- xtreg roa divbrat divliqebitda invpl liqcor capgir mliq Inrec capexdepamort gov valormerc evebitda cfech divacao beta5anos vol5anos retornoibov OIEEPOP CONSRESPIB PIND PRES VARPIB INVEST CMB SELIC, fe

\begin{tabular}{|c|c|c|c|c|c|c|}
\hline \multicolumn{4}{|c|}{ Fixed-effects (within) regression } & \multicolumn{2}{|c|}{ Number of obs } & 56 \\
\hline Group variable & : id & & & Number 0 & groups $=$ & 16 \\
\hline R-sq: & & & & Obs per & roup: & \\
\hline within $=$ & 0.9431 & & & & $\min =$ & 1 \\
\hline between $=$ & 0.0628 & & & & avg $=$ & 3.5 \\
\hline overall = & 0.0947 & & & & $\max =$ & 5 \\
\hline & & & & $F(19,21)$ & $=$ & 18.33 \\
\hline $\operatorname{corr}\left(u \_i, x b\right)$ & $=-0.8401$ & & & Prob $>\mathrm{F}$ & $=$ & 0.0000 \\
\hline roa & Coef. & Std. Err. & t & $P>|t|$ & [95\% Conf. & Interval] \\
\hline divbrat & .0282284 & .108109 & 0.26 & 0.797 & -.1965965 & .2530533 \\
\hline divligebitda & .6731906 & .2881363 & 2.34 & 0.029 & .0739785 & 1.272403 \\
\hline invpl & .093245 & .031098 & 3.00 & 0.007 & .0285732 & 1579169 \\
\hline liqcor & 2.707215 & 1.359636 & 1.99 & 0.060 & -.1203032 & 5.534733 \\
\hline capgir & $3.88 \mathrm{e}-08$ & $4.98 \mathrm{e}-07$ & 0.08 & 0.939 & $-9.97 e-07$ & $1.07 e-06$ \\
\hline mliq & .2960591 & .0359895 & 8.23 & 0.000 & .2212149 & .3709033 \\
\hline Inrec & 3.430434 & 3.120093 & 1.10 & 0.284 & -3.058155 & 9.919022 \\
\hline capexdepamort & .0096484 & .0206568 & 0.47 & 0.645 & -.0333097 & .0526065 \\
\hline gov & -.9776287 & 2.190704 & -0.45 & 0.660 & -5.533447 & 3.578189 \\
\hline valormerc & $2.48 \mathrm{e}-07$ & $2.62 \mathrm{e}-07$ & 0.95 & 0.354 & $-2.97 e-07$ & $7.94 e-07$ \\
\hline evebitda & -.4199248 & .1850206 & -2.27 & 0.034 & -.8046962 & -.0351534 \\
\hline cfech & .0164179 & .0206149 & 0.80 & 0.435 & -.0264531 & .059289 \\
\hline divacao & .8153228 & .3972044 & 2.05 & 0.053 & -.010709 & 1.641355 \\
\hline beta5anos & 1.413367 & .580955 & 2.43 & 0.024 & .2052049 & 2.621529 \\
\hline vol5anos & -.0681859 & .058195 & -1.17 & 0.254 & -.1892091 & .0528373 \\
\hline retornoibov & .0177603 & .0414163 & 0.43 & 0.672 & -.0683696 & .1038902 \\
\hline OIEEPOP & -.0283398 & .0467965 & -0.61 & 0.551 & -.1256584 & .0689787 \\
\hline CONSRESPIB & .0290959 & .9421931 & 0.03 & 0.976 & -1.930302 & 1.988494 \\
\hline PIND & -.0907248 & .2641536 & -0.34 & 0.735 & -.6400624 & .4586127 \\
\hline PRES & 0 & (omitted) & & & & \\
\hline VARPIB & $\theta$ & (omitted) & & & & \\
\hline INVEST & $\theta$ & (omitted) & & & & \\
\hline CMB & 0 & (omitted) & & & & \\
\hline SELIC & $\theta$ & (omitted) & & & & \\
\hline _cons & 48.25864 & 122.3468 & 0.39 & 0.697 & -206.1754 & 302.6927 \\
\hline sigma u & 12.663619 & & & & & \\
\hline sigma_e & 1.643433 & & & & & \\
\hline rho & .98343715 & ractic & Jari & ce due & u_i) & \\
\hline
\end{tabular}


Apêndice 5.6 - Comando de saída do Stata para a estimação Efeitos Fixos com erropadrão robusto com a variável dependente roa

- xtreg roa divbrat divliqebitda invpl liqcor capgir mliq Inrec capexdepamort gov valormerc evebitda cfech divacao beta5anos vol5anos retornoibov OIEEPOP CONSRESPIB PIND PRES VARPIB INVEST CMB SELIC, fe robust

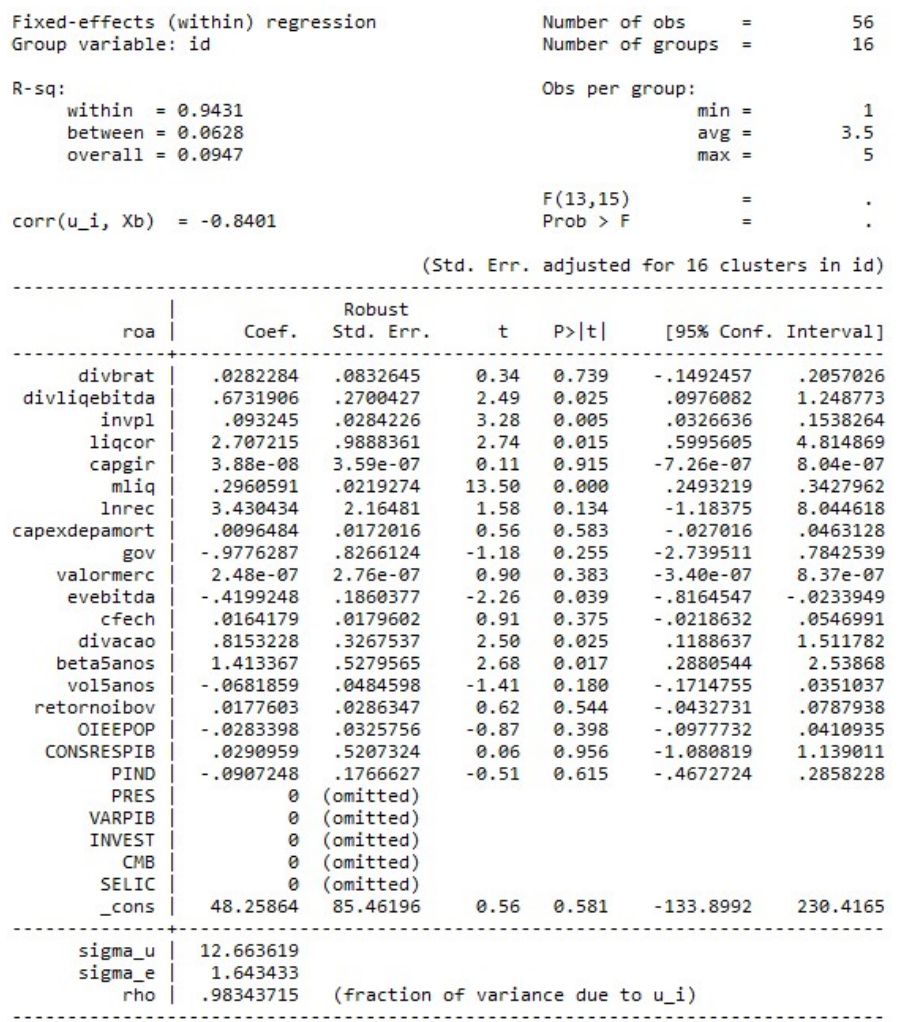


Apêndice 6 - Saídas do Stata para o terceiro estudo - diff-in-diff

. gen time $=(t>2012) \&$ !missing $(t)$

. gen treated $=($ id $>3) \&$ ! missing(id)

. gen did $=$ time*treated

Apêndice 6.1 - Comandos e saídas do Stata para o teste diff-in-diff para a variável dependente roe

. reg roe time treated did, $r$

Linear regression

$\begin{array}{llr}\text { Number of obs } & = & 129 \\ \mathrm{~F}(3,125) & = & 0.65 \\ \text { Prob }>\mathrm{F} & = & 0.5869 \\ \text { R-squared } & = & 0.0089 \\ \text { Root MSE } & = & 33.304\end{array}$

\begin{tabular}{|c|c|c|c|c|c|c|}
\hline & & Robust & & & & \\
\hline roe & Coef. & Std. Err. & $t$ & $P>|t|$ & [95\% Conf. & Interval] \\
\hline time & -.4330864 & 5.029531 & -0.09 & 0.932 & -10.38715 & 9.520979 \\
\hline treated & -.9165976 & 6.561179 & -0.14 & 0.889 & -13.90199 & 12.06879 \\
\hline did & -5.615904 & 8.464654 & -0.66 & 0.508 & -22.3685 & 11.1367 \\
\hline cons & 11.87652 & 3.782357 & 3.14 & 0.002 & 4.390764 & 19.36227 \\
\hline
\end{tabular}

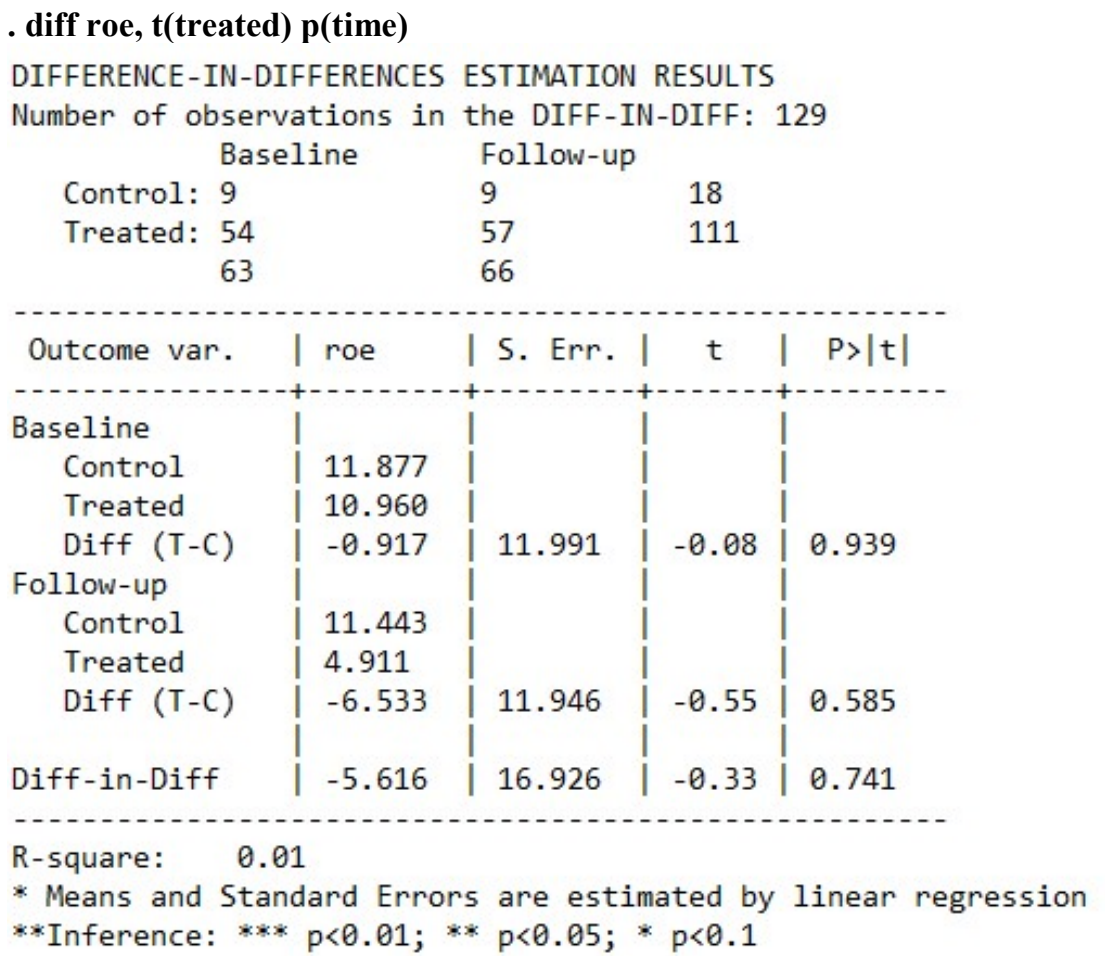


- reg roe divbrat divliqebitda invpl liqcor capgir mliq Inrec capexdepamort gov valormerc evebitda cfech divacao beta5anos vol5anos retornoibov OIEEPOP CONSRESPIB PIND PRES VARPIB INVEST CMB SELIC time treated did, vce(robust)

\begin{tabular}{|c|c|c|c|c|c|c|}
\hline \multicolumn{4}{|c|}{ Linear regression } & \multicolumn{2}{|c|}{$\begin{array}{l}\text { Number of obs } \\
F(21,31) \\
\text { Prob > F } \\
\text { R-squared } \\
\text { Root MSE }\end{array}$} & $\begin{array}{r}53 \\
118.12 \\
0.0000 \\
0.8873 \\
9.1291\end{array}$ \\
\hline roe & Coef. & $\begin{array}{l}\text { Robust } \\
\text { Std. Err. }\end{array}$ & $\mathrm{t}$ & $P>|t|$ & [95\% Conf. & Interval] \\
\hline divbrat & .39061 & .2253859 & 1.73 & 0.093 & -.0690676 & .8502876 \\
\hline divliqebitda & .449893 & .929102 & 0.48 & 0.632 & -1.445023 & 2.344809 \\
\hline invpl & -.1590304 & .1467042 & -1.08 & 0.287 & -.4582355 & .1401747 \\
\hline liqcor & 1.764707 & 7.094983 & 0.25 & 0.805 & -12.70561 & 16.23502 \\
\hline capgir & $-8.16 e-07$ & $1.92 e-06$ & -0.43 & 0.673 & $-4.73 e-06$ & $3.09 e-06$ \\
\hline mliq & .9435337 & .2319197 & 4.07 & 0.000 & .4705303 & 1.416537 \\
\hline lnrec & .4824379 & 1.165616 & 0.41 & 0.682 & -1.894852 & 2.859727 \\
\hline capexdepamort & .002961 & .0652713 & 0.05 & 0.964 & -.1301606 & .1360826 \\
\hline gov & -6.201917 & 6.121126 & -1.01 & 0.319 & -18.68604 & 6.282203 \\
\hline valormerc & $6.35 e-07$ & $6.71 e-07$ & 0.95 & 0.351 & $-7.33 e-07$ & $2.00 e-06$ \\
\hline evebitda & .072148 & .5457335 & 0.13 & 0.896 & -1.040883 & 1.185179 \\
\hline cfech & .0579396 & .0692869 & 0.84 & 0.409 & -.083372 & .1992513 \\
\hline divacao & -.3565257 & 1.522751 & -0.23 & 0.816 & -3.462196 & 2.749144 \\
\hline beta5anos & 5.071795 & 1.562991 & 3.24 & 0.003 & 1.884054 & 8.259536 \\
\hline volsanos & .187401 & .1627531 & 1.15 & 0.258 & -.1445362 & .5193382 \\
\hline retornoibov & -.5940776 & .3159042 & -1.88 & 0.069 & -1.238369 & .0502134 \\
\hline OIEEPOP & .2236245 & .111997 & 2.00 & 0.055 & -.0047948 & .4520438 \\
\hline CONSRESPIB & 0 & (omitted) & & & & \\
\hline PIND & -.0969483 & .4047198 & -0.24 & 0.812 & -.9223797 & .7284832 \\
\hline PRES & .5238526 & .2747659 & 1.91 & 0.066 & -.0365361 & 1.084241 \\
\hline VARPIB & 0 & (omitted) & & & & \\
\hline INVEST & 0 & (omitted) & & & & \\
\hline CMB & 0 & (omitted) & & & & \\
\hline SELIC & 0 & (omitted) & & & & \\
\hline time & 0 & (omitted) & & & & \\
\hline treated & 6.070315 & 10.55342 & 0.58 & 0.569 & -15.45353 & 27.59416 \\
\hline did & -7.725374 & 9.507385 & -0.81 & 0.423 & -27.11581 & 11.66507 \\
\hline cons & -801.6493 & 419.4753 & -1.91 & 0.065 & -1657.175 & 53.87624 \\
\hline
\end{tabular}

Apêndice 6.1 - Comandos e saídas do Stata para o teste diff-in-diff para a variável dependente roa

- reg roa time treated did, $r$

Linear regression

$\begin{array}{llr}\text { Number of obs } & = & 134 \\ \mathrm{~F}(3,130) & = & 1.56 \\ \text { Prob }>\mathrm{F} & = & 0.2021 \\ \text { R-squared } & = & 0.0384 \\ \text { Root MSE } & = & 8.1059\end{array}$

\begin{tabular}{|c|c|c|c|c|c|c|}
\hline roa & Coef. & $\begin{array}{l}\text { Robust } \\
\text { Std. Err. }\end{array}$ & $t$ & $P>|t|$ & [95\% Conf. & Interv \\
\hline time & .1069432 & 1.638962 & 0.07 & 0.948 & -3.135547 & 3.349 \\
\hline treated & 2.529843 & 1.637377 & 1.55 & 0.125 & -.7095117 & 5.7691 \\
\hline did & -3.496036 & 2.294008 & -1.52 & 0.130 & -8.034457 & 1.0423 \\
\hline _cons & 4.54133 & 1.094925 & 4.15 & 0.000 & 2. 375151 & 6.7075 \\
\hline
\end{tabular}


. diff roa, t(treated) $p($ time $)$

DIFFERENCE-IN-DIFFERENCES ESTIMATION RESULTS

Number of observations in the DIFF-IN-DIFF: 134 Baseline Follow-up

\begin{tabular}{|c|c|}
\hline $\begin{array}{l}\text { Control: } 9 \\
\text { Treated: } 5\end{array}$ & $\begin{array}{l}9 \\
60\end{array}$ \\
\hline
\end{tabular}

$65 \quad 69$

Outcome var. | roa | S. Err. | t $|\mathrm{P}>| \mathrm{t} \mid$

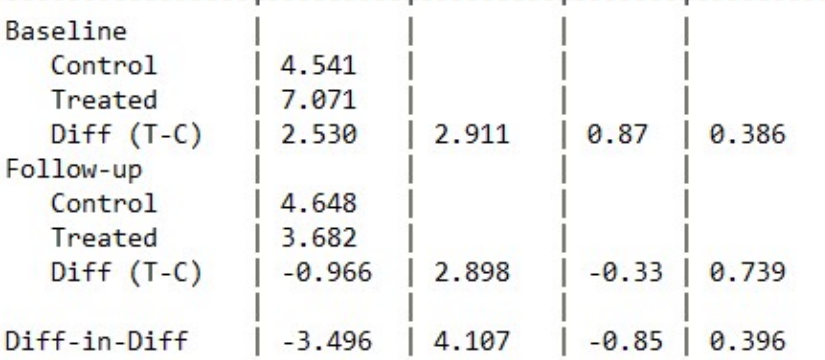

R-square: 0.04

* Means and Standard Errors are estimated by linear regression

**Inference: *** $p<0.01 ; * * p<0.05 ; * p<0.1$

- reg roa divbrat divliqebitda invpl liqcor capgir mliq Inrec capexdepamort gov valormerc evebitda cfech divacao beta5anos vol5anos retornoibov OIEEPOP CONSRESPIB PIND PRES VARPIB INVEST CMB SELIC time treated did, vce(robust)

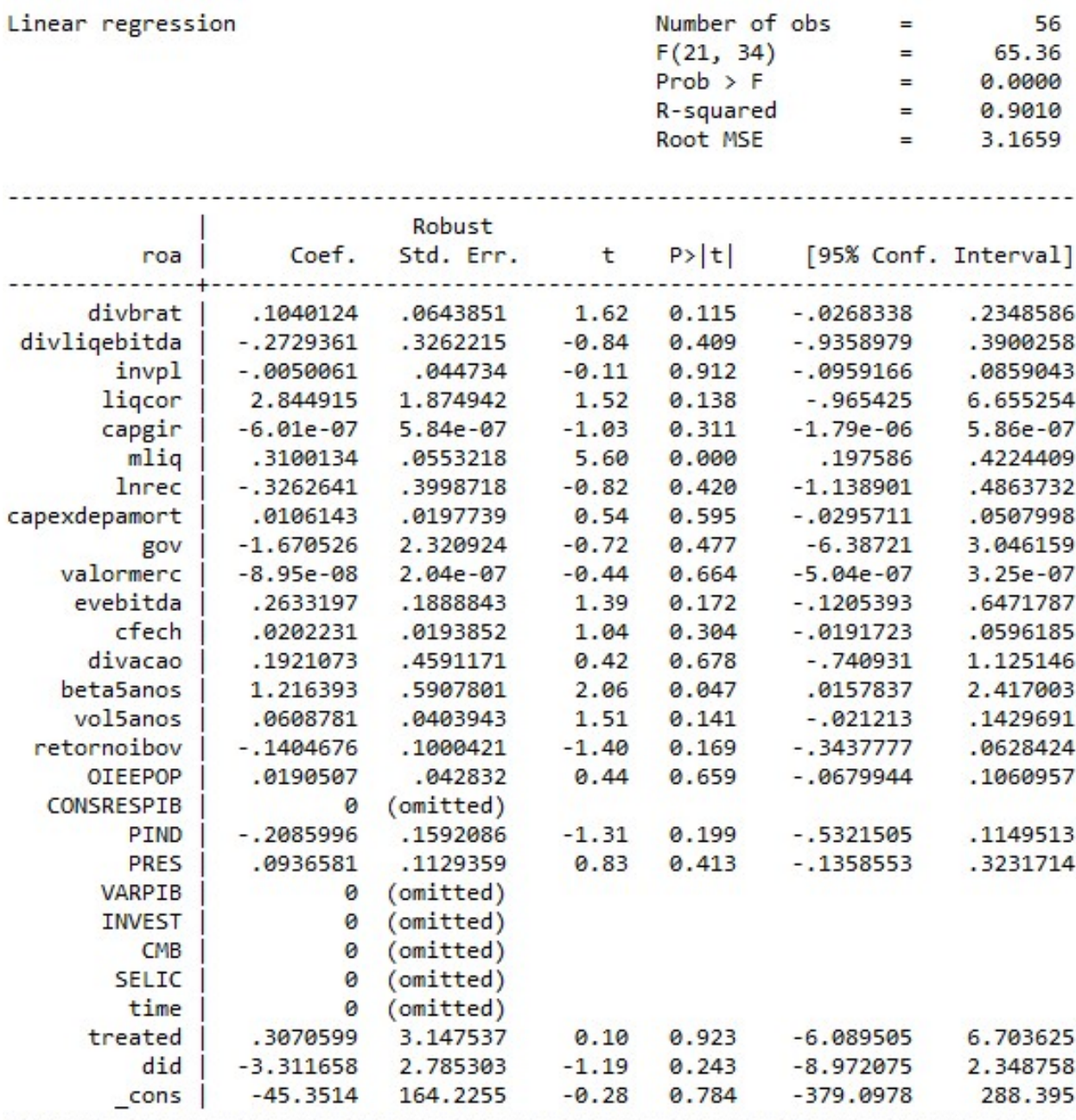

